\title{
Eating Dinner, Writing Culture: \\ The Unique Communicative Power of Food and Travel Journalism
}

by

Robert McKeown

A thesis submitted to the Faculty of Graduate Studies and Postdoctoral Affairs in partial fulfillment of the requirements for the degree of:

Master of Journalism

in

School of Journalism and Communication

Carleton University

Ottawa, Ontario

(C) 2016 Robert McKeown 


\section{Abstract}

By examining a body of articles about the food of Thailand, this thesis argues that food and travel journalism represents a unique strain of the craft in the way it regularly and positively engages with other cultures. Discussing texts from magazines like Saveur and celebrated publications like The New York Times, this thesis attempts to show that the editorial coverage of food culture demands an approach that is distinct from more traditional topics like politics and hard news. From engaging with multiple senses at once to the intensely personal nature of eating, food and travel journalists have the rare opportunity to provide insight into the various tastes of cultural Others in a way that is both powerful and positive in its ability to emotionally connect with their readers. Through content and framing analysis of the aforementioned publications and ethnographies of celebrated Thai restaurants, this thesis argues that as experiences surrounding Thai food are textualized, journalists thus create an arena that is at once practical (for the knowledge of readers and audiences) and symbolic in its ability to represent not just a single meal, but an entire culture as well. 


\section{Acknowledgements}

Beginning, well, at the beginning, much is owed to Professors Susan Harada and Chris Dornan for giving me the chance to come to Carleton for my Master's. The school's combination of commitment to excellence and personal attention to students really helped me focus, get inspired, and begin to achieve my academic goals.

My Canadian family and my Dad, whose generosity in time and car seat space also helped make this possible. I always knew I'd return to Canada and my experience the last year in Ottawa only went to show the decision was the right one. To that end, an extended Chelsea family thank you to Jess Milton and Josh Kilberg, for the initial inspiration for my graduate (and soon Doctoral) study and the many wonderful meals, e-mails, and conversations that their friendship gifted me.

To my dear Mom, without whom none of this would be possible and who has always shown me strength, grace, and unconditional love in her actions, her words, and her knowing and supporting silences. Beyond her, my American family the Scanlons of Florida and North Carolina and my brother Alex, whose belief and dedication was unwavering in the beginning of what I hope will be a lifelong process of culture, food, and communication.

Last, but not least, the small but steadfast support system from Asia and the food world - JB, RC, EMR, IG - from whom I've learned how to succeed, but also fail and learn to succeed all over again. 
Finally, my advisor Professor Chris Waddell. He took me in quickly and showed me belief in my pursuit of a new (-ish) area of journalism scholarship, an ease of intellectual application and a talent for quick transitions between disciplines. His easygoing yet pointed approach to scholarship is the reason why no doubt so many more will follow in my footsteps, achieving more than they thought and illuminating just how much is possible in the years to come. My academic foundation will forever bear his name. 


\section{Table of Contents}

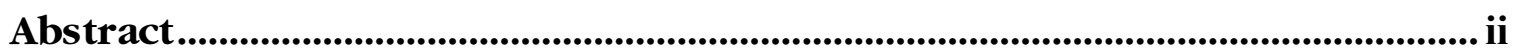

Acknowledgements ..............................................................................................iii-iv

Table of Contents ............................................................................................. vi

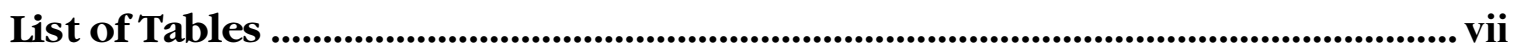

Chapter 1: Introduction ........................................................................................................ 1

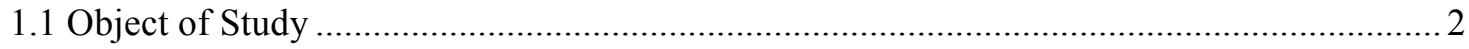

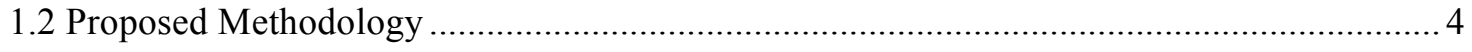

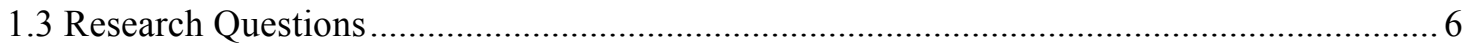

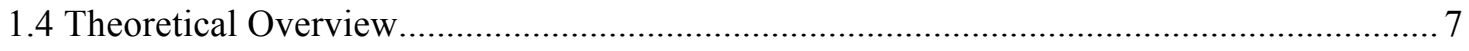

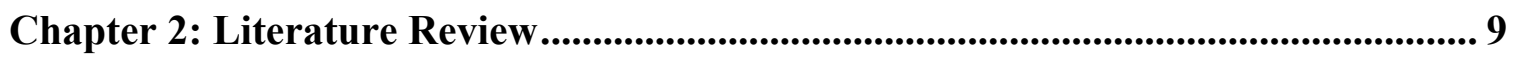

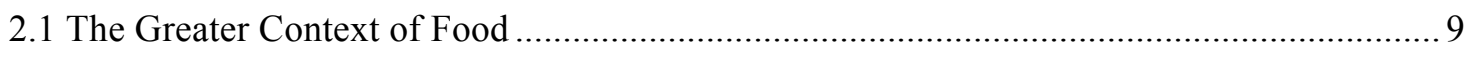

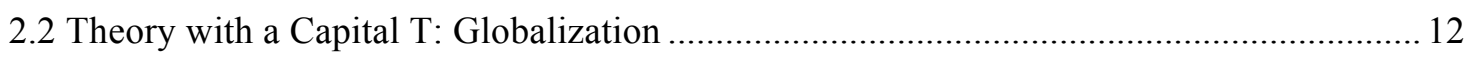

2.3 Representation, Power, and (Culinary) Others ........................................................ 16

2.4 Changing Notions of Ethnography, Travel, and Culture ............................................... 19

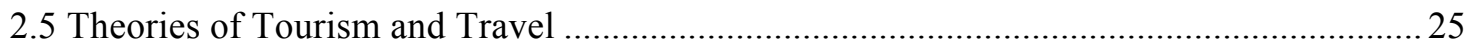

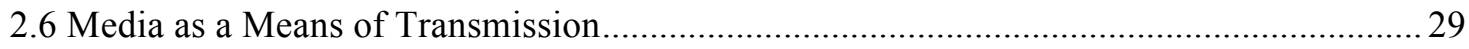

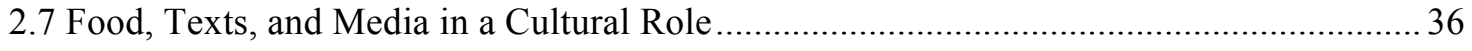

2.8 Food, Language, and the Role of Art and Craft......................................................... 40

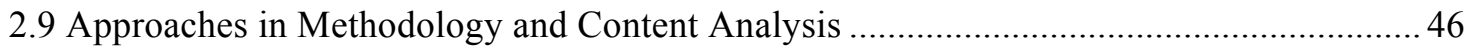

Chapter 3: Methodology......................................................................................................... 51

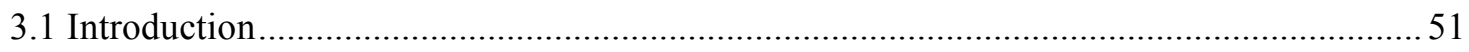

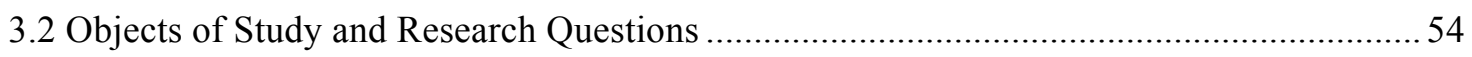

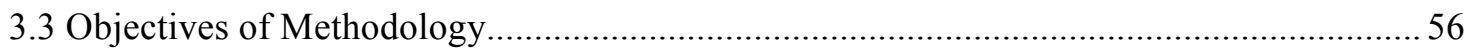




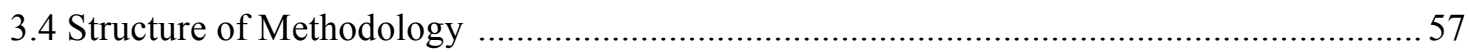

3.5 Quantitative and Keyword Analysis Results and Tables.............................62

Chapter 4: Findings and Context.................................................69

4.1 Saveur Magazine:Thai Food, Culture, and Travel Articles ................................................ 69

4.2 Eat, Read Compare - San Francisco's Kin Khao and Bangkok's Nahm ............................ 71

4.3 Controlled Coverage - The New York Times and Thailand in News and Taste................... 73

Chapter 5: Discussion Part 1 ......................................................................... 75

5.1 Tasting Local, Cooking Global: Thai Street Food and Traditions in Saveur Magazine...... 75

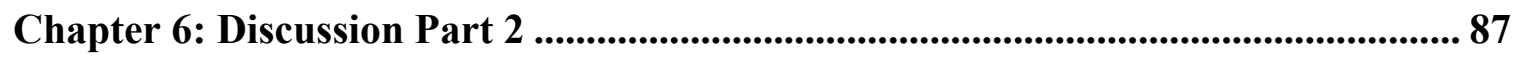

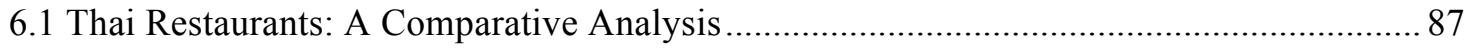

6.2 Thai Cooking 'Far': Kin Khao in San Francisco ............................................................ 95

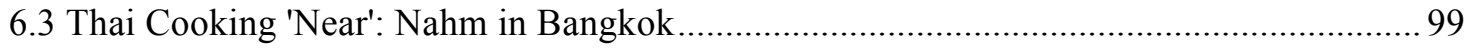

6.4 Relational Cuisine - In Authenticity and Chefs We Trust .............................................. 103

Chapter 7: Discussion Part 3 ................................................................................................. 107

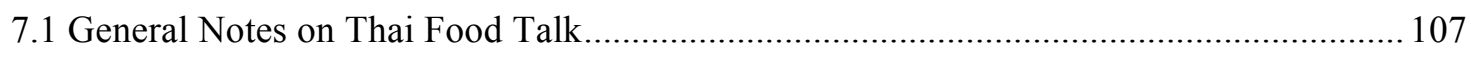

Chapter 8: Conclusion .......................................................................................... 117

8.1 Towards a Set of Normative Practises for Food and Travel Journalism .......................... 125

Bibliography ............................................................................................................. 129 


\section{List of Tables}

Table 1 Saveur Magazine Corpus (2007-2015) ................................67

Table 2 Nahm and Kin Khao Comparison Corpus ..............................67

Table 3 New York Times Comparison Corpus (2015)............................68 


\section{Chapter 1 : Introduction}

The food of Thailand, as some might put it conversationally, is having a moment right now. It is trending in cities of all sizes in North America, as well as Asian financial hubs like Hong Kong and Singapore, where waves of openings advertising 'regional' or 'modern' Thai cuisine are scorching a chili-hot path to renown. The revered Michelin Guide - the fire-engine red and religiously followed source of valourization for restaurants worldwide - has awarded its much sought after 'stars' to several small, casual Thai eateries in cities like San Francisco, Copenhagen, and New York, whose marketing plans boast of authenticity and regional taste. Even Bangkok, once a hospitality laggard, is birthing new restaurants celebrating its national cuisine with some ranking in the top few dozen spots in the foodie-beloved San Pellegrino's World's 100 Best Restaurants survey. Food culture is now pop culture.

Polls and statistics show a robust level of interest in Thailand by travellers and tourists seeking culinary experiences. In 2014, the country hosted some 24.77 million tourist arrivals. In 2015, by the end of September alone, there were more than 22 million arrivals. One of the greatest attractions of the country is its food. A survey by the Kellogg School of Management found Thai cuisine ranked fourth in global perception of best-known cuisines behind those of Japan, Italy, and China. It ranked sixth in terms of best quality of food globally in the same survey (Tourism Authority of Thailand TAT, 2015). The Thai government takes an active role in linking the areas of tourism, culture, and gastronomy, while independent tour operators sell street food safaris and morning market visits with the same zeal as they do elephant rides. A program called Thai Kitchen/World Cuisine has for more than a decade helped promote the development of Thai restaurants abroad. In 2003, there were 6,875 Thai eateries globally. 
As of 2012, that number had grown to more than 20,000 worldwide (Department of International Trade Promotion - DITP, 2013). From single-dish street cooks and organic farming to restaurants abroad, food has become an important site for the mediation of Thailand's culture and the food and travel media dominate the site in which it is textually inscribed.

These numbers reveal far more than trends. They highlight the growing power of an internationally recognized cuisine and its ability to transfer meaning and engender conversation from one culture, people, and place to another. For food is more than just an act of consumption, sustenance, or aesthetic enjoyment. It is a form of - and a medium for - mediation between cultures, an arena of symbolic interaction that allows cooks, eaters, travellers, and tourists to enter into a series of experiences and negotiations that can help us better understand those who we consider different than us. This marking of difference is best described as a cultural or, for our purposes, edible Other (Hooks, 1992; Hall, 1997; Heldke, 2003). This is a crucial concept that will be explored from all sides in this research, from daily tourist interactions to the voices employed in various forms of food and travel media.

\subsection{Object of Study}

Using Thai gastronomy as it is recorded and represented in food and travel journalism as an object of study, my research seeks to show how food - and the people and cultures it gives representation to in media texts - functions as a powerful and unique form of mediation. Through case studies, theoretical discussion, and textual analysis, this thesis seeks to show how understanding the way a food culture (here, that of Thailand) is communicated and inscribed in journalistic texts can help us transcend the often reductive notions we attach to cultural Others and, in turn, initiate lively 
conversations and moments of positive and shared meaning across national, geographic, and ethnic boundaries. This research proposes studying these phenomena through the textual exploration of three different sites and examples of Thai food consumption.

The first examines the social constructions surrounding street food, traditional markets and other favored travel food experiences in Thailand, especially the form of culinary play undertaken between tourists and locals (or cooks and eaters) as a key site for negotiating ideas of localization, regional expression, and authenticity. The corpus of articles will also include those written about Thai food outside of its place or origin, so long as the general interests of what is real or traditional as related to the cuisine of Thailand are still apparent. The subject of food and travel experiences will be explored by gathering, studying, and analyzing related texts from a leading food and travel magazine (Saveur in the US), which is unique because it has a focus that goes beyond the new, trendy restaurants and glamourized celebrity chef culture of most food-related publications. At Saveur, the focus goes beyond food as sustenance or a night on the town. The magazine celebrates, instead, the culture that grows from and is attached to the experience of eating the food of nations the world over. As its website claims in a section designed to appeal to new subscribers: "SAVEUR is a food magazine for people who experience the world "food first," ...We'll tell you about food all over the world, and show it to you in beautiful pictures. Every country, every city, every street has a delicious story within it - and we'll share those stories with our readers."

The second case study will undertake a comparative exploration of two of the most written about and critically acclaimed Thai restaurants in the world, Kin Khao in San Francisco and Nahm in Bangkok. By examining how Thai food is played out in 
different countries by different chefs, the goal is to engage with the ideas of authenticity and culture, and their roles in an increasingly fluid and global. An investigation of how Thai taste and culture is represented will be conducted through a discussion of the way Thai chefs and proprietors make decisions about design, narrative, flavour, notions of the exotic and the new, menu language, and sourcing in the daily operation of their restaurants. Newspaper reviews, magazine features, and guidebook reviews will be the media sites used to conduct this research textually. This will provide common ground for the way a present-day chef/owner is depicted in the media, while revealing how the decisions they make about their restaurant contribute to the construction their identity with audiences around the world.

The final stream of research trains its focus on a second set of comparative studies of journalistic works, in this case using the long-running and highly-regarded newspaper The New York Times. Two bodies of texts will be selected for examination. The first will be taken exclusively from articles written about Thailand, with the focus being breaking news or politics. The second set selected will also take Thailand as its central topic, but will consist of solely Thai food-related articles. Whereas the comparison of restaurants was meant to tease out relationalities within the same general ideas, here the idea is to begin in the same place - the same paper, with one assumes common standards and practices - and then see whether wholly different topics are nevertheless treated with the same voice and journalistic techniques, or with an approach that is exclusive to a certain topic? Here, the concern is how language, voice, tone, and narratives are included or excluded and thus made salient, and in what ways this influences cross-cultural mediation and meaning-making as it pertains to the perception of Thailand and its culture in different forms of journalism. 


\subsection{Proposed Methodology}

My methodology will consist of several layers, each meant to help illuminate a different aspect of food and travel journalism, as they relate to my aforementioned case studies - Saveur, Kin Khao and Nahm, and The New York Times. The goal is to gain insight in to the greater communication process that motivates, shapes, and informs trans-national exchange, measuring how cultural representation - or a lack thereof - in the media shapes encounters with edible Others along the way (Hooks, 1992; Said, 1979; Heldke, 2003). The first layer involves the nature of the publications themselves. For example, the case studies have been selected in a way that will isolate different aspects of this process, with each publication type (food magazine; general reviews and features; a long-running newspaper) beginning with a different set of editorial approaches to reflect its brand, its employees, and one assumes its audiences.

The second layer will involve a deeper examination of how Thai restaurants construct meaning locally and globally, focusing on the process of inclusion and exclusion that is undertaken as they choose how to represent Thai cuisine and convey their brand of authenticity to their customers through seasoning, décor, marketing, and language decisions. From newspaper and magazine articles and blog posts to menus and marketing collaterals, all forms of textual representation will be examined to identify both symbolic markers and other forms of cultural authenticity that are consciously created by the decisions of each restaurant. Drawing on anthropologist James Clifford's (1997) idea of using a geo-spatial chronotope - in his case, a motel lobby...here, a Thai restaurant abroad - the goal is to uncover how a place is constructed as a site for meaning-making and cultural encounters. 
The third layer of the methodology will involve a shared approach to content analysis of all the texts culled from their group by topic or by publication type. After selecting texts about Thai food, travel, tourism, and restaurants, I will conduct a quantitative analysis of keywords, vocabulary, and phrases in the categories of subjects and pronouns (I versus We, etc.); descriptors of authenticity, tradition, or culinary exoticism (words concerning authenticity, locality, and regional cuisines or cities); words representing exotic Thai flavour like those evoking hot, sour, salty, sweet, spicy, or fragrant. I will also log how often sources are quoted (Thais versus foreigners, locals versus tourists) or given a voice. The overall objective is to identify patterns and highlight stylistic choices made by journalists within the food/travel genre, and to identify how journalists undertake a sort of cultural and transnational pedagogy in this area of interest. The final layer of methodology will involve readings and qualitative content analysis of these same texts. This will serve to give further analytical context to these journalistic works and demarcate the discursive arena forged by the editorial choices taken by each of the publications while covering Thailand's food culture. This two-step approach is inspired by Margaret LeCompte's (2000) assertion that this tactic “...makes interpretation possible, requires researchers to first determine how to organize their data and use it to construct an intact portrait of the original phenomenon under study and second, to tell readers what that portrait means (p. 147)."

\subsection{Research Questions}

The following research questions will serve as topical anchors across both my case studies and the ensuing theoretical discussions: How does food travel across cultures and national borders when recorded in journalistic texts? What makes food and 
media texts unique as a site of mediation not only for our senses, but as an experiential locale for encountering those different from us - i.e. cultural Others? Based on the methodology and findings, what can food and travel journalism learn or appropriate from other forms of journalism (i.e. news), and how might it create its own set of normative journalistic practices and standards?

The aforementioned questions are important because they cast a rigorous academic eye on a site where Others, cultural transnationalism, representation, communication, media, journalism, and audiences converge. They help to explore how foreign cultures might better understand and relate to each other, and how the special case of food and travel journalism can play a crucial role in the process. The import of the research questions corresponds directly to the power of social agency - specifically, the way readers, travellers, chefs and cooks, and eaters can take clear actions to effect cultural exchange - while investigating what type of structures are in place to support this unique brand of journalism. If the answer is a weak one, the opportunity exists to develop a normative set of standards to better the efficacy of the craft.

\subsection{Theor etical Overview}

As a starting point, theories of globalization that discard typical top-down economic, marketing, and structural focuses in favour of cultural comprehension at a grassroots level and process-driven epistemologies (Appadurai, 1996; Appadurai, 2001) will be embraced. Notions of cosmopolitanism that embrace transnational experiences alongside localized geographical and historical experience (Robbins and Cheah, 1998; Hannerz, 1990; Anthony Appiah, 2006) will be central to understanding the world of 
mass travel, culinary diaspora, and media representation, such as the one Thai food culture occupies. John Hartley's (2001) inclusive conception of the mediasphere and semiospheres that dominate popular culture is important for understanding how cultures are broadcast both symbolically and physically. Works of anthropology that focus on how different cultures attach meaning to daily activities (Geertz, 1971; Geertz, 1994) and that occupy different points on a continuum of travelling-in-dwelling, dwelling-intravelling, and in-betweenness (Clifford, 1997) are valuable for the way they explicate meaning from the everyday.

The idea of the cultural Other is a powerful one that will be pursued across ethnic, national, and topical lines (Hooks, 1992; Hall, 1997; Heldke, 2003; Heldke, 2005), and it is central to all elements of this research. The idea of the Other is also closely linked to how modern travellers seek out the new and the exotic. The Western obsession with and - persistent search for - authenticity in activities such as tourism and dining is both problematic and idealistic and needs to be challenged. Interdisciplinary in their approach, tourism theories provide another way of engaging with authenticity from experiential examination (Rojek and Urry, 1997) to the Erving Goffman-influenced construction of front and back staging (MacCannell, 2013) areas in touristic encounters. Having an in-depth understanding of the way senses and aesthetics function is a crucial part of unpacking how we experience food as cultural mediation. This means moving beyond the traditionally dominant visual sense as it relates to imagery, social construction, and touring (Sontag, 2001; Rojek and Urry, 1997) and considering taste culture from a sensory and aesthetic viewpoint (Kornsmeyer, 1999; Telfer, 1996; Spence, 2014) in which taste and touch and, in the end, a multi-sensory approach is given primacy. 
The subject of tourism as an experiential pursuit has produced several theories of the modern tourist (Rojek and Urry, 1997; Larsen and Urry, 2012; Haldrup and Larsen, 2010). Thai cuisine has been addressed at touristic, gendered, and philosophical levels (Long, 2004; Yasmeen, 2006; Heldke, 2005). Food media - and to a lesser extent

journalism - have been discussed with a focus on populist Western TV, print, and social media networks (Johnston and Bauman, 2009; Rousseau, 2012; Rousseau, 2013) and an eye to celebrity chefs (Mennell, 1985; Parasecoli, 2008), but is usually more theoretical and less focused on experience. In journalism, the popular culture genre has been debated and dissected in the thematic sense, as have the sweeping typologies of lifestyle and travel journalism (Hartley, 1996; Hanusch, 2012; Hanusch and Fursich, 2014). Discussions of practices and standards are a deeply researched topic, but are mostly examined in the context of corporate news journalism (Schudson and Anderson, 2009; Witschge, 2013). Finally, the way in which certain ideas (i.e. food as culture) gain societal import, while undergoing concurrent commodification with equal speed, will be examined in the context of transculturation (Hepp, 2014).

\section{Chapter 2: Literature Review}

\subsection{The Greater Con text of Food}

While there are very few theorists who have directly addressed my general topic, if approached thematically, there is a rich body of literature that provides insight into several of the pointed subject areas that concern this thesis, including food studies; media and journalism studies; cultural studies; tourism studies; practices of representation; the concept of the Other; cosmopolitanism and globalization; the 
anthropology of culture and travel; and the study of popular culture. This literature review will provide an overview of the key theoretical works that shall provide the foundation and context of this thesis. It will also use these works as sources for identifying potentially important theoretical connection points along the way.

Food as a general object of study is a suitable starting line. Food, drink, manners, and broad cultures of consumption are the recurring themes in the scholarship of sociologist Mary Douglas. She investigates both traditional and typical modes of eating in her native England and examines them in a series of practical exercises and graphic diagrams. Douglas makes a firm distinction between something that is crafted and something that is functional. She draws parallels with other functional examples of cultural production such as fashion, architecture, and utensils. Yet she also makes clear food does not generally equate with high (as in culture) artistic mediums such as music, painting, or sculpture. In assessing the sensory manifestations of food, she demonstrates how other social creations can serve as parallels. For example, on formal occasions one serves more refined foods, such as cream sauces and lobster, just as one wears finer fabrics like cashmere or silk to such a dinner party. On casual occasions, roughly textured foods like meat braises or chunky soups are served, mirroring the rough jeans or thick wool sweaters attending guests might wear as well. Thai food culture creates similar manifestations of functional contrast. Royal cooking tends to formality, employing smooth coconut milk, luscious white fishes, and golden sugar confections in the name of texture and visual impact, while less-formal street foods rely on cheap cuts of pork, chicken, and animal intestines as proteins. Says Douglas of the symbolic codes endemic in a meal (61): "If food is treated as a code, the messages it encodes will be found in the pattern of social relations being expressed. The message is about different 
degrees of hierarchy, inclusion and exclusion, boundaries and transactions across the boundaries."

In her much cited article, "Deciphering a Meal," Douglas seeks to uncover meaning endemic in the social structures and typology of meals as they are acted out by different types of social classes and on varying occasions. Hers is a sequential way of looking that aims to establish order amidst cognitive and sensory items such as liquids, solids, meats and starches. She extends this system of meal classification to manners and utensils - for example, the nature, length, and shape of forks or spoons that are selected for presentation and use. Douglas makes the case that what is at work in the context of a meal is less related to food consumption, and more about local traditions, social strata, and the practices they produce as objects and symbols. For Douglas, every eating decision is assigned its own brand of social agency, and thus with every physical manifestation in a meal one confronts powerfully manufactured symbolism. Douglas asserts that these ways of shaping a meal are so deeply conditioned in us that very few people actually realize when they are enacting them. Difference in patterning can be dictated by culture, geography, social class, or historical time. Though the rigidity of Douglas' analysis makes it a forced fit for some edible examples, the ideas of symbolic patterns borne by cultural and class demands is one that can be theoretically useful in many applications. Thai food has similar schisms that break down along lines of function, cost, and regional tradition. What kind of plates are used (plastic for street foods, celadon for Royal), what kinds of utensils are deemed suitable (fork and spoon for formal occasions, chopsticks for noodle soups on the streets), regional food types (informal grilled items from Esarn, slow-cooked upper class curries in Bangkok) - in-the-know Thai diners look for and read these signs and 
symbols when sitting down or choosing a place to, as they say, kin khao (eat rice, or eat a meal in Thai), and they act, dress, and consume accordingly.

Anthropologist Sidney Mintz's (1985) work on power, sweetness, and trade offers insight in to the comprehension of foods on a macro and cultural level. He divides the process of culinary meaning - and symbol-making into two streams, each with its own process and resulting attributes. The first is labeled by Mintz as "intensification." This identifies how certain eating habits are initially dictated by higher classes of society, and are then later adopted by a lower class through regular consumption, thus intensifying meaning through action and re-contextualization. He gives as an example the wedding cake as a centrepiece, which despite large discrepancies in wealth and circumstances, has retained the same meaning across class lines, thus undergoing "intensification" (as opposed to dilution) within food culture. The second process is one he terms "extensification." This refers to the manner in which the higher, richer, more powerful strata of society control the economic means and origins of a product (for Mintz, the example is sugar). Despite such large gaps in wealth and education, when lower social classes eventually get a hold of such a commodity, they are able to expand upon its inherited meaning through the different ways they incorporate it in their daily life, thereby adding new external values and symbolic meaning.

A much-debated topic, Mintz (1996) grapples with the subject of whether cuisines can be national, insofar as they are produced in social- and class-specific settings. Mintz is clear in establishing that he does not believe a national cuisine can exist without the amplification provided by the cultural marketing powers of nationalist settings (state dinners, high-class urban restaurants) and structures that also have political and economic power behind them (the nation-state, government, or some form of corporate might). Mintz more precisely labels cuisine as a concept that can only fully exist in a 
regional sense, underlining that it is in these localized settings that the circumstances arise and conspire to create an "ongoing, active producing of food and of opinions about food, around which and through which people communicate daily to each other." He lists methods, recipes, ingredients, and a transcending of class lines as other aspects of regional cuisine. For my work on Thai food culture, this is a very salient definition, one that can help illuminate possibilities and establish powerful means by which to communicate specific styles of cooking and eating in cultural settings.

\subsection{Theory with a Capital T: Globalization and Cosmopolitanism}

Food and its many manifest forms - restaurants, recipes, home cooking - exist on a global scale. To engage with cuisine means understanding the current context of what it means to be global in various cultural, media, or personal senses of the world. The works that follow represent an ambitious body of theory that will thus shape the context of our discussions of Thai food culture to come. The theorist Arjun Appadurai (2001) is best known for his writing on globalization, culture, and difference, as well as for more pointed essays on food, class, and culture in South Asia. In opposition to the way capital, politics, and economics structured the first wave of globalization as from above - or top-down as it is often pegged - Appadurai proposes an opposing view and dynamic for this same process: grassroots globalization, or globalization from below. The hyper-local exchanges and activity taking place under the larger structures of this process are something we must both observe and heed attention to, as they can go from being local to transnational in nature as they are inscribed in the media or exported in the form of culture - in this case of this thesis, of course, that of Thai food. In an era characterized by swift historical pivots and emerging cultural scenes that accompany them, this is a powerful way of calling attention to difference. In a famous 
call to action, Appadurai invoked the need for - and powerful agency of - certain "symbolic analysts" - loosely, this group might be identified as those with capital that is cultural, intellectual, or creative (9). Appadurai's aim is to motivate an alliance across borders and other boundaries to figure out new ways to look at both old and new problems, and to at the least engender conversation across borders and classes. Here, in the imagination of the many, Appadurai offers hope for a strain of globalization in which the energies of the hyper-local are given dimension and power through the process of globalization, and thus provide opportunities that can grow from bottom-up and not just top-down. Supporting and recognizing the hyper-local can thus serve as a counterpoint to the process of globalization.

Bruce Robbins (1998) takes a different approach to the same global subject matter, aiming to re-position the idea of the cosmopolitanism, a concept that initially implied a set of global elites who moved freely in their roles as expatriates, capitalists, and diplomats, within a world of dissolving borders. He re-jigs this definition in a way that is inclusive and future appropriate (1). This subsequent alteration of who falls under the cosmopolitan grouping means that some of the same cohorts that might well represent Appadurai's globalization-from-below- twenty-something travelers from emerging economies like Mainland China and urban India, foreign backpackers chasing noodles in Hong Kong, young chefs working for free in urban Thai kitchens - should now be seen as cosmopolitans as well. These cohorts, Robbins argues, have specific, important, and ultimately cosmopolitan viewpoints and should not be excluded (1). "This change in personnel implies a change in definition," he argues, and "...like nations, cosmopolitanisms are now plural and particular...they are weak and underdeveloped as well as strong and privileged" (2). Such tension between the plural and the particular is also of great importance in food and travel journalism. Or as Robbins 
puts it, “...instead of an ideal of detachment, actually existing cosmopolitanisms is a reality of re-attachment, multiple attachment, or attachment at a distance" (3).

Highlighting the emotional connections implicit in Benedict Anderson's concept of print-capitalism, Robbins believes that we are now living in an era of "electronic-and digital-capitalism, and now that this system is so clearly transnational it would be strange if people did not get emotional in much the same way, if not necessarily to the same degree about others who are not fellow nationals, people bound to them by some sort of trans-national fellowship" (7). By emphasizing trans-national and emotional attachments of current cosmopolitanism, Robbins re-constitutes Anderson's idea of an imagined community. Here, where borders dissolve like ice at midday in a Thai market, the readers of food and travel texts forge their own imagined communities through digital- and electronic-capitalism, transcending borders, pursuing new ideas and understandings in the context of food, travel, journalism, and culture. As Robbins describes, cosmopolitanism is fast becoming an "...effort to describe, from within the multi-culturalism, a name for the genuine striving toward common norms and mutual translatability that is also a part of multi-culturalism" (11-12).

A complementary approach to this idea by the Swedish theorist Ulf Hannerz's (1990) provides an equally useful mobilization of the term cosmopolitan by also accounting for the ever-mounting connections between cultures globally, and embracing the way people relate to one another as an act that is part of the negotiation of self-definition. His sketch of what is a cosmopolitan is an inclusive one based upon the defining relationship between those who are cosmopolitans journeying from outside a places borders and those who are local insiders. Some of the characteristics he deems crucial to this definition are a willingness to engage with Others; a comfort in dealing with daily life in varying global places and cultures; a construction of the self in the 
space where cultures reflect one another; an embrace of foreign-ness, but not a capitulation to it; and a propensity for finding shared moments or discourse with disparate people and ideas (239-240).

Hannerz forges the idea of cosmopolitans as in constantly changing relation and also in balance - to locals. Showing a concern for the importance of those seemingly opposite from us in culture and concern, he identifies locals as those who can easily identify a cosmopolitan for being at ease in a foreign zone. But what separates locals-as-locals is the deeper nature of their knowledge and community relationships. They are connected in the most basic and social ways to people in their own direct areas, bound by language, customs, and shared historical and current experiences that only they can understand on a certain level (249-250). To that end, Hannerz's concept of the cosmopolitan can serve as a useful way for me to connect food cultures from one part of the world for another. With their talent for identifying what is 'authentic' and understanding cultural applications in many geographical settings, cosmopolitans (in this sense) will help provide a powerful tool of connection and articulation in my research. They will help me construct a middle ground between tourists, travelers, and locals both in a country like Thailand and, perhaps, in Thai realms of culture - restaurants, Little Bangkok parts of town - around the world by utilizing the experiences of this unique breed of traveler and global citizen.

While Ulf Hannerz's previously discussed work on cosmopolitans and locals remains an iconic work for cultural studies, it is nevertheless almost two decades old. While still relevant in its broad conception, it is useful to supplement it when using it to help theorize things that are happening today. To this end, Ulf Hannerz's Interview on Transnational Cosmopolitanism with Teri Rantanen (2005) serves an important role as a tool for articulation and as a theoretical bridge between an evolving notion of what is 
cosmopolitan. There are many interesting and useful features of this interview, ones that serve to illuminate different aspects of his work in a variety of areas. First, it is perhaps important to know that both Hannerz and Appadurai knew each other's work well and, while they did not collaborate, this may account for some of the compatibility of their theories. Second, his work took as a form of inspiration migration studies between the first and third world, a path that while different for the foods of Thai culture, nonetheless has some parallels in the route the cuisine takes as it travels across borders. Third, Hannerz discusses his conceptualization of what is cosmopolitan as helping to attend to ideas, people or cultures that can be located somewhere between the ideas of what is transnational and what is global (13-14).

Giving specificity to such a cultural experience also helps to buffer the experience of something such as Thai food culture and those who relate to it through travel. Going further, he emphasizes the importance of inter-connectedness on a human level, as well as the continued diversification of trans-national contacts. This insistence on the transnational warrants attention and importance of the word and term as one that should be circulated alongside - if not in place of - ideas such as cosmopolitanism and globalization. Fourth - and another term to add to key vocabulary in the conversation to frame what is global - is the idea of a network, which Hannerz recommends to deal with "borders, space, and scale (15)." To this effect, he cites the role of the British social anthropology tradition on this type of work, and gives as an example following personto-person connections that transcend borders and establish networks through social media, smart phones, and other modern technological devices. Fifth and finally, Hannerz re-affirms his obsession with the media and, specifically, foreign correspondents - calling them out as perhaps the ideal cosmopolitans, a topic he devoted an entire book to. Given that food and travel journalists fit this role, it is a 
telling parallel to draw. Taken together, these points help locate the importance of Hannerz's work and contextualize it for the times we currently live in.

\subsection{Representation, Power, and (Culinary) Others}

One of the most crucial ideas in cultural studies is the system of representation and the idea of how certain dominant cultures contribute to the construction of the 'Other' - in short, the way we demarcate and delineate ourselves from one another in relation to ethnicity, race, culture, and perceived differences. This idea will play a central role in this thesis, focused more precisely on the culinary Other of Thai food culture. Stuart Hall's (1997) defining work concerning this idea, "The Spectacle of the Other," guides readers through definitions of as well as various counter-strategies of representation. Focusing on photographic representations of black athletes, he examines the binary relation of Us and Them, unpacking racial discourses through historically informed observation, semiotic analysis, and anthropologically rooted commentary (228). Such ideas of cultural binaries are also an area of conceptual concern for food and travel journalism. Hall tables a way to interpret these situations, saying "Meaning Floats. It cannot be finally fixed. Attempting to fix it is a work of a representational practice, which intervenes in the many potential meanings of an image in an attempt to privilege ones" (228). A quick look at some scenarios that might arise in the context of this thesis: locally-educated readers in a global capital such as Sydney will bring to their reading of an article on regional Esarn Thai food a different set of preconceptions than a Thai, perhaps educated in London, perusing a piece on where to find 'authentic' regional Thai food in Las Vegas. Here, the set of circumstances under which Thai cuisine assumes a global profile is, and its meaning is constantly re-defined depending on audience and diner interaction. 
Foucault's (1983) work on the subject as it relates to the circulation of power observes many of the same issues within the process of identifying Others, shedding light on the origins of power and the re-imagined role they play when looked at with the media and journalism as subjects. Foucault focuses on "dividing practices" both within the personality of the subject and in relation to the subject's role vis a vis others (208). His concern lies less with macro ideas foisted from one dominant group onto another weaker one, and more with the individual/subject themselves (209). Foucault takes as his object of debate a "series of oppositions" - men and women, parents and children - with a broad focus on authoritative power. At the core of these struggles lies the role of the individual, the process of one being trying to assert themselves against the power and authority of a many.

It is this very power that "categorizes the individual, marks him by his own individuality, attaches him to his own identity, imposes a law of truth on him which he must recognize and which others have to recognize in him. It is a form of power, which forges individual subjects (212)." Foucault frames these struggles in a cross-cultural way - ethnic, social, and religious - that departs from that of Hall. These categories reflect the same social class concerns that inform the globalization work of Appadurai and the cosmopolitan approaches of Robbins. Foucault assigns social agency to the "knowledge of man around two roles: one, globalizing and quantitative, concerning the population; the other, analytical, concerning the individual" (215). The tension between these dueling roles, in an operating theater defined by power, could be an editorial focus for food and travel editors. Questions they might ask themselves while writing story briefs include: How might we empower those different from us? How might we diffuse the imbalances endemic in the act of covering developing countries such as Thailand? And 
how can we engage with and represent the cultural and culinary other in a positive way?

Philosopher Lisa Heldke situates concerns about Othering in relation to food and culture (2003). She identifies an increasing obsession among foodies and "food adventurers" with consuming the culinary cultures of those different than us. In this way, eaters from a richer, more dominant culture turn another, developing culture in to an edible Other. The process is characterized by the marking of difference from one cuisine to another, and deploys ideas and descriptions of foreign foods as the exotic, the regional, the authentic, and the local in a way that forms a conceptual fence in which various ideas are linked together and contribute to a binary definition that forges a gastronomic us and them.

Returning to Hall's discussion of Others, he also presents a useful set of strategies for battling the oft-negative process of cultural representation. Broadly defined as transcoding, the proposed techniques include actively reversing stereotypes; expanding the range of complexity and representation; and rocking the boat of representation by contesting it from within (272-274). It is in this between-worlds space of power and representation - and re-appropriation - that the editorial and publishing structures of food and travel might offer alternatives for change.

\subsection{Changing Notions of Eth nogr aphy, Culture, and Travel}

The binding theme of the following theorists is the broader idea of culture and how it has become an important mode of experience for those who partake in the cultural side of experiences such as tourism, food, and travel. Historically, the idea of travel was very narrowly defined as leaving one's own country or home to get away to 
another, ideally far-off, distant destination - or as the saying goes, attempting to 'get away from it all.' Since its canonization in Theodore Veblen's Theory of the Leisure Class (1900), tourism has been a pursuit - and social phenomenon - d riven almost solely by upper-middle and upper class members of Euro-American societies. For the better part of a century this relationship was unbroken, though at various times it took on Colonial, post-Colonial, and Orientalist modes of perception. Engaging with the following theorists will help better define the role played by food cultures in their relationship with travel (and tourism) and also to give more depth to the act - or is it a performance? an experience? - of cooking and eating the food of 'other' countries like Thailand in its cultural, touristic, or sensory dimensions.

Sociologists Chris Rojek and John Urry (1997) take as their objects of study tourism and culture, focusing on how these concepts are mobilized as signs, objects, or individuals in various systems of relation and representation. On a macro level, they look to question and de-construct the entire category of tourism, asking whether one can delineate any boundaries between it and more straightforward acts such as leisure, culture, pastimes, or even taking a walk in a new neighborhood. Their works' exploration of the relationship between a tourist to those in the country they are touring is a robust parallel to the experiences of those eating in foreign countries, or those simply eating a foreign cuisine in their own country - after all, the idea of tourism need not demand actually going somewhere far away. Rojek and Urry underline the fact that tourism is often defined, at any one time or place, by a relationship with an Other, a process based on changing locations and thus one which changes the meaning of tourism as it is constantly in flux geographically (1-2).

Rojek and Urry are concerned as well with the relationship between New Media and mass travel. They describe it as one increasingly defined by and focused on culture 
- they label it culturalisation - especially the ways in which people of varying classes are, in areas near and far from home, constantly seeking, defining, constructing, and deconstructing forms of culture. As a result of these complex processes, Rojek and Urry believe the boundaries of tourism and culture are becoming forever blurred. They also further identify tourists as semioticians, people seeking out cultural signs and markers with which they can forge their identity and confirm their relationship from one area of the world to another (4).

Of special interest to this thesis is the way in which Rojek and Urry cast an academic gaze on the role the senses play in relation to tourism. Historically, they demonstrate, sight has always been treated as the most privileged and powerful sense, so much so that other senses were treated with shame. They give examples of this in the way smells in places like slums were reduced to dirty, foreign areas to be avoided, and how this act of going to see lower-class parts of a city helped originate the culturallyapplied term 'slumming.' For the purposes of my research, being able to extend the importance of the senses in the context of eating captures their importance in a way that is socially relevant for tourism. So, too, does their approach to tourism and culture, as it provides an alternative to what can become all-encompassing or reductive concepts and re-focuses them in a way that helps approach more specific problems and objects. These theoretical are powerful ideas in relation to my topic and its combination of tourism, culture, sensory engagement, and communication (7-8).

Much like the journalistic texts that transmit the encounters with Thai food culture at the center of this thesis, anthropology also foregrounds the observation and textualization of cultural experience as a core part of their mission. Clifford Geertz (1994) achieved renown for his essays on foreign cultures and the importance and meaning of conducting ethnographic research. His most famous essay is about the 
mobilization and application of the term 'thick description' (as adopted from Gilbert Ryles) - the ability to inscribe events in the field in a way that conveys their social meanings and symbolic values without sacrificing the local context (6). For Geertz, culture is the defining concept for his field - and, indeed, it holds a similar primacy for my topic - and doing on-site work and research takes unlocking the meaning of this word as its primary goal, then explicating it on a level that allows little details, actions, and events to speak to greater issues. What one must look for while in the field are the way that social structures merge with - and attach themselves to - more complex conceptual structures, allowing small actions to unfold into deeper meanings for a society at large. It is in the details that meaning hides, and in identifying, parsing, and recording these that the ethnographer earns his keep. Geertz writes passionately of this search for meaning: "A good interpretation of anything - a poem, a person, a ritual, an institution, a society - takes us into the heart of that of which it is the interpretation (18)." Turning his focus to the act of writing something down after thoughtful observation, he proclaims the role of the writer - or the ethnographer: "The ethnographer 'inscribes' social discourse; be writes it down. In so doing, he turns it from a passing event, which exists only in its moment of occurrence, into an account, which exists in its inscriptions and can be re-consulted (19)."

By understanding how to take a deeper look at events that unfold in real time within one's site of study, it is possible to enlarge the realm of discourse that surrounds the fields we as academics have chosen to examine. As my object of research is the food culture and local interactions of a developing Southeast Asian nation - not unlike the island of Bali where much of Geertz's work was centered - the lessons and tactics Geertz's work promotes and operationalizes provide very useful tools of examination. Geertz's methods provide a way to enter into conversation with a world far away from 
one's own, an intellectual thruway for deciphering the meaning of objects and symbols in the context of travel and culture. Above all, they provide a way to think about texts with which audiences can interact and foreign cultures can thus penetrate regions and peoples beyond their own.

Anthropologist James Clifford's (1997) work represents a more contemporary step in ethnographic explication, for he goes beyond mere small-village/large-meaning binaries that defined the field before his intervention. He tackles a combination of issues ranging from the problems inherent in ethnography to the way cultures and travelers can no longer be neatly marked in any way. He also deals with localization, questioning under whose terms the idea of being a local are discussed and emphasizing the ways in which different communities cordon off insiders from outsiders. Picking up the idea of socially constructed cultures and touring from sociologists like John Urry and Chris Rojek, he asserts that roles inevitably become mixed when travelling and cultures are involved or represented, citing its use as such a lens in Pico Iyer's travel classic Video Night in Kathmandu (97). For Clifford, ethnographers have foregrounded a way of dwelling abroad over the equally important and complex way of travelling especially in subtle ways - and forgotten that the role of the traveler is personal and contextual, something he finds highly problematic (102-103). Clifford also underlines the importance of remembering that even if in far-off (read: exotic, new, and foreign) places the locals also maintain varying types of relationships to the outside world and that these must be attended to, even if they occupy very different points on a insider/outsider, local/global continuum - culture "as travel" as Clifford points out (103). Here, the defining poles of Hannerz's cosmopolitan-and-local relationship are similarly prescribed and re-cast as a relationship between the internal and external member of a culture. 
Clifford seeks to find - and seems to imply the same for those who follow him "chronotopes," or places which help systematically and symbolically organize time, space, and representation, as a way of setting the scene for relations between different peoples and for culture and travel to play out as actors whose actions must be interpreted for meaning (101). He uses hotel lobbies, traveling Hawaiian musicians, and the unique mix of connectivity and networked transience of motels as examples. Through these examples, Clifford confronts the idea of culture as travel, and he tries to balance specificity and movement with the ideas of dwelling-in-traveling (how one relaxes into settings or carries home while on the road, so to speak) being reconceptualized as cultures that serve as sites of both dwelling and travel. Here, his ultimate goal, whether through chronotope or cultural demographic, is to dislodge the term travel from the highly privileged, wealthy, male, and Western history of this particular endeavour. Clifford terms this a "cultural studies approach to specific histories, tactics, everyday practices of dwelling and traveling: traveling-in-dwelling, dwelling-in-traveling." Merged with Clifford's work on thick description, this highly specific way of measuring and meaning-making in the service of attempting to translate foreign cultures is something that this thesis can apply to various types of eaters, cooks, travelers, home cooks, and the many hyper-specific and local moments this thesis seeks to de-code.

A very recent work, "Transcultural Communication" by Andreas Hepp, is an important "bridging" or "articulation" theory along with the others identified in this section, a way to connect what may seem as disparate ideas or personnel from distant cultures. Working in the area of media and communication studies, his book develops concepts that capture the dynamics of people, ideas, goods, and other cultural flows that move, to take a term from Hannerz, across borders, but not in ways that are entirely 
global. His ideas can be used to help pinpoint the person-to-person relationships that may originate in a smartphone keystroke in one country and, in a flash of date and a beep of reception, be received on the other side of the globe almost instantaneously. From end to end, this journey of social actualization constitutes issues of what it means to be local and act global, alongside questions of culture and consumption. Working through an historical arc to identify the postcolonial era we now function in as a result of a larger process, Hepp asserts that it is also a process that cannot be confined to any one place of "cultural encounter and mixing." For Hepp, the inherently global ways of communication are now the everyday and their contradictory state must be accepted and looked at critically. He provides a very useful four-part breakdown of ways to understand both transculturality and transculturation. Philosophically, he notes that the transcultural transcends our ordinary notions of culture, but also "passes through traditional cultural boundaries as a matter of course." His goal, thereby, is to try and "articulate" this act of cultural embodiment. Anthropologically, he identifies these twin concepts (transculturation and transculturality) as a way in which to elucidate how one transitions between cultures - from East to West, for example - illuminating the fact that with such an act culture is not merely acquired, but uprooted (15). Economically, he looks at transculturation from a perspective of HR or management, citing diversity as a lens from which to view corporate environmental engagement between individuals, as well as how to take decisions, resolve conflict, make deals, and other types of working together. Though this is the least natural fit for my work, it also has issues if, say, a set of cooks must operate across linguistic or cultural boundaries. Finally, he looks at this process from a media and communications perspective, and establishes that when it comes to transculturalism, the core belief is that one must think of "all cultures to be inherently mixed (15)." 


\subsection{Theories of Touris $m$ and Travel}

Whether in travel, dining, or cooking, the notion of authenticity lies at the centre of any quest for what we perceive to be culturally essential and traditional, thereby framing the experiences of present-day tourists and eaters. Dean MacCannell's (2013) ethnography not of tourism, but of the tourist herself places this concern with authenticity at the heart center of its work. He traces an evolutionary arc from Charles Sander Peirce's original formulation of how signs represent certain things to certain people through Ferdinand de Saussure's identification of the arbitrary relationship between signifier and signified. He limits markers of meaning to include only the information they present. Finally and crucially, he mobilizes Erving Goffman's division of front and back stages in social settings as a way to describe the process of performance and negotiation that actors on the stage of tourism undergo while searching for the elusive confrontation with what is authentic (110-118).

The idea of staged authenticity in constructed front and back areas provides a lens with which to view many touristic situations. For MacCannell, the drawing of such social boundaries constructs meanings that sprawl "across the bridge between structure and consciousness built by Goffman (92)." MacCannell introduces the idea of mystification to his analysis of the interaction between hosts and guests within social staging areas. He wields this term in a way that gives substance to actions that eventually help one party defend or deflect against the advances of an Other. In brief summary, this aims to describe the way social actors on either side of a tourist interaction locals/foreigners or insider/outsiders - produce and then protect a version of "authentic 
reality" by employing some kind of technique or enactment. In the context of Thai food, this might mean choosing to theatrically finish cooked dishes in front of guests, while locking meat preparation and other 'dirty' actions away from curious tourist eyes in order to preserves the back/front division and thereby script social confrontations. Through this premeditated construction of what can or can't be interacted with by a tourist, mundane actions or visual arrangements appear mystical in the eyes of a traveller and reinforce the front/back division in favor of the local.

MacCannell identifies the potential for an uninvited penetration of a back region by a tourist/guest as a source of stress in the lives of the local/host. There is an unease, he finds, that circulates on both sides of the authenticity/staging bridge, underlining the imbalance of many interactions in the context of travel. As he puts it, the "possibility that a stranger might penetrate a back region is one major source of social concern in everyday life, as much a concern to strangers who might do the violating as to the violated." This relationship between unknowable confrontation and fetishized authenticity adds a phantom tension to the way locals approach any potential encounters with visitors. As MacCannell concludes: "Everyone is waiting for this kind of intrusion not to happen, which is a paradox in that the absence of social relationships between strangers makes back region secrets unimportant to outsiders (93)."

Philosopher Lisa Heldke's (2003) essay on food adventuring take culinary travel as their central concern, and as such are very useful for deepening this idea of authenticity. She speaks of a recurring set of concerns that defines the culinary travelers search for authenticity, one which seeks out edible or culinary Others, new-ness, and the exotic, and symbolically layers them one on top of the other, adding greater conceptual strength to the whole. Citing a National Restaurant Association poll, she demonstrates that a large majority of American diners assess a restaurant on whether or 
not it is authentic and value a mark of authenticity (and not taste) as the primary reason to seek out new places to eat and travel (24). In a later essay on the same topic, Heldke expands on this pursuit of the authentic (2005) as it relates to exoticism: Novelty is also attractive to adventuring food colonizers because it marks the presence of the exotic, where exotic is understood to mean not only 'not local' but also 'excitingly unusual.' The exotic, in turn, we read as an indication of authenticity (331).”

There is a common disdain for framing the Other in a reductive way that runs though the work of both MacCannell and Heldke, and there is much to learn by stirring their viewpoints together. The former equates the glee with which Westerners assign exoticism to the tourist clichés of "off the beaten path" and "in with the natives." MacCannell observes that, often times, a situation where a tourist does make "an incursion into the life of the society they visit, or are at least allowed to peek into one of its back regions," happens by accident and underlines that certain tourists do knowingly create situations in which this is likely to happen (96-97). As it would follow, the hosts who engage with such guests also tend to create staged settings with more intimate registers than the typical front stage order would imply. This layered construction adds intrigue to all situations involving a local and tourist, and beckons ethnographers to keep this consideration in mind as they attempt to "write the culture" of an Other.

In one last example of staging, MacCannell identifies restaurants in Denmark as having a uniquely subtle dissolution of the front and back stages. He zeroes in on the now-frequent restaurant design choice to have an open kitchen, one that blurs the boundaries between front and back by presenting what MacCannell terms a "living museum for which we have no analytical terms (99)." As theatres where multiple actors (waiters, bartenders, cooks, honeymooners, corporate dinners...) come for multiple purposes (an engagement, business, family matters, tourism...), restaurants are buffet 
tables-full with symbols and signs of cooking, design, and consumption. Socially, staff are trained to create pre-scripted interactions when they encounter guests (service philosophy, visual plating standards), who in turn embrace these rituals as fact when they are actually simply stops on the way to a more layered product redolent with symbolic authenticity. These increasingly complex social constructions in the context of culinary consumption are important ideas to keep in mind when evaluating the eater/restaurant or eater/cook divide when it comes to Thai food culture and the media.

The subject of Thai food culture and the tourists and texts that give it symbolic shape also demands a re-ordering of the way we approach them with our various senses. Historically, sight has for many centuries been the dominant sense, and it continues to be the most powerful way to transform viewers or readers into social actors. (Witness, for example, the global reaction to the photograph of a young Syrian child, his life expired, against the tranquil backdrop of the seashore). Susan Sontag's essay on photography (1977) demonstrates this powerful cognitive privilege, and Hannah Arendt argues that "from the very outset, in formal philosophy, thinking has been thought of in terms of seeing (5)." Rojek and Urry (1997) cite several instances in which theorists such as Walter Benjamin and Michel Foucault duly demonstrate the allencompassing influence of the image. To loop our discussion back to tourism, the things one seeks to view as tourist sites - a Hindi shrine, a view of the Mekong River, teak Lanna temples - become signposts for travel and thereby give form to the experience of the tourist. Rojek and Urry believe the primacy of visual tourist symbols and signifiers "...gives shape to travel" and "constructs a twentieth-century sense of what is appropriately aesthetic... and it produces an extraordinary array of signs and images which constitute a visual culture. (9-10)" 
There are many ways food culture demands a re-deployment of the senses. Couples go out to dinners where they take perishables prepared by the bare hands of another (cooks) and put them into their own bodies (those of lovers), an incredibly intimate act. Scientists have long championed aroma and smell as accounting for the majority of what we conceive of as taste, with sound and texture adding oomph to the discussion of sensory consumption. The last decade has also seen the rise of technology-driven cooking and molecular gastronomy, whereby scientific methods are used to subvert foods in often counter-intuitive ways - the spherification of olives, root vegetable 'powder,' and liquid nitrogen-frozen ice creams in flavours like bacon and eggs, to name a few. Texture and temperature have long served as cultural markers for identifying what we are eating and when and where we are eating it. Take the favoring of cold foods in hot weather for Westerners, and the way many of the same demographic struggle with eating hot foods in the tropics, for example. As Mary Douglas has shown us in her writing on meals and social patterns, how we prepare what we eat and when and where we eat it builds meaning socially. The sensory turn will hold great import as it comes to evaluating food experiences as they relate to Thailand.

\subsection{Media as a Means of $\operatorname{Tr}$ ansmission}

This section of my literature review trains an eye on journalism as a whole, as well as how its historical development has affected its many forms today. It examines a broad range of scholarship, from an inquiry into what defines journalism by newspaper editors Bill Kovach and Tom Rosenstiel, to research on the divide - or is it dissolving lines? - between audiences and publics by Sonia Livingstone. John Hartley's work illustrates how popular culture interacts with journalism and, by extension, the many 
forms of media it uses to deliver information to readers of all types. Finally, Folker Hanusch and Elfriede Fursich's writing on the highly specific field of travel texts helps answer questions and pinpoints how this particular strain of journalism continues to rise in both the volume of work produced and the importance of the content itself.

Bill Kovach and Tom Rosenstiel (2001) take present-day journalism on as a kind of professional project, and they begin by answering the question, what is the purpose of journalism? Among the core answers that are of importance to my work on journalism about foreign cultures and their food are an obligation to the truth, loyalty to citizens, being a discipline of verification, acting as independent practitioners, striving to make things significant and relevant, exercising a personal conscience and recognizing the rights and responsibilities of citizens (9). For Kovach and Rosenstiel, journalists can help create a sense of community beyond ordinary national or political controls. By helping define such a community, journalism can, in turn, help readers identify with like-minded others, a sentiment that recalls Benedict Anderson's (2006) concept of imagined communities that come together in a public way when united by emotions and ideas. The main difference being that, in the age of Web 3.0, it is digital-capitalism and not (as Anderson originally wrote) the role of "print-languages" that serves to shape consciousness on a national level (58).

Kovach and Rosenstiel offer an expansive definition of journalism, one that goes beyond being a mere nod to social connections. They underline that every generation, no matter the century, has re-defined journalism in relation to the available technology and social environments. Yet, despite the difference in topics, almost every one of the current media cohorts (fashion, sports, city news) tends to list almost identical values such as verification, truth, providing a sense of being a public - when asked what defines their field as a profession. To that end, Kovach and Rosenstiel highlight certain 
roles (and goals) that journalists must now play. They include being an authenticator, helping readers make sense of the world around them, and bearing witness to things others cannot. Further, they identify some secondary yet wholly contemporary roles such as intelligence or information curator, community builder (especially online), and as an empowerer helping audiences re-tool and learn about how to operate in the current media environment (27-29). Of special interest for my work is a section devoted to the rising coverage of culture, trends, art, travel, and other so-called entertainment topics. Despite some criticism from traditional news supporters, Kovach and Rosenstiel are firm in their stance that the more ways a reader or audience can navigate their lives, the better: "...the reporting of culture, social events, trends, and sports, and much more form a vital part of how we come to understand community and civil society and how, as citizens, we navigate our lives (31)." The aforementioned roles and responsibilities lend context to understanding the place and power of the more specific types of journalism - food, travel, culture - my research seeks to engage with. Through discussion and examination, this will also help me identify a similar set of professional norms and values, rules that can potentially better the still-maturing area of food and travel journalism.

Media theorist John Hartley (1996) takes a broad and semiotics-driven approach to journalism and all related media forms on as his project. To begin, he declares it to be the most important sense-making practice and textual system of modernity we have. Comparing it to drama in the way it spans wide global territory through multiple modes of representation (and for multiple social classes), Hartley also declares journalism an especially interesting site for discussion as journalism as, unlike many textual forms, it claims all it puts forward to be the truth. For Hartley, as with many of the aforementioned theorists, different social classes exercise different types of power. In 
journalism's case can be readily observed in the language of journalism and its various forms of delivery and media. As a textual system in which symbolic signs and discourses circulate, he feels journalism "needs an interdisciplinary investigation, organized loosely around its textual features...around its social existence (35)." Hartley identifies journalism as a purveyor of "knowledge, symbol, image, information, story...Journalism is a capitalization of language, adding value to culture (37)."

As a greater system of communication, journalism constantly produces and transfers images, objects, signs, and symbols. Hartley demarcates three levels at which this occurs. The first is the public sphere, a concept that was originated by Jurgen Habermas as a place where readers and news consumers go to become part of a larger, connected, and opinionated public - to create, crucially, public-ness and generate symbols and discourse. (This idea has also been re-cast in modern terms by Yochai Benkler (2006) as the networked public sphere, a space where web-driven configurations and aggregates of readers create their own inter-connected public sphere in virtual space). Here, informed and inspired by journalistic texts and linked to one another through ideation, audiences and readers become - in name and symbol publics and distributors of discourse. (31)

Hartley pinpoints the second level of media functionality as the semiosphere, a place in which objects produced by music, art, advertising, writing, and speech commingle. And he demarcates the third and final level as the mediasphere, one where external signs such as logos, brands, catchphrases, even Roland Barthes' "empire of the sign," are operationalized. Taken together, these three sites of symbolic interaction and media production, root into the notion of print-capitalism furthered by Benedict Anderson in his work on imagined communities, only now their interaction is highly 
globalized and fed by a post-Web 2.0 existence of digitized-and virtual-capitalism (3132).

Beyond his semiotic system, Hartley takes a sweeping approach to the media across time and topic. He links journalism to a series of historical developments that include urbanization, industrialization, developmentalism, and consumerism. He also echoes Kovach and Rosentiel by calling it a sense-making practice. As a profession, Hartley makes it clear that, while journalism teaches certain technical skills at the entry or university level, it does not ultimately control its own work conditions, like architecture, medicine, or the law do. (As an example, even bylined writers do not own their copy, the corporations they work for do). His observations are telling. For example: while ethnography and journalism share common values such as verification and the use of sources, academics MUST cite theirs, while reporters do not have to. An awareness of the political economy of journalism and the media profession as a whole will be important considerations for my thesis as it tries to assess and measure which values, norms and structures - or lack thereof - need to be mobilized to provide a potential set of best practices and standards in the area of food and travel content.

The work of Folker Hanusch and Elfriede Fursich (2014) helps connect the dots between traditional newsroom norms and ideals and travel journalism's more specific relationship with foreign places and cultures. They assert that foundational ideas such as verification, fairness, independence, and truth seeking are also adopted by travel journalism. They also generally define journalism as a greater textual system that helps define various audiences, and in some cases create groups of readers who, in the end, become publics. This distinction is an important one, as the seriousness of journalism is often correlated with its ability to motivate audiences to act and, in their most powerful state, to create moments of "publicness," as Habermas outlined in his work on the 
public sphere and as contemporaries such as Yochai Benkler (2006) have adapted as the "networked public sphere."

Identifying travel journalism as a singular field within the greater bounds of media, Hanusch and Fursich then outline what they view as the most salient features of this particular craft. First, the importance of representing Others, their cultures, and their countries is "the main purpose" of this medium. Second, they emphasize that media can fundamentally shape the way tourists think about other cultures. Third, they stress the sheer expense of travelling to, working in, reporting from, and producing journalism about foreign places. Fourth, they underline the market-oriented stance of some lifestyle journalism - of which food and travel is a specific subset - in which some editors and publishers approach audiences as consumers rather than citizens (9-10). For them, these are potentially problematic issues, and they might be readily extended to the chosen area of this thesis, adding food to the mix with travel journalism. Here, a similar logic and practice can be seen at work, effectuating what Hanusch and Fursich describe as: “...factual accounts that address audiences as consumers of travel or tourism experiences, by providing information and entertainment, but also critical perspectives (11)." This duo's work on travel journalism is by far the most exhaustive of its kind, and the only one that directly addresses at least part of my topic (travel and journalism). This thesis makes clear distinctions on how it departs from their definition, and how their theories might be contextualized differently when the topic is a more specific blend of culture, food, and journalism.

Sonia Livingstone's (2005) theorizes the relationship between audiences, readers, and content, as well as the journalistic practices that separate and constitute them. She highlights systemic issues that include political, economic, and professional influences on media institutions, and explores how to interpret the multiple aspects of meaning in 
media texts. It is in this space that Livingstone highlights matters of interest for the field of food and travel journalism: the complex interplay between audiences and texts, and the public friction created by the polar tendencies of "centralization/standardization and diversification/innovation" in the current environment of technology (27). Livingston argues against the reductive polarization of "public and audience," asserting that "...media appear to be simultaneously expanding the scope of the audience and diminishing the realm of the public, leaving few if any aspects of social or personal life unaccompanied by or independent of the media (19)."

Livingstone's elucidation of the most current phase of audience development provides a framework for my food/travel audience to emerge as a networked set of citizen-consumers: "...the diffused audience is no longer containable in particular places and times, but rather is part and parcel of all aspects of daily life, certainly in industrialized nations and increasingly globally. (26)" Here, in a space that can be as transnational as it is driven by special interests, the highly globalized, obsessed-with-theforeign structure of food and travel journalism can find ways to further grow the roles of audience and public in a way that brings them closer with each new reader. Livingstone's work dovetails readily with Hartley's thoughts on audiences. It also helps further address the complex role of audiences and Hanusch and Fursich's concerns about the market slant of travel journalism.

Although the still-evolving practices of food and travel journalism are, in some ways, unique and divergent from the structures of traditional news, there is still a strong link between the standards and practices of the latter and the professional norms of the former. Relying on cultural theories and a historical approach to the development of journalistic professionalism, Schudson and Anderson's (2004) discussion of concepts such as objectivity and truth seeking identifies core ideas which food and travel 
journalism can adopt as their own (92). They underline the normative importance of such ideals as the bedrock on which journalism should be structured as a respected and important profession. As pillars of the craft, these ideals also occupy the same role for food and travel journalism, albeit with a divergent set of story structures, audience relationships, and approaches to representation than the more classical stance of news. In mapping various levels of professionalism across international borders and foreign strains of the profession, Schudson and Anderson cite Hallin and Mancini, noting that while professionalism might be consistent, "the social bases of their professionalism" and "the specific content of their values" diverge (94). While splitting socio-cultural foundations, they again invoke Hallin and Mancini in a future context that opens the door for new strains of journalistic professionalism as might apply to the food/travel area: “...professional journalism might have different bases cross-culturally, historically, and even in the future. The end of objectivity, even if it arrives, may not signal the end of professional journalism" (94).

It is within this precise context that food and travel journalism operates. Unlike news reporting, the opposing (at least to traditional journalism) idea of oft-subjective, narrative-based, first-person stories are the focus of food and travel journalism. Heavily freelance-based, food and travel journalists share a set of common goals for discovering other food cultures and revealing their subtleties through personal experiences. Their goals include inspiring the reader/audience to act, while actualizing food travel and forming emotional connections. Buoyed by a billion-person tourist market, this is one strand of journalism that is healthy, active, growing, and potent.

Examining how journalists - and the vocation as a whole - have reacted to the new forms of media birthed by emerging technologies and their adoption by audiences around the globe, Tamara Witschge (2013) provides an up-to-date assessment of 
journalism as a professionalized craft. She looks at the different strands of thought in the newsroom, evaluating how traditional values are point-counterpoint with fluid systemic changes and challenges (161). One of her main issues is trying to square "high standards versus low practices," with the idealistic nature of journalists in a commercially driven, time-tight environment with unrelenting deadlines (161). Witschge pinpoints journalists as "knowledgeable people working with certain standards," and she emphasizes that standards are regarded as professionalize ones that serve commercial and entertainment aspects, but also ones of public service or political value. According to interviews, things cherished by journalists include providing good information and expert commentary, as well as long-form and original stories - though in traditional newsrooms these are also in decline (164-165).

\subsection{Food, Texts, and Media in a Cultural Role}

Fabio Parasecoli approaches the human consumption and interaction with food through the lens of pop culture (2008). Unlike other theorists who take more philosophical or literal approaches, his view is of the bigger societal picture. Drawing on the work of Arjun Appadurai and Guy Debord, he paints a picture of our relationship with food as one of spectacle, imagination, and fantasy that we, as humans and eaters, construct through social action. He elevates the buzz, the talk, the media surrounding food to the level of discourse and cultural identification. His is a highly social approach to food culture theory, one in which food is on par with other forms of pop culture (film, theater) in the way we use it to delineate where we stand as individuals and with regard to social class.

This approach forms the foundation for a proprietary system of signs, denotations, and connotations influenced heavily by Roland Barthes' approach to 
culture in the way it produces myths and creates signs with salient meaning. Much as we have already seen the meaning of Western identity sliding or in relational form depending upon the foreign culture or Others in readings by Heldke, for Parasecoli this same process of relation and relocation holds true for the meaning of various elements of a food culture (136-137). For example, a salad has different meaning depending upon the culture/geography it is assembled and eaten in, just as a plate of offal is received with disgust in some places and desire in others. As explicated from the work of Jacques Lacan, for Parasecoli the materially bound sign may stay the same, but the meaning constantly shifts with the corresponding geographic and social spaces (91). Because the work of Parasecoli takes a meta-view of the processes behind food culture, it will be of great use to me as I try to place local Thai food culture as it is represented in Thailand and abroad within both reader actions and editorial decisions. Re-applying some of the linguistic and sociological theory Parasecoli puts into play will allow this thesis to better measure the power of the media in relation to a food culture that's quickly gaining a global profile in presence and meaning.

Josee Johnston and Shyon Bauman (2010) approach food in a more interdisciplinary and cultural way. They begin by re-applying the topical and socio-cultural framing of Arjun Appadurai's concept of the "scape" to one more fitting the topic of this thesis - as a foodscape. For the co-authors, this is a space where eaters, readers, and cooks socially construct a world of place, meaning, and people in relation to their consumption of food and its ascending cultural power. The term is useful in that it recognizes that food and its meaning are under constant mediation by the media, the government, and corporate and media concerns. This idea helps highlight the bundled relationships between culture, taste, and physical spaces (2-3). Johnston and Bauman characterize their use of the term as "the cultural spaces of gourmet food...a dynamic 
social construction that relates food to specific places, people, and meanings...a foodscape may variously capture or obscure the ecological origins and social implications of food production and consumption. First, it recognizes that our understandings of food and the food system are mediated through social mores and cultural institutions like the media; second, it suggests the interrelationship between culture, taste, and physical landscape (2-3)."

The second over-arching point that Johnston and Bauman make takes aim at giving a name to the current way food culture - or taste cultures as Herbert Gans might say - is constructed. Much as in film or music, they stress that the once-firm divide between high and low culture no longer exists, and in its absence cultural elites constitute their food culture by taking a little bit from here (say, molecular cuisine) and a little bit from there (say, regional Thai cooking or street food) and thus assemble their own take on culture that can be labeled "omnivorous." Bauman and Johnston identify a tension - one to be explored - between open-arms inclusion (foodies saying they love all foods, rich, poor, far, wide) and status-defined exclusion (someone who draws boundaries over, say, only eating authentic regional Chinese). Johnston and Bauman's work is much more outspoken in its approach to problematic terms (foodie vs. chowhound) and concepts (authenticity and the exotic) than that of other related theorists (54-55). Their focus on establishing boundaries in the different ways North Americans construct food culture stakes out clear cultural spaces of operation in which the intentions of different social classes can be measured. This hyper-specific approach will be useful to this thesis, as it takes as its vantage point the divide between things global and local.

Signe Rousseau (2012) examines the impact that celebrity - and celebritized restaurant chefs - has had on the way people consume the culture of food. Her work is 
also highly relational in the way it places chefs in a lofty and influential space and their fans in the blurred-together positions of audience, fan, or consumer (XX). Rousseau reveals a skepticism about the power - or lack thereof - in culinary audiences. She demonstrates that when we allow media and celebrity chefs to dictate how we might cook or eat, we also relinquish our own power in the equation. In other words, the more presence food media and figures who dictate via the structures of such media acquire in our lives, the less apt people are to make their own decisions about something as important as what we eat or how we understand something, whether in the context of health, travel, culture, foreign gastronomy, or home cooking.

Rousseau also explores a cross-disciplinary set of theories by the economist Herbert Simon: the theory of attention economics. The first posits that the more information piles up - either capturing or distracting the audience - human attention itself becomes the scarcer commodity. Simon follows that we only really pay attention to a certain amount of information, and we discard the rest in this attention deficit. Information, Simon puts forth, will always be there, but our ability to absorb it remains finite and every day the competition for it gets more intense. The audience reaction to such an attention deficit is something Simon terms 'docility,' or the dependence on recommendations, tips, and info coming from primarily social or entertainment channels (XXVII-XXVIII). By replacing the term celebrity chef with exotic authenticity as it applies to traditional Thai food, there is potential for this thesis to open up an entirely new way of thinking about how Thai food is related to and socially constructed from the streets of Bangkok, to the pages of key food and travel periodicals, and finally, to journalist texts about new, original, Michelin-starred, or "authentic" Thai restaurants in North America. 
The most recent work of sociologist Priscilla Parkhurst Ferguson (2014) focuses on what she calls "food talk," an accessible brand of culinary discourse in which diners (for as she explains it, who can't share their food) choose to publicly share their experience. This act turns the private into public, roots into the personal to begin a discussion of the potentially universal, and above all puts an emphasis on the uniquely social role of food culture. For Parkhurst Ferguson, the power and links between taste and flavor to imagination and memory is greater than the act of eating itself. However, it is the ephemeral nature of food that also necessitates the need to write it down or memorialize it in some form. Here, Parkhurst Ferguson notes that texts can take this talk and meaning to another level, one where judgment, reviews, response, and analysis take place. More important, through the imaginary power of the media - and today's globalized culture of communication, both text and image - a practice that was once local and limiting can become a foundational culinary act for the global many to consume. As Ferguson says of the growing role of talking about food: "In one of the most striking developments of the past half-century, food talk has turned to promoting the connection between food and place, between cuisine and country. Cuisines once defined and perhaps dismissed as regional are promoted to national honor. As one country after another offers its cuisine as an authentic product of place, food talk flou rishes (193).”

Parkhust Ferguson's work presents a way of considering food talk and sociocultural impact in a way that is not just more aware, but can be easily applied in present times and throughout this thesis. The drama of eating out, the social classes of diners, the human need to have a way to mark its appreciation verbally or textually, and the importance of communicating shared pleasure (or disgust) with others - these are universal ideas that also play a role in evaluating the purpose and meaning of texts 
targeting Thai food culture. As with so many things, even as the globalized world moves speedily from one food trend to the next - flattening boundaries of taste and product as it goes - our ways of relating to them may not change nearly as much as we think.

\subsection{Food, Language, and the Role of Art and Craft}

Food and language are inseparable, and they work together to circulate ideas and meaning amongst different peoples. They help fix ideas like flavor, texture, and tradition in a series of letters and words that conjure up meaning that often transcends cultures and certainly transcend taste. Linguist Dan Jurafsky's (2014) book on the language of food explores how the languages we use to define food helps us to highlight the "interconnectedness of civilizations and the vast globalization that happened, not recently, as we might think, but centuries or millennia ago, all brought together by the most basic human pursuit: finding something good to eat (4)." Of great interest to this thesis is a chapter he devotes to menus, and the writing strategies and patterns that are used to define them.

He approaches this with a set of precepts that is very similar-and could prove very useful - to the same general ideas of classification I'd like to examine in my methodology section on topical frames in food and travel texts. Using information culled from a database of over 6,500 menus, Jurafsky writes that "All innovation happens at interstices. Great food is no exception, created at the intersection of cultures as each one modifies and enhances what is borrowed from its neighbors. The language of food is a window onto these "between places," the ancient clash of civilizations, the modern clash of culture, the covert clues to human cognition, society, and evolution (6)." This same thought process will be highly applicable to this thesis in its assessment of how Thai menus and dishes are presented in various urban restaurants, and how 
their specific dishes are given definition through descriptive devices used when Thai food is textualized in various forms of media. Jurafsky identifies several useful patterns including the relation of food origin mentions versus price, the number of menu choices versus price and the way in which exotifying or "Orientalist" menu words are deployed, also affecting value (13-14). How these choices are made and what they help reveal about the people and culture they are representing is something this thesis will consider carefully when looking for clues of meaning about Thai food menu items and the choices made to produce them going forward.

The tradition of food writing, guides, and a public obsessed with the subject of eating and cooking is not something new. It goes back centuries and includes the late, great cultures of ancient Rome and the sixth-century Persians, among others. But, for the purposes of this thesis, the era that has the most telling and direct correspondence in the way writing about food spoke about society is that of France and England - and especially Paris and London - in the $18^{\text {th }}, 19^{\text {th }}$, and early $20^{\text {th }}$ centuries. Sociologist Stephen Mennell (1996) argues that the gastronomic writers of these eras not only helped to shape tastes, but also helped to democratize it throughout society at large. He traces a continuous historical arc of this type of scribe, beginning with Grimod de la Reyniere, an early $19^{\text {th }}$ century writer whose Almanach des Gourmands helped lay the groundwork for food criticism and culinary guides for centuries to come, and going all the way to early modern (Michelin and Good Food Guides) to modern times (Egon Ronay, Gault-Millau), with a focus on food tourism and critical travel guides. Although Mennell is careful to identify these guides as part and parcel of an elite, he focuses on how they have an ability to shape and democratize taste, and that with each year and with the introduction of each new text, the balance shifts away from the higher reaches of society to the consuming masses. 
Many of the patterns of gastronomic writing that Mennell outlines still hold true today. He lists several recurring features, including constructing stories in a way that history serves as myth and myth serves as history, highlighting dietetic concerns and a focus on ingredients and identifying the nostalgic evocation of certain meals or culinary moments and the way they are memorialized. Mennell also underlines the significant social role that gastronomic writing plays in society as a whole (134). This involves an interplay between the writers themselves and the much larger base of eaters and diners, whose fervor for going out to eat continually mounts in correspondence to the amount of texts that are circulated. Beyond a concern for taste or discrimination, he argues that food writing furthers the "civilizing process" that Norbert Elias devotes his work to, setting the bar for manners and social mores as a whole through the acts of a small, but elite portion of society. To this end, he maintains that "gastronomes have, whether they intended to do so or not, also performed a democratizing function in the shaping of taste (266).”

Mennell explicates from historical food and travel writing in a way that identifies much larger issues and affects on society, eating, and the culture that surrounds it. Though engaging with writers from two centuries ago, he demonstrates how their engagement with social roles, food tourism, and mass crowds is mediated through text and their opinions backed up by substantial followers when carried out correctly. Mennell also singles out a polarizing trend that still exists in different forms of media today, maintaining that the functions of "articulating elite standards and of democratizing taste - always co-exist in gastronomy, though the balance between the tow has titled gradually during the last two centuries (266)." These meditations on textual power and social agency will play a crucial role in this thesis. 
For decades, Arjun Appadurai has made a name for himself by theorizing new ways to look at globalization. One of his early articles critiques the way cuisine is constructed within the context of English-language cookbooks in India (1988).

Interrogating the process of how a national cuisine comes to be, Appadurai investigates how the various local, ethnic, and regional cuisines of India have been re-assembled and given national form after they were textually recorded in cookbooks and printed recipes (3-4). The process must be looked at in several steps. First is in the social worlds of middle-class women and the dual worlds they occupy both preparing food at home and sharing meals outside of the domestic realm. As these female cooks encounter new recipes from regional cuisines and flavors outside their immediate social class or area, they begin to incorporate them slowly into their world and, thus, as this process transcends regional borders through a nationally-distributed form of media - the cookbook - the foundation of a national cuisine begins. Showing the need for consideration of cultural specificity when dealing with food culture, Appadurai also demonstrates that a Hindi national cuisine - due to its highly complex system of beliefs and gods - failed to gain culinary embodiment on a national level, and instead was replaced, in certain respects, by the closest thing India has to a Royal cooking style, Mughlai food along with various regional cooking specialties and cuisines.

Appadurai underlines the multiplicity of cookbook genres in India, and exhibits how they do within the Indian context what many foreign food and travel texts do for cuisines from far-off places. In his words, "Like tourist art, they begin to provide people from one region or place a systematic glimpse of the culinary traditions of another; and they also represent a growing body of food-based characterizations of the ethnic Other (15-16)." Appadurai's layered and cultural approach to assessing how Indian food culture is constructed offers an intellectual entry point for how this thesis might consider 
the case of Thai food culture and the way it is shaped by English-the language texts at the centre of this research project. Much as Appadurai does, this thesis will assert that the types of encounters promoted by writing on food culture are, above all, positive even when they seem, in some ways, to be stereotypical. While Appadurai's strategies are well-formed, they will need to be adapted to the context of Thai food culture.

Philosopher Elizabeth Telfer (1996) assesses the way in which society embraces food as a form of art and culture. How do we perceive eating in terms of aesthetics, and how does this change in regards to food? Why have intellectuals historically rejected the notion of art as food? Can food be an art form and if so, under what circumstances? Telfer divides the evaluation of something as an art in to two categories: classifying and evaluative. Classifying means to "say something about how the object is regarded, whereas to use it in an evaluative way is to say something about the extent to which it merits the label 'work of art' (44). She gives as a food example a mid-day meal of rye bread. If one likes the way rye bread tastes in its contrasting texture between the toasty bread and melted ricotta cheese, this is an aesthetic reaction. If one is pleased with this snack because it is low calorie, it is not. As a potential basis for evaluating food as a work of art, Telfer believes we can absolutely have aesthetic reactions to food, that we can separate out those who experience food vividly, with the senses and that food can be approached with the same objective-critical way of judgment that is a part of our relationship with art.

For J.O Urmson, art represents the former, an "artefact primarily intended for aesthetic consideration (45)." Which is to say that the person who created it did so with the intention that it be looked at for its own sake, in the second sense of the term, society treats the work of art as something for aesthetic consideration. The evaluative 
definition is mobilized when a viewer of an artwork decides or interprets something as not worthy of the label of art.

For this thesis, cooking must be regarded as a process. In addition, one must also consider the role of the chef as the chief creator - or to take a film studies term, an auteur - while comparing the way Thai food is produced by the restaurants Kin Khao and Nahm. Telfer's idea of the origin of creation or intent is especially valuable in evaluating how meaning and culture circulates - in my case, for Thai food. Is it art or craft? What was the cook's intent? Does that change with the eater having a different notion? Is it a form of culture, or merely a human act of necessity and creation-forconsumption? These are some of the questions I will need to consider when discussing the who, when, and how of That food and its existence as a form of culture.

Food is, if anything, a cultural production, and also one that is very much about the use of culinary ideas and various materials - raw and uncooked, permanent and architectural, ingestible, rendered and sold. As such, it is apt for comparison to other such forms of art and craft. As an inter-disciplinary subject with many of the same attributes, art history provides one such point of comparison. It is from this area that Ming Tiampo (2011) has proffered the theory of cultural mercantilism, in her case as applied to a group of Japanese artistic practitioners known as Gutai. For her the process of cultural mercantilism roots into Adam Smith's economic theories concerning the way Colonial masters and companies appropriated cheaply available raw materials from other cultures (from the periphery and the colonized) and then exported them as finished goods (from which the center will profit through value-add) for great profits. Tiampo implies that this process obscures and distorts certain historical experiences and groups, as well as the cultural understanding of their position and value in society. She positions her theory to help produce a narrative that counter-acts that enacted through 
cultural mercantilism, endeavoring to-rebalance such cultural subversion and dominance, as well as the hegemonies that come along with it. In relation to Gutai, Tiampo cites $19^{\text {th }}$ century Paris and post-1945 New York City's as specific cites of such discourse in art history, as relating to this Japanese movement. For her, the result in artistic terms is that non-Western cultural products are treated with the same aggressive de-valuation as raw materials were for the economist Adam Smith, objectified, cheapened for reproduction, appropriated, and sold (abroad) for profit. Given the same tension between culture and craft, art and consumption, Thai food culture provides an apt object for application of this theory - perhaps re-jigged as culinary mercantilism. What happens when a non-Thai encounters traditional food? Is it any less Thai food when sold abroad for profit or commodified as cuisine in an upper middle/upper-class restaurant in New York or San Francisco? To be sure, the entire process of cultural mercantilism here described is not fully paralleled by the way Thai food is appropriated by restaurants abroad. The ideas of objectification and subversion demands, at the least, recognition, as Thai food takes many forms as it journeys from street stalls, markets, and home kitchens to modern chef/owner-driven restaurants inside and outside the borders of the Kingdom.

\subsection{Approaches in Methodology and Content Analysis}

Susana Priest (2009) helps locate the role content analysis in the bigger picture of the media by describing it as a "systematic study of what is contained in media messages" (84). This approach for measuring keywords is the first of two methodological approaches engaging what Priest calls the manifest meaning or material in the texts. Adapting these ideas to focus on particular voices and people - and not just topics - the methodology will aim to first identify and then underline how the focus 
and dependence on one type of voice or engagement with Thai food culture reveals opportunities for food and travel journalism to better engage its subjects.

For Priest, however, sometimes the role of content analysis is "...to go further to classify certain elements of media material...in a particular way... in order to answer the question the researcher has posed" (85). To this effect, this thesis will use Robert Entman's (1993) concept of framing analysis as a way to "select some aspects of perceived reality and make them more salient in a communicating text" (52). As Entman observes, "the concept of framing consistently offers the way to describe the power of a communicating text" (51). This thesis will, in turn, use the text, as supported by the aforementioned keyword analysis, to isolate what frames are most strongly associated with the content and data to be analyzed. Among the questions this framing analysis will attempt to answer are: What frames can be identified within the text? Do these frames make certain, consistent judgments about the journalism surrounding Thai food culture? What viewpoints are revealed and promoted by such frames, and which are the most dominant in the selected food and travel texts?

This two-step approach of quantitative and qualitative analysis roots in to Margaret LeCompte's (2000) interpretation of multi-level analysis, which "makes interpretation possible, requires researchers to first determine how to organize their data and use it to construct an intact portrait of the original phenomenon under study and second, to tell readers what that portrait means (p. 147)." Engaging further with LeCompte's ideas, a dual emphasis will be placed on the juxtaposition between frequency ("Items sometimes can be identified because they are numerous") and omission ("Items can also be identified because they never appear, even though researchers might think it reasonable that they would.") (p.148). 
As the methods progress to qualitative analysis, the simple yet powerful idea of comparing one object of study to another brings with it issues that must be resolved. Shu Mei-Shih (2013) identifies these problems as two-fold. In almost all cases, she asserts, we tend to privilege one thing over the other, as there is no such thing as level ground. Here, the Foucauldian stance prevails, by which issues of power will always circulate and, at least in the West and Global North, that with the most modern experience and developed political economy and behind it, will tend to have the upper hand. Shih asserts that this also holds true for the idea of difference and culture, and that in this case the Western one will also prevail.

In her essay on literature from places that have lived through - and continue to be imbued by - colonialism and the socio-cultural hangover it leaves behind, Shih proposes an approach she calls Comparison as Relation (79). Broadly, she defines this as a way to try and directly relate two things that may not necessarily share the same path historically, but nevertheless share many of the same experiences and other social characteristics or topics. She aims to take differing objects of study and throw them into "relation terms that have traditionally been pushed apart from each other due to certain interests, such as the European exceptionalism that undergirds Europe-centrism (79)." Much the same could be said about the Western ideas of food culture - and especially restaurant culture and taste in the West - that are always in circulation when tourists, readers, or eaters fork or chopstick into their plates of Thai food, whether in the street in Bangkok or in a contemporary Thai restaurant in North American cities. How do we bring these ideas together in comparison? How do we balance the imbalance between their contexts? Shih's Comparison as Relation offers a potential solution for this thesis to pursue in its methodology and findings. 
Structuring Shih's approach is a two-part methodological approach to lining things up and assessing them in a historical way. First, she recommends searching for historical parallels. Second, she prescribes searching for inter-related causality. By using these, one must then tack in pursuit of seeing a system that may not be equal, but can similarly constitute experience or ideas globally. One particular issue she identifies for literature, which may be very different when realized in food culture - and maybe different again in food and travel journalism - is the role played by translation. What role do cooks/chefs play as translators? Do they mediate? And, if so in what way do they alter the original culinary content or context? How does English journalistic text "translate" - or not - globally? What role does food play in mediation? And how is a food culture altered in different environments? These are key questions to be addressed. When comparing literature, she does not look at things in terms of national literature, but rather as text that can be consumed in different ways through powerinflected inter-relations. Relation, for Shih, is also a deep network that is dynamic and characterized by constant creolization - at a basic level, the mixing together of two cultures - both in practice and in theory. Relation is also the act of movement, both personal and cultural, that helps to transform and affect people and cultures. One must consider relations in a way that is both vertical (privileging one over the other as in economics or power) and horizontal (shared time, geography, trade). Relation, above all, contextualizes and tries to see things in their own balance. Here, borders dissolve, but perhaps new areas (the power of neighborhoods and cities, dining/cultural movements), emerge and also create new things. This is a theory about recognizing process, and then digging deeper to try and find the sources of change or causes of transformation as the food culture or Thailand moves across borders to North America. Used in relation with other cultural and global theories as related to food culture, this 
can be a very powerful theory to mobilize in this thesis. It can serve to help interrogate how Thai food is transformed as it moves across borders and into transnational culinary arenas, and to question how the notion of authenticity is transformed in the process. It can, in the end, serve to identify the sources for and reasons behind changes and similarities in Thai food culture as it moves across borders. 


\section{Chapter 3: Methodology}

\subsection{In troduction}

Recent numbers and surveys illustrate a robust level of interest in the country of Thailand by travellers, tourists, and those generally seeking experiences related to the country's culture - as well as its food. For example, in 2014, 24.78 million tourists arrived in the Kingdom (Thai Websites). By 2015, that number had risen to 29.88 million, and the Thai Ministry of Tourism expects that to rise to 32 million during 2016 (Reuters, 2016). For Thailand, tourism accounts for approximately 10 percent of the overall GDP, up from about $6.5 \%$ a decade ago (Reuters, 2016). For a country that has experienced political turmoil in the past few years, this makes tourism a very important industry.

Much of the interest among travelers and tourists in the country relates to its food. A survey by the Kellogg School of management found Thai cuisine ranked sixth in the same survey in terms of quality of food globally (Joys of Thai Food). Another global survey of 35,000 people by CNN Travel asked people to list their favorite dishes around the world. Thailand ranked first among all countries with some seven dishes in the Top 50, including tom yam goong, phat thai, green curry, and som tam, mostly home cooking and street food favorites (Cheung, September 7, 2011).

The Thai government takes an active role in tourism, culture, and gastronomy. For example, a program called Thai Kitchen/World Cuisine has for more than a decade helped to promote the international development and support of Thai restaurants - and thus Thai food and culture. In 2003, the program estimated there were 6,875 Thai restaurants open around the world (Sunanta, 2005). As of 2012, that had grown to more than 20,000 restaurants in 93 countries (Bangkok Post). Several recent Tourism Authority of Thailand campaigns have also put food first. For example, a 2012 campaign called 
"Thailand Splash \& Spice" worked with 145 restaurants in 5 provinces to promoted eating at Thai restaurants (Tourism Authority of Thailand).

It is important to at least attempt to track this interest in the form of more specific questions about how Thai food culture operates. For example: How can we harness its meanings and the way it affects daily exchanges between diners, guests, travellers, tourists, consumers, and most of all, experts and opinion-shapers? How do the audiences of North American or Western countries receive their information about Thailand? Where do they turn to get insight and expertise on these topics? Journalists, on- and offline media, magazines, and newspapers represent a crucial source for the distribution of information. They help disseminate and circulate consumer news (places to stay and eat; shorter texts) and stories about actual jou meys taken (longer texts about specific places, cuisines, or markets) in the Thai kingdom. By recording first-hand experiences and information in newspapers and magazines - not to mention the many TV shows and video links broadcast in concert in dozens of countries at any one time journalistic texts play a crucial role in amplifying the appeal and approachability of this Southeast Asian nation's cuisine and overall food culture. These texts also encourage their audience to be highly active, to act upon the information by taking their own trips to Thailand or visiting a local Thai restaurant, making a related recipe or simply living the experience vicariously through the text. Unlike other fields of journalism, the primary focus of food and travel is often to recount first-hand experience, as well as providing useful service information to help guide readers who may choose to take a journey there themselves.

The following methodology section will look at three different types of media outlets or publications, each with a corresponding area of research concern, cultural angle, and specific geography and audience type. The first is Saveur magazine, perhaps 
the only major publication in North America to focus on a balanced blend of food, culture, and travel. Saveur will be used to examine how ideas of tradition, culture, and authenticity as experienced through travel are approached in related journalistic texts. The second set of texts will use two specific Thai restaurants as an entry point, and collate related texts from major newspapers, guidebooks (online and offline), or magazines in their corresponding regions of the world. The first set relates to Kin Khao, a now Michelin-starred Thai restaurant owned by a Thai-born blogger in San Francisco. The second relates to Nahm, a Bangkok-based restaurant considered by many surveys and critics to be the best of its kind in the world, one controversially (for some) and fascinatingly (for most) owned by an Australian chef who reads and writes fluent Thai. Taken together, these two bodies of journalistic texts will consider identical concerns of authenticity, experience, and culture but within the contrastingly modern (and upscale) arena of modern Thai restaurants. Finally, perhaps the world's best-known Englishlanguage news source, the New York Times, will be used to examine how general ideas about Thailand are broached. Using the same time frame, one set of articles from news pieces will be compared to another set about food news. The goal is to uncover whether the concerns, media techniques, and subject approaches seen throughout various publications with Thai food can also be applied to 'hard' Thai news stories. 


\subsection{Objects of Study and Research Questions}

Texts concerning Thai food culture represent a unique journalistic approach that can also serve as a powerful yet positive arena for encounters with foreign cultures and edible Others. The methodology for this paper will focus on objects of study that help to peel back the layers of Thai food culture and address how and why it is represented in the corresponding media texts. Additional objects of study for this thesis are:

- Techniques used in the creation of food and travel journalism and related texts

- Keyword, content, and framing analysis of the above texts

- Comparative analysis of the above texts

Several research questions lie at the core of this thesis. They examine the ways food culture - in this case, that of Thailand - is treated in related journalistic texts. They question the modes of representation used in these text, asking why such methods are used in the hope of gaining information that might help better journalistic craft. They search for deeper meaning as related to notions of Other-ness and authenticity, and they seek to address who is represented, how they are represented, and what this means for general discourses surrounding Thai food culture. The objective, through examination of the tone, voice, and technique of different media outlets, is to discover patterns and habits that might be discussed critically or altered to better the overall approach. Examining both high (upscale modern restaurants) and low (street food, markets, traditions at their roots) cultural forms, this thesis seeks to understand how Thai food culture is perceived as consumable product in specific journalistic contets. Finally, they examine how food and travel journalism can strengthen its approach to standards 
and practices as a unique and important contribution to the professional media landscape, asking: Why should we take it seriously and why will it continue to matter?

To these ends, this paper poses the following research questions:

- How is Thai cuisine represented in the media?

- What frames emerge from the texts and how do they, in turn, contribute to the approach to or perception of Thai food culture?

- What viewpoints and patterns emerge most regularly from the texts?

- How is food uniquely discussed and engaged with as a form of culture?

- Why is food and travel journalism important, and what way be strengthened as a genre? 


\subsection{Objectives of Methodology}

These questions are important because they help raise questions surrounding culture, representation, cosmopolitanism, authenticity, and globalization in journalistic texts. A central aim of this thesis is to help reveal how journalists and citizen-readers might better understand and relate to those from other cultures in the way our experiences are recorded and circulated, and how the special case of food and travel journalism can play a crucial role in the process.

The thesis examines how audience members are motivated to become active travellers, paying diners, and actors within the theatre of food culture and tourism experiences, by casting an academic gaze on the tropes that food and travel journalists, writers, and editors employ to connect with readers - and perhaps advertisers, too. The methodology helps shed light on the processes behind food and travel journalism and its approaches to Thai food culture. Above all, it hopes to uncover unexamined patterns of journalistic framing and contribute to the general area of journalism studies and the more specific area of food and travel journalism as it relates to foreign food cultures in this case, that of Thailand.

The methods section will provide a deeper understanding of how ideas such as cultural representation and translation, authenticity, cosmopolitanism, and other-ness, among others, are treated. Using both quantitative keyword and qualitative analysis, this thesis will show how food culture and the comprehension of foreign cuisines have the potential for re-invention in transnational contexts when they are addressed in food and travel journalism. Using the findings of this methods section, this thesis further aims to 
study the ways food and travel journalism might address foreign cuisines in the current and future mediascape.

\subsection{Str ucture of Methodology}

The initial focus will be a counting of keywords, voices, and sources in the selected texts of Saveur-specifically, any texts found in the Saveur online database from the years 2007 to 2015 under the headings "Thai food" or "Thai food travel." Articles were selected if they dealt directly with the subject of Thai food, no matter the country they focused their efforts on. Articles were eliminated if they only mentioned Thai or Thailand as a modifying word or place. Articles that were focused on a non-food area like hotels were eliminated, as were articles which had a focus on recipes, but commentary that was under 50 words. In total, 21 articles between the years 2007 and 2014 met these criteria and were examined. Six total areas were applied to the quantitative analysis. The goal was to produce a by-the-numbers look at what kind of voices, descriptive approaches, and journalistic methods were used, and which of these was either dominant and thus influential on the text and reader, or minor and infrequent in their use and thus not a direct factor for audience members. The categories were

1. I/Me/My: the amount of times first person voice is used.

2. We/Our/You/Us: the number of times a collective, non-first person voice is used. 
3. Direct Quotes and Voices/Sources: the number of times chefs, locals, cooks, or other direct sources are given a voice. Counted once for each time a subject is addressed.

4. Narrative: the number of times background information or narrative information was introduced. Counted once for each piece or instance of information represented.

5. Words indicating Typical/Thai Flavour: the number of times typical words representing Thai flavour are used, including hot, sour, salty, sweet, spicy; words implying heat/spiciness and fragrance.

6. Words concerning Authenticity/Exoticism/Localization: the number of times words representing these ideas or concerns are used, including street food, markets, regional/a specific Thai region or town (the South, Chiang Mai), and other words representing concern with tradition, authenticity, exoticism, localization.

The second body of journalistic texts will address how Thai restaurants abroad are discussed and approached in the media. The first restaurant is Kin Khao in San Francisco, owned by celebrity blogger, Thai-born Pim Techamuanvivit, addressed in 15 articles, drawn from major sources through an online search. The articles were chosen if their central subject was Kin Khao and included a diverse assortment of newspaper and online reviews and re-reviews; interviews with the chef or owner; guidebook entries published online and offline; travel articles from foreign or non-San Francisco publications; features on the chef or owner; and major blog entries. Articles were excluded if they only mentioned the restaurant and did not dedicate a whole entry or 
section to its discussion. The articles stretch from the pre-opening months in 2013 to 2016. The unique combination of a Thai owner, ex-blogger and industry insider, and Michelin-starred restaurant in San Francisco should enrich and challenge the way Thai food and authenticity is addressed.

The second restaurant is located in Bangkok, and named in many surveys and considered by many critics to be the world's best Thai restaurant. Nahm has as its unique point, that one of its chefs/owners is actually Australian. The types of articles also included the same range of reviews, awards, discussions, chef/owner interviews, critical discussion, and travel and food features as just described for the San Francisco restaurant. They ranged from 2010 to 2016 and total 16. They were highly international, spanning the UK, the US, Asia, and Australia. Such wide distribution will help raise issues of how ideas spread across borders, and thus give depth and breadth when their results are thrown into comparison against the other restaurant-as-study-object, Kin Khao.

The third and final set of articles to be examined come from a single source - the New York Times. Using a single publication as source for content is purposefully done to provide a controlled editorial arena in which to consider the enactment of journalistic codes, standards, and practices. To compare and contrast to pical approaches, two groups of articles were drawn. The first from the year 2015, address Thai food. In total, 11 articles were found that focused on the topic of Thai food whether in food, travel, or general articles. In the same 2015-only time frame, 11 articles were drawn focused on news and editorials about Thailand. Using two types of article about a single country from a single news organization allows for a comparison between disciplines. For the Thai food pieces, the same six areas will be analyzed and counted. However, for the 
Thai news pieces, they will be slightly adjusted to match primary or central concerns within a news article. The categories to be analyzed are:

1. I/Me/My: the number of times first person voice is used.

2. We/Our/You/Us: the number of times a collective, non-first person voice is used

3. Direct Quotes and Voices/Sources: the number of times a source is quoted. Counted once for each time subject speaks or addresses a specific thought.

4. Facts/Narrative: the number of times facts or narrative information are introduced. Counted once for each piece or instance of factual information presented.

5. Words concerning Authenticity/Exoticism/Tradition: the number of times words representing these ideas or concerns are used, including tradition and authenticity.

The rationale for such methods is rooted in ideas from several academic theorists. Susana Priest contextualizes the use of content analysis as a "systematic study of what is contained in media messages" (84). Through its use of keyword content analysis, this paper will measure "the actual amount of space or time given to particular topics" (Ibid.) Adapting these ideas to focus on the use of particular voices and descriptive approaches - and not just general topics - my methodology will identify and then underline how the focus and dependence on one type of voice, as well as the recurring strategies for the representation of Thai food culture reveals opportunities for food and travel journalism to better engage its subjects.

Priest also acknowledges the limits of content analysis and proposes researchers “...go further to classify certain elements of media material...in a particular way... in order to answer the question the researcher has posed" (85). To this effect, this thesis 
will employ Robert Entman's (1993) concept of framing analysis to "select some aspects of perceived reality and make them more salient in a communicating text" (52). As Entman observes, "the concept of framing consistently offers the way to describe the power of a communicating text" (51). The goal will be to identify which frames emerge from certain texts, as well as to identify any broader patterns of meaning associated with each of the five groups of texts. Among the questions the framing analysis will attempt to answer are: What frames are most prominent within each thematic textual group? How do these frames represent or select certain aspects about Thai food culture textually? What judgements or general discourses might the readers than come to learn as a result of these frames? What ideas are generally revealed and promoted by these frames, and which are most dominant?

Taking a two-step approach to concurrent quantitative and qualitative analysis is a method espoused by Margaret LeCompte (2000) in her interpretation of multi-level analysis, which she declares "makes interpretation possible, requires researchers to first determine how to organize their data and use it to construct an intact portrait of the original phenomenon under study and second, to tell readers what that portrait means (p. 147)." Extending LeCompte's ideas once again, a dual emphasis will be placed on the juxtaposition between ideas and words that represent ideas and whether they are marked by frequency ("Items sometimes can be identified because they are numerous") or by omission ("Items can also be identified because they never appear, even though researchers might think it reasonable that they would.') (p.148). Media is, at its core, a process that gains its strength from an ability to make decisions about inclusion and exclusion. This methodology hopes to uncover what is included and what is excluded when Thai food is represented in food and travel journalism. It may also help determine 
what this process says about food culture and the way journalism approaches it as a subject. 
3.5 Quan titative and Keyword Analysis Results and Tables

This section presents the quantitative findings of the study, broken down by the type of article group, then listing the findings by category. Every category is listed on one page below:

\section{Saveur Magazine Cor pus}

\section{Analyzed Thai Food \& Travel Clips}

Total Articles in Group: 21

Range of Articles by Year: 2007-2015

I/Me/My: 213

We/Our/You: 92

Voices/Quotes: 17

Words of Thai Flavor/Scent/Heat/Taste: 136

Words of Authenticity/Exotic/Traditional: 153

Narrative/Storyline Information: 125 
Nahm Restaurant Corpus

Analyzed Thai Restaurant in Bangkok Clips

Total Articles: 16

Range of Articles by Year: 2010-2016

I/Me/My: 36

We/Our/You: 40

Voices/Quotes: 95

Words of Thai Flavor/Scent/Heat/Taste: 71

Words of Authenticity/Exotic/Traditional: 45

Narrative/Storyline Information: 89 


\section{Kin Khao Restaurant Corpus}

\section{Analyzed Thai Restaurant in San Francisco Clips}

Total Ar ticles: 15

Range of Articles by Year: 2013-2016

$\mathrm{I} / \mathrm{Me} / \mathrm{My}: 55$

We/Our/You: 47

Voices/Quotes: 11

Words of Thai Flavor/Scent/Heat/Taste: 91

Words of Authenticity/Exotic/Traditional: 17

Narrative/Storyline Information: 69 


\title{
New York Times Corpus
}

\section{Analyzed Thai News Clips}

Total Articles in Group: 11

Range of Articles by Year: 2015

\author{
I/Me/My: 0 \\ We/Our/You: 0 \\ Voices/Quotes: 70
}

Words of Authenticity/Exotic/Traditional: 17

Narrative/Storyline Information: N/A 


\section{New York Times Cor pus}

\section{Analyzed Thai Food Clips}

Total Articles in Group: 11

Range of Articles by Year: 2015

I/Me/My: 41

We/Our/You: 22

Voices/Quotes: 11

Words of Thai Flavor/Scent/Heat/Taste: 59

Words of Authenticity/Exotic/Traditional: 24

Narrative/Storyline Information: 59 
Table 1

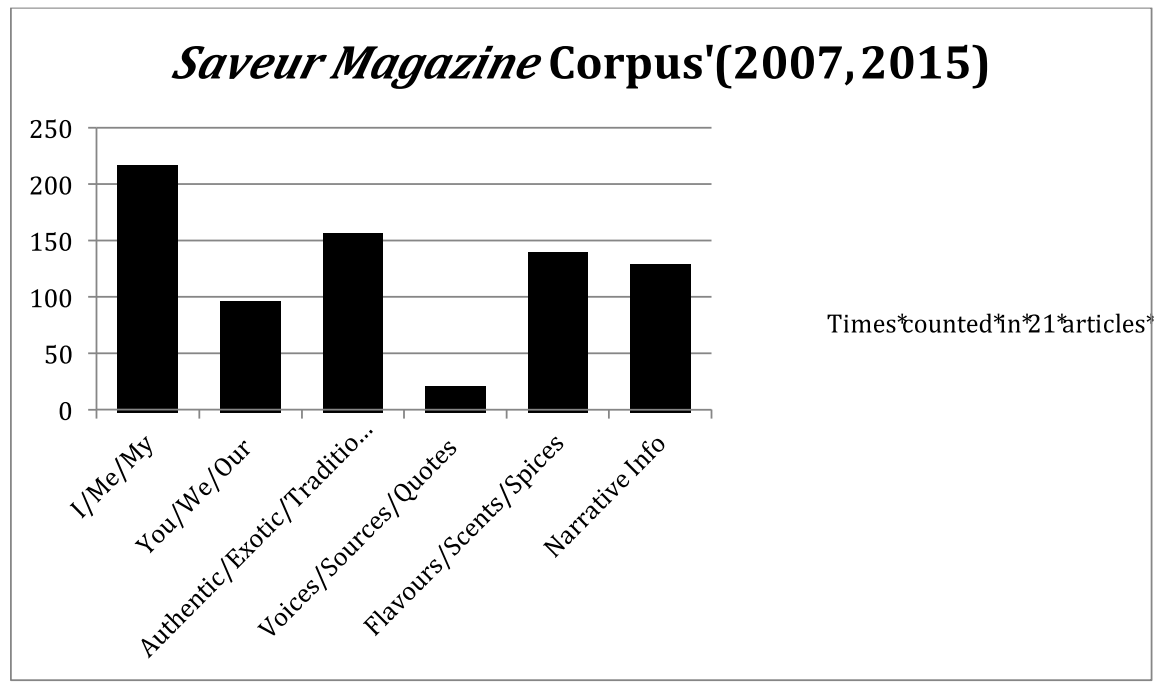

Table 2

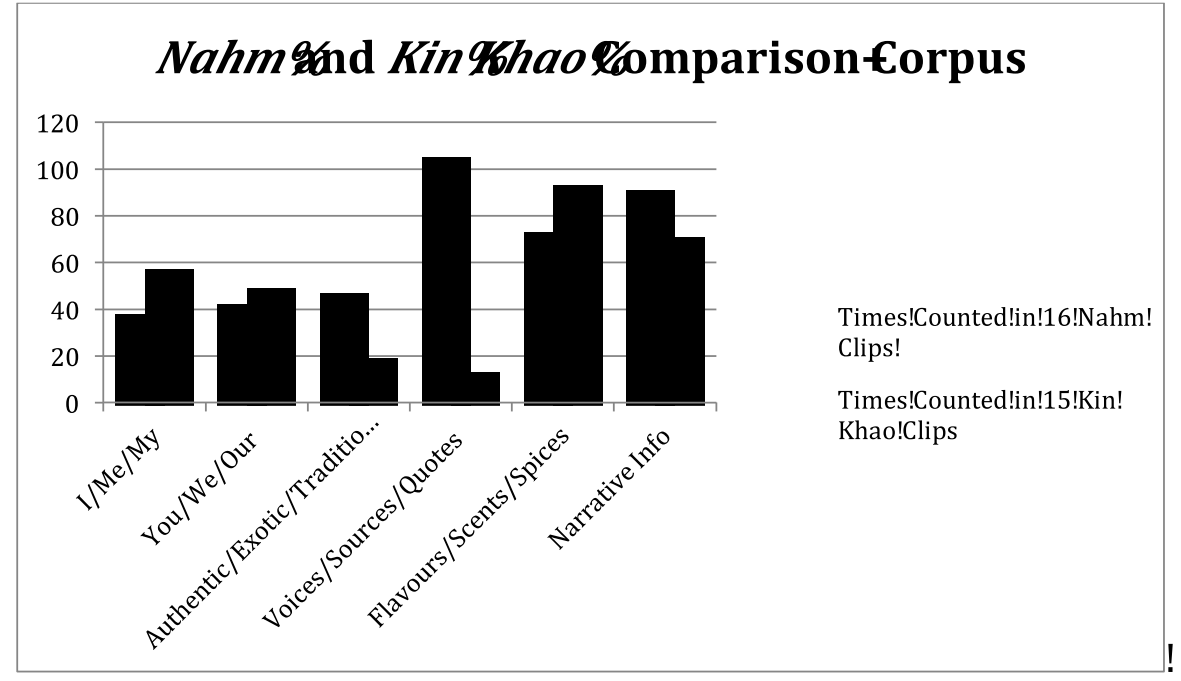




\begin{tabular}{|l|r|r|r|r|} 
& & & & \\
& & & & \\
Table 4 & Times Food & Times News & & Saveur Clips \\
\hline I/Me/My & 41 & 2 & 213 \\
\hline You/We/Our & 22 & 2 & 92 \\
\hline Authentic/Exotic/Traditi: & 24 & 17 & 153 \\
\hline Voices/Sources/Quotes & 11 & 70 & 17 \\
\hline Flavours/Scents/Spices & 59 & 2 & 136 \\
\hline Narrative Info & 30 & 2 & 126
\end{tabular}




\section{Chapter 4: Findings and Context}

The following section presents the outcomes from the content analysis in the methodology section. It is broken down by each set of articles and the related keyword and quantitative results. This does not include a full qualitative analysis of these same sets of journalistic texts - that will follow in the subsequent Discussion sections, as isolating certain bodies of content and focusing on their own set of concerns and dynamics will make for a richer discussion. The goal here is to present the basic findings and then address their more general meanings, while evaluating the context and background they create for the deeper analyses that will follow.

\subsection{Saveur Magazine: Thai Food, Culture, and Travel Articles}

The New York City-based magazine Saveur has circulation of 329,642. It also gets an average of 4.3 million page impressions per month on its web site, 884,000 of which are unique (Saveur Media Kit.) It was chosen for its position in an editorial space that is equally concerned with food, travel, and culture, and much less focused than other general food and travel publications with celebrity chefs and high-end restaurants. Analyzing Saveur's editorial approach allows for a glimpse into a brand of journalism that puts equal value on food, culture, and travel, rather than pushing dining out, celebrity, or a mix therein on their readerships as other publications do.

The keyword analysis was based on 21 articles with a focus on food, culture, or a travel-based combination of those two as related to Thailand. They ranged in date from 2007 to 2015 . With some 213 counted uses of the first-person, they revealed an intensely personal approach to the Saveur brand of food and travel journalism. In 
addition, the conversational "from us to you" and royal "we" approach to article narration were also used an additional 92 times in the same set of articles. Given that traditional hard news journalism is, in most cases, predicated on the neutral third-person voice that is a foundation skill taught to many journalists at schools and colleges, this is a huge degree of such usage. It underlines the everyman role of the food and travel journalist, as well as the intimate relationship the writers seek to forge with the experience at hand and the readers to whom they are delivering it in prose.

Another bedrock of journalism as it is taught and practiced is the idea of using sources, and in doing so giving a voice to the subjects of a particular story and thus providing a balanced representation of those they are writing about. In the 21 articles, despite mentioning or describing different and particular markets, restaurants, street food stalls, and various "locals" working or cooking at these locations of culinary production, there were only 17 instances of the author giving one of these subjects a voice through direct quotes. The first-person - the "me/my/I" of the writer - dominated in opinion and reconstruction of events or experiences to the point that while "Other" subjects existed in colourful descriptions and interaction, they did not come to the surface, so to speak, as an equal given the same opportunity to contribute to the experience as the journalists themselves did with their me-driven prose.

As its interest is primarily food cultures from very specific and often far off places, the way Saveur approaches the idea of something different - a culinary Other as either authentic, exotic, or Other (to use the approach discussed by Lisa Heldke) is enormously important. Is the "foreign" cuisine of Thailand approached in a way that promotes exoticism or authenticity? Saveur employed words surrounding and supporting this idea - assessing local, street food, regional, and traditional - some 153 times in just over 20 articles, a high incidence. Similarly, words that represent the typical description 
of Thai and Southeast Asian cuisines - hot, sour, salty, sweet, relating to levels of scent or spice - were used an additional 136 times. A reliance on what might be termed an editorial straitjacket across more than eight years was in evidence, emphasizing a clustering of "typical" terms that reveals an almost obsession with the exotic nature of Thai food as a topic.

\subsection{Eat, Read, Compare - San Fran cisco's Kin Kh ao and Bangkok's Nah m}

Based upon the Thai government's commitment to tourism and its focus on creating a global image in relation to the country's food, the next iteration of the methodology examined two modern Thai restaurants. The goal was to compare and contrast media coverage of these pricey, air-conditioned sites of Thai food consumption that employ resources, personnel, and techniques beyond that of a home or local Thai cook. In such a setting, journalists and critics re-contextualize the idea of Thai food outside the rustic confines of Thai markets and street food stalls. Concerns such as criticism, informing the reader, local geography and audiences, and chefs/owners must be balanced or selected, one over the other from the design of restaurants to the way they are spoken about in the media. Kin Khao in San Francisco and Nahm in Bangkok are both acclaimed eateries receiving international attention and critical praise. They also both take as a prime concern using Thai flavours considered to be traditional or authentic.

Of course, the ultra-modern and ultra-liberal, Anglo-Saxon confines of downtown San Francisco are, by nature, very different than the cosmopolitan but chaotic Southeast Asian city of Bangkok as a site for a Thai restaurant. Despite such outward contrasts, the 15 articles about Kin Khao and the 16 giving the same feature treatment to Nahm, showed a marked incidence of international media attention. They also turned up 
shared patterns in their editorial treatments. Both revealed a high level of interest in the respective chef/owners, as well as their unique backgrounds (this will be covered in depth in Discussion sections to follow). Here's what the numbers revealed:

The Kin Khao articles used the first-person 55 times, mostly in pieces written by formal restaurant reviewers leveraging their regular relationships with their readership. The Nahm articles had slightly less of a reliance o the first-person with 36 uses, most in longer travel pieces involving subjective experiences eating with and interviewing the chef/owner, David Thompson. The "us and them" or royal "we" approach was used respectively 47 and 40 times, reinforcing the personal narrative that dominates food and travel writing. An intense focus on the personal was once again the rule.

Contrasts emerged, however, in the differing use of voices and direct quotes. Journalists writing about Kin Khao used this classic technique of letting sources speak only 11 times (perhaps a result of the preponderance of reviews, a popular American approach to new restaurants), while those covering Nahm included 95 quotes. This no doubt reflects the intense interest in chef David Thompson's unique Australian-citizen, Thai-speaker background and the many interview or eating-with-David-Thompson formats used to best get to the heart of his much-debated role as a foreigner cooking Thai in Bangkok. Kin Khao's Pim Techamuanvivit was also much-discussed, but less quoted, as the aforementioned review format tends to place an emphasis on evaluation and background, the chef/owner as a subject, not a mouthpiece.

In the way their menus are written and waiters are trained to engage guests, both chefs are very clear about their particular commitments to - and personal translations of - traditional or authentic cooking. As both the Saveur and Thai restaurant corpuses show, most food and travel journalists use a common voice for discussing the idea of Thai food and the flavours it creates. But, just as chefs take a role in the translation of 
any cuisine, does this mean that the journalists covering them relied less on the key flavour words or key Thai-food concepts of authenticity, et al.?

Interestingly, the articles concerning Nahm and David Thompson relied much more on ideas of authenticity/tradition/localization, using such words 45 times. In contrast, the same concepts and key words emerged only 17 times in the Kin Khao stories. Does the nationality of the chef factor into this? Or is it the nature of the restaurant or assigned journalist? This, among many other questions, will be discussed in the sections to follow. Interestingly, Kin Khao coverage showed a greater reliance on key flavour words, using them 91 times while articles covering Nahm, used them 71 times. Both sets of stories relied on narratives and background facts about their characters. - Kin Khao did so 69 times, compared to 89 for Nahm. Storytelling, then, is a clear concern in food and travel writing even when simply assessing or imparting the experience of a single restaurant. But why is this important and what does it mean for the cultures at the centre of discussion? In turn, how does a food culture such as that of Thailand re-assemble itself when far from the place of origin or when a Thai restaurant is headed by a foreigner?

\subsection{Con trolled Coverage - The New York Times and Thailand in News and Tas te}

Every study needs a control to allow for a dependable point of comparison, preferably one with highly developed structures and standards. Knowing that there are, at some level, established ways of working and expectations, allows for comparing ideas in a manner that removes some of the modulations of intention. This is the role of the New York Times corpus. It is a long-running, well-established source of traditional journalism with highly developed ways of approaching reporting and writing, especially when it comes to editorial practices and standards. Using this as a final site for 
quantitative analysis, I selected two sets of articles from the same time frame (2015) with the same general topic (Thailand), but with different subject specifics (Thai food and travel versus Thai politics and news). Each set of articles had at its centre a focused subject matter. The modes of analysis were altered slightly to attend to the more rigid approaches assumed to be the foundation for editorial work at the Times - the inverted pyramid, the 5W's, using and quoting sources, for example. Each set of articles was thereby analyzed for use of first-person voice, use of we/us/you/our, the amount of times sources were given a voice in quotes and the number of mentions of words invoking tradition/authenticity/exoticism/locality. Story and narrative, however, were not analyzed as with Thai food/travel the concern is with storytelling and with Thai news/politics stories, presenting facts is the primary concern. This core split, if the hypothesis that food and travel journalism has a unique voice and set of concerns was true, would be revealed and supported by the returned numbers in the above categories.

The results were striking in their stylistic differentiation between news and food/travel articles. Despite the general commitment of the New York Times to classic journalistic practices like neutral voices and using sources - the results from the set of articles considering Thai food and travel were consistent with the other stores analyzed. They showed an enormous reliance on non-traditional (read: not third person) voices such as the first-person (41 uses), the "us and them" and royal "we" tactic (22 uses). There was a also a low concern with giving subjects voices through quotes (11 times) in the 11 articles chosen. Allying themselves with the Saveur and restaurant corpuses, key flavour words were employed 59 times, while the common food/travel concern for frames of authenticity/tradition/regional-localization were deployed 24 times. 
The results from news articles were in stark contrast, clearly revealing a split in approach, voice, and concern for the particularities of the subjects. In news articles, there were 0 uses of first-person and 0 uses of the "us and them" or royal "we" voices so prevalent in the many food and travel pieces. Despite very different context, concepts of "tradition/regional-locality/authenticity" were still employed 17 times. The number that stuck out most, however, pertained to voices given to sources - in just 11 articles, this occurred some 70 times. The difference in treatment of the same topic in different contexts within the same publishing structure and journalistic culture merits investigation and discussion in the pages to follow. 


\section{Chapter 5: Discussion Part 1}

\subsection{Tasting Local, Cooking Global: Thai Street Food and Traditions in Saveur}

Like any specialized branch of a broader craft, food and travel journalism have embedded in their treatment of a chosen topic - a specific sets of codes that writers often use in their articles in the form of themes and clutches of keywords. They deploy a highly specific vocabulary that helps depict the meals they consume and their farflung settings they temporarily inhabit. As the methodology revealed, the approach taken to Thai food in Saveur magazine was one supported by multiple journalistic tropes and narrative tactics. These included the dominant use of a first-person voice, a reliance on frames of authenticity and exoticism and the subsequent sensory illumination of Thai food culture with recurring descriptive bunches of words such as hot, sour, salty, sweet, and varying forms of fragrant, among others.

Food is nothing if not a sensual pursuit, and this is another area where using food as an object of study and journalistic interest creates an unusual set of circumstances. From tourism and cultural studies to art history and representation, the visual sense - and images in turn - has long been dominant in practice and foregrounded in theory (Berger, 1972; Sontag, 1977; Urry, 1990; Hall, 1997). While there has, for sure, been some obsession with the visual in the popularity of food porn - the catchy name for luscious, sexed-up imagery of certain food preparations - it does not match the power of a dish, or a chef, or a food culture trend to mobilize reaction amongst the imagined food community. The keyword study of Saveur did not reveal dependency or favouring of one single sense over the other. Rather, the multi-sensory 
act of eating is reflected in its concurrent routing and flavour translation through all of the available senses.

One Saveur article describes the making of a tom yum goong soup, then alternates between evocative descriptions of scent and sound, using anglicized Thai names in place of English descriptions, building towards a finishing flourish about the powerful nature of its flavours: "I know it is finished because the smell is good," the local cook named Pattcha quips, hinting at her instinctual method of working (Oseland, 2007). The writer of the article then picks the experience up where Pattcha the Cook left off, detailing how "..she added a few spoonfuls of nam dtan, several quartered plum tomatoes, a spurt of fish sauce, and fresh lime juice....it tasted miraculously complex. The subtle broth allowed the warm flavours of the chile, lemongrass, and galangal to come through like rays of sunshine on a cloudy day, and the prawns were sweet as candy. Within minutes, I had slurped down an entire bowl. Sweat pouring from my brow, I asked Pattcha for another (Oseland, 2007)." The distribution of words in this description means references to fragrance, texture, sound, and taste are grouped together. The effort seems to be in service of summoning the multi-dimensional complexity for which Thai food is known. Though visuals are employed to set the general scene or emphasize something like the size of the tomato chunks, when it comes to food and travel texts concerning Thai food, the most frequently used keywords are here about anything but just looks. The focus is on sensory evocation candy-sweet prawns, aromatics warm and insistent as sunshine.

In her book on street foods in Southeast Asia, Irene Tinker (1997), emphasized the way foods prepared in the open-air are ready for consumption almost immediately and could be eaten on the spot or taken home. Tinker notes that all such businesses sell finished products or "ready-to-eat foods from a place having no more than three 
walls (17)." Writing in the Thai-focused treatise on similar culinary productions in "Bangkok's Foodscape," Gisele Yasmeen (2006) noted the very Thai characteristics of food being available 24 hours a day, an embrace of the same types of foods by both rich and poor, who choose not to cook at home and a much greater incidence of ThaiChinese vendors than their percentage of the overall population who run such stalls (1218). There are, of course, many other types of eateries in Thailand such as shopping centre food courts and cafes, traditional Thai restaurants (with four walls) and Royal Thai eateries with plush interiors. But the texts of Saveur tend to focus predominantly on street foods through their coverage inside the borders of Thailand. They generally describe them in ways that celebrate their lack of pomp, and they are thus positioned in a way that seems to equate their simplicity with purity and tradition.

Each writer has a slightly different approach in voice and in subject, but they all put learning about the food culture with a wide-eyed wonder at the forefront when discussing street food. One writer describes his time living in Bangkok and the development of his relationship with street food: "I started seeking out the best street food and photographing my discoveries...A decade later, I'm still amazed by what I find.... Whether it's a stir-fry or a curry, it's all the proof I need that eating in Bangkok is an ongoing education (Bush, 2009)." Another writer carried out a similar quest in search of a particularly iconic dish from the country's Northeast - note the ongoing search for the superlative and the identification of a specialty as 'regional' and thus prized: "One of the most delicious things I've eaten in all my travels to Thailand is gai yahng (grilled chicken) a specialty of Esarn, a province in the country's Northeast (Ricker, 2013)."

In much of news reporting, the first and foremost goal is to inform the readers and to arm them with information to perhaps form their own opinions or engage with those of others in the public sphere. Unlike typical news reporting, when food and 
travel publications deliver content such as articles and publish them for the consumption of their readers, the ultimate goal goes well beyond this. By providing stories that serve as inspiration for the audience to travel or experience the subjects in their own right, food and travel journalists motivate their audience and also assist them in taking action to travel to the same country the article was written about, or perhaps to clip the piece and by following the given recipe, to create it for themselves. The same information-then-action dynamic affects articles and reviews about restaurants. The active nature of the audience makes the reader-content relationship an incredibly intimate one, and it also alters the relationship of the journalist-subject. In food and travel writing, journalists are far more than reporters. They are a surrogate for the reader, and as such a sort of touristic everyman, gathering information, filtering experience, making decisions about cultural representation, and functioning as the eyes, palates, and ears of hundreds of thousands of other readers. The media kit of Saveur magazine re-emphasizes the active nature of its audience. Revealing statistics include the fact that its readers spend on average of $\$ 14,261$ on travel annually, are three times more likely than other Americans to have traveled internationally and they re-visit the magazine's webpage regularly, in total creating more than eight million page views monthly (Saveur Media Kit, 2014). Reader interest is at once cumulative and active.

Instead of factually and objectively reporting events from a foreign place, as a war correspondent might, food and travel journalists assume and inhabit the very human condition of the tourist. Just as humans recount their trips to friends and family in the first-person, or try to relate to their audiences with the inclusive "we" or "you" as they re-count what they saw, did, and ate, so do food and travel journalists recount from one-to-many, often attempting to capture an entire culture - or at least its food - in words. As the findings have shown, the food and travel journalists of Saveur deploy 
certain recurrent words that, when read together, help their audiences relate to their experiences in a knowable but sensual way. An apt comparison might be the reliance on recurring vocabulary in wine criticism, another gen re where key descriptive words are put into play to validate and detail flavours for an audience intent on having the same experience themselves.

Using these words and frames as structures and lenses through which they evaluate cultural experiences, the writers commissioned by Saveur also measure their encounters on a sliding scale of what is authentic, exotic, traditional or local. Given the interconnectedness with pleasure, it would seem this holds great appeal for their readership. Some writers apply the same experience and ideals abroad and at home: "Plenty of people fall in love with a dish while traveling, return home raving about it, and launch a quest to find the most authentic version they can get in their own city. Before a recent trip to Thailand, I operated in reverse (Feldmar, 2013)." Speaking to an obsession with a Northern Thai noodle dish called khao soi, this journalist "set about sampling every version of this dish my city has to offer" and later "set out to Chiang Mai determined to eat as much khao so $i$ as possible (Feldmar, 2013)." By establishing at the outset the experiences to come, the writer thus sculpts his piece in to a single-minded journey of flavour. When encountering Thai food experiences abroad, the gold standard is time and again that of the homeland. One Los Angeles-based journalist recounts the hunt for authentic Thai food in her hometown: "...the city showed me facets of Thai cooking that I hadn't known existed - street food straight from the Bangkok markets, Burmese-style stews from the north of the country, fiery-hot dry curries from the South (Robbins, 2011)." Once again, she uses the ability to educate and a related learning curve as the measures of culinary achievement: "Simply living here is a true culinary education - and it doesn't ever stop (Robbins, 2011)." The true point of such 
stories seems to be a meaningful and romantic search for what is true Thai cooking - a journey, it seems, that does not necessarily ever have to end.

Rooting back to the seminal work of Edward Said on Orientalism (1983) and Stuart Hall on representation (1994), there has been a long line of theorists concerned with the intentions and the way those from Western cultures engage with the Orient or the Far East. Through discussion and examples, they have illustrated how West tends to dominate the East, marking it as different or Other from themselves. Texts have for centuries served as the prime medium for the representation of and engagement with the Other. With the current emergence of travel as one of the world's largest businesses - creating 284 million jobs and $9.8 \%$ of the world Gross Domestic Product along with over a trillion dollars of spending per year (World Travel and Tourism Council, WTTC) understanding these texts and the ways in which journalists approach the subject grows in importance every day.

As the leisure-based activity of tourism has grown steadily in the last few decades, a group of theorists has emerged focusing almost solely on the subject of travel. Marking intellectual ground halfway between the socio-cultural concerns of art history and the ethnographic focus of anthropology, tourism studies places the focus on experience in both the personal and cultural senses. The related theories detailed herein are an important reference point for helping to contextualize such a specific brand of journalism as the food and travel blend of Saveur. John Urry's (2011) visually dominant development of the "touristic gaze" attends to the same establishment of socio-cultural and class difference at issue in Said's work. Urry divides the gaze in to two types - a personal and a collective. This is very much what we witnessed in the voice of Saveur writers, as they flip between what is driven by the "T" and what calls upon the royal "we" or the attendant "you" to ensure the maximum impact of personal narrative and 
collective impact. Enacting this dualist tendency, a sort of call-and-response from writer to reader, one Saveur article (Oseland, 2010) switches between declarations ("Let's get right to it...Ganda...serves the most authentic Thai food in America") first-person history ("I went to Ganda five days in a row for the pla dukpad ped, crispy catfish") and metaphors invoking their audience ("a chile paste that's hot enough to curl your hair").

The other tourism theory that demands engagement is that of Dean MacCannell and his conception of the eponymous subject The Tourist (2013). MacCannell employs a more semiotic approach, while foregrounding the idea of - and relationship with authenticity that he believes is ultimately at the heart of what most tourists want to seek out. For MacCannell, the tourist is a philosophical stand in for "modern man in general," wherein if one commits to "following the tourists, we may be able to arrive at a better understanding of ourselves." Extending this idea would thus position journalists specializing in this topic as not just stand-ins for their readers, but for a universal journalist-as-human representative as well. In his recently updated foreword, MacCannell puts the focus back on tourism, not as an act, but as a process of sightseeing as "a ritual performed to the differentiations of society (13)."

Various food studies scholars have broached these topics in an even more focused way, highlighting concerns of cultural appropriation and culinary Othering (Johnston and Bauman, 2010; Heldke, 2003; Heldke, 2005; Ray, 2012). Books have also been written exploring culinary tourism and even hyper-specific ideas such as Thai food culture and street foods (Tinker, 1997; Yasmeen, 2006). Tourism theorists and geographers have further examined the consumption of food and the site of restaurants as crucial for tourist activity domestically and abroad (Long, 2004; Haldrup and Larsen, 2010; Urry and Larsen, 2011). But these have not gone beyond a very limited realm of 
personal experience, or a very straightforward treatment of restaurants as a social phenomenon or global fast-food chains like McDonald's.

Unlike much of the imagery and media that are critiqued in discussions about the Other by Stuart Hall and Edward Said, the texts of food and travel journalism reveal an almost uniformly positive approach to foreign cultures. While the recurrent use of word groupings to attach ideas of exoticism, authenticity, and tradition do drive home a certain level of obsession with marking difference, the overall approach of the journalists shows a real curiosity, a willingness literally to sample and ingest the cultures of others. This means making a conscious choice to go beyond surface-level engagement or to retreat back to the "safe" confines of a hotel restaurant, Americanized restau rant cooking, or other sanitized versions of cuisine. But rather than be happy with what a local might cook to momentarily appease a foreign palate, the writers of Saveur are determined to put in the extra effort to find an all-hours noodle vendor on the street or a local-beloved café serving regional favorites in a less-travelled area, like the south of Thailand.

Working under these conditions and with these ambitions, food and travel journalists are attuned to search for, describe, and deliver articles that are bound to touch in some part on difference. To help bring clarity to their readers amidst the sometimes-complicated food cultures of places like Thailand, Saveur sometimes carefully chooses a writer who has ample years visiting the country to serve as a journalistic guide. For example, chef and Thai-speaker Andy Ricker leads readers through a how-to article about making Thai curry from scratch. He carefully switches between concerns for teaching and experiential narration as he goes (Ricker, 2014): "The ingredients might seem disparate," he begins. "but when you make one of the curries in these recipes, you discover that, through careful cooking, they come together 
into something delicious (Ricker, 2014)." Touching not just on food, but the larger culture of Thailand, he invokes something greater than curry, an Other in spirit and taste: "In Thai Buddhism, there's a word, sati. It means mindfulness. That's what making a curry takes (Ricker, 2014).”

Similarly, food critic Jonathan Gold uses his printed words in Saveur (Gold, 2012) to recount a story from over a period of years about his experience with what was then a little-known Thai restaurant in Las Vegas, while on assignment for Gourmet, a prestigious food magazine at the time. It reads as an historical metaphor for how the American dining public has moved from faceless, pricey continental cooking to dynamic, far-flung cuisines of developing countries in a period of just two decades. "So on the third day, I canceled my reservation at a dining room known for its individual beef wellingtons and drove a mile or so off the strip to a new Thai place jammed into an enormous strip mall where Led Zeppelin once played (Gold, 2012).” As he gets to the plates he trumpets as more typical of true Thai cooking, he engages readers with a well-placed use of "you" as he leads them through from what is banal and worth missing, to what is authentic and exciting: "But when you opened the menu and leafed past the expected fried wonton and mee krob noodles, there was a wonderland of dishes from all over Thailand (Gold, 2012)." As if placed there symbolically, he describes the real treasures as relegated to the back of the menu, but implying through more-detailed description, that they are what one must order. "There was a roster of the restaurant's real specialties: the robust, salty-bitter cooking of northern Thailand, including a fleshy jackfruit salad, the roasted green chile-dup nabm phrik nubm, and an almost-perfect version of the delicate curried-noodle dish khao soi (Gold, 2012)." From his measured use of Thai language dish tags to demarcate what is unusual, to the metaphorical journey off the strip to encounter something culturally singular, this piece 
exhibits the importance of attaching the authentic/exotic/traditional frame to Thai food, equating these characteristics of difference with value and superb taste, but in a wholly positive way. The emphatic use and common occurrence of these topical frames as supported by keywords for flavour throughout the Saveur corpus helps underline the importance of these ideas not just within food, but for tourism and travel as well.

As a style of journalism that demands more than its current share of academic attention, the food and travel genre gains import from its ability to transmit not just personal experiences, but entire cultures as they take shape from one side of the globe to the other. The varying sites in which Saveur chose to commission journalistic work on the topic of Thai food spans well over ten thousand miles - from cities on both coasts of the United States, to Thailand, Burma, and Laos, over to Australia and back again. They include suburban Thai home cooking restaurants in Sydney, Thai families and cooks selling curries-and-rice as they would in Bangkok, but in a Los Angeles storefront, regional Thai cooking in a Las Vegas strip mall, markets in the rural South of Thailand and street-side noodle vendors, some of whom serve well past midnight in the humid, chaotic streets of Bangkok. In each case, the concerns for the roots of what is being cooked and the pursuit for what is authentic or traditional are given the same attention, no matter whether the trip took place inside or outside of Thailand.

By choosing to give the food culture of this developing Southeast Asian nation coverage on a global scale, Saveur also helps permanently represent these very ideas and the journeys taken to encounter them in textual form. They are engaged with by the hundred thousand-plus readers and viewers who punch millions of monthly page hits that comprise the Saveur readership. As they read and react to these articles, a community begins to form and ideas and connections gain a global dimension. It is important to note the many parallels between food and travel journalism and 
anthropological writing. Much like an anthropologist undertaking research with the end goal of writing an ethnography, the best of food and travel pieces inscribe experience and culture in a permanent form. While their process may differ in that there is, as yet, no rigid process or values food and travel journalism must stick to, they are both intently focussed on eventually conveying the meaning and experience of cultures. Saveur thus goes beyond the act of providing a media service or reporting a story to its travel- and culture-hungry readers. It contributes to the actual building of what is now a global identity for Thai food. As these texts are engaged with online and offline, they take on another life in the imagination of Saveur readers and, by extension, those interested in Thai food culture. This is given both additional form and life in online discussions, dinner table conversations, message boards, and for some the use of Saveur clips as reference and guide for the audience members who take their own trips to Thailand or the restaurants they've read about. In the spirit of Benedict Anderson (2006), an imagined community is formed through engagement and action, fed by electronic capitalism and given shape at the intersection of journalistic texts documenting travel and food experiences.

The role of the media in the formation of food cultures and the larger communities who find interest in them can be traced back to the 1800 s in France, when a newly-forming community of chefs, restaurants, and proprietors was given wider social purpose and cultural capital by a series of writers and guidebook publishers who helped create the notion of French cuisine (Mennell, 1996). What makes the treatment of the food of Thailand in Saveur special is that it is a country still considered by many to be a still-developing nation, and yet its cuisine punches far above its weight thanks to its textualization in the media. Moreover, it is located in the Far East, a traditional source of domination for Western powers and their cultures, especially through historic colonies 
in all other Southeast Asian countries like Malaysia, Singapore, Vietnam, and Cambodia. Thailand, however, has never been colonized and this is a very important point as it is subject to the same Colonial domination or feelings of weaknesses as other nations are. While Thai food bears influences of those near (China) and far (Portugal), its multipronged approach to flavour and reliance on the finishing flourishes of individual cooks creates something Bangkok locals might call 'very Thai.' Thai food incorporates broadly Asian techniques (stir-frying; steaming followed by frying) and flavourings (fish sauce instead of salt; galangal, finger root, and turmeric, not just ginger) with ingredients that range from native (lemongrass, kaffir lime) to Western ones that were part of the age of trade and Colonial exchanges with the New World (chilies, eggplant, tomatoes). Thai food respects the flavours and usefulness of all ingredients, but re-fashions them into a whole that marries improvisation and dynamism with balance and subtlety - thus, the five-part tag so well known of its food: hot, sour, salty, sweet, and spicy

In flavour and in culture, the writers of Saveur describe these many distinct facets with enthusiasm. They balance discussions about traditional approaches with an emphasis on the personal - tastes created by one cook in one place, dishes experienced by one writer at one time. These same fundamental aspects contribute to the ability of Thai cuisine to be successfully re-created everywhere from street food noodle dishes in Los Angeles to Chiang Mai and Lanna cuisine at a restaurant that began in a garage in Portland, Oregon. In their book Cosmopolitics, Bruce Robbins and Pheng Cheah (2013) argue for a more inclusive cosmopolitanism, one that can account for cultures that are, through mass travel and immigration, can be quickly scattered like dust in the wind around the world. It is a bottom-up cosmopolitanism, as it were, meant to provide a socio-cultural counterpoint to the more elite traveler-friendly cosmopolitanisms espoused by the likes of Ulf Hannerz (1990). The way in which Thai 
food is represented in equal strength throughout varying countries and settings in Saveur shows how a culture given prestige and momentum by food and travel journalism, can constitute itself far beyond its borders, yet remain loyal to what is considered authentic in its place of origin. Cosmopolitanism thus gains impetus from the cook's respect for and pursuit of an understanding of the culture at its place of origin, even if it is tossed in the pan and put on the plate ten thousand kilometers afar. Authenticity, then, can be found in the hands, experiences, and intent of the creator, and can only ever be looked at in relation to its experience with the food culture at issue. As Saveur and its articles on Thai food culture demonstrate, the zip code this all takes place in does not matter nearly as much as the moment and the personnel in play. Food cultures are now transnational, and the food and media journalists of Saveur who document them continue to play a crucial role in the process. 


\section{Chapter 6: Discussion Part 2}

\subsection{Thai Restaurants: A Comparative Analysis}

For decades, the importance of the restaurant in the social and cultural landscapes has grown with every passing year. Considered here in the context of the growing awareness of Thai food culture, the restaurants and celebrity chefs/owners who have made Thai food their focus now occupy a powerful in the global foodscape. In the last decade, the destruction of trade barriers, the ease and affordability of mass travel, and the informational flattening of the world by Web 2.0 has fully re-cast the culinary world order. Barriers that used to exist when it came to finding the ethnic ingredients or exotic foodstuffs - galangal or kaffir lime, for example - necessary to replicate cuisines outside of their place of origin have disappeared almost entirely. Once rooted firmly to a far-off place (or at least the cooks born or raised there), traditional Asian food cultures like that of Thailand are now wholly transnational in their character, from the roots of their recipes and culinary training of their staff to the inspiration of their chefs and the target markets of their restaurant kitchens. Fed by ever-expanding media coverage and the amplification provided by social media and easy online access to articles, travellers and diners have joined a near-constant stream of talk and chatter that has given restaurants an intrinsically public character that grows with each passing day, meal, and media post.

Dining rooms are now recognized as important stops along the cultural and culinary route for tourists, locals, expats, and all types of diners in between. Of course, there is a class aspect that can't be ignored here. Much like modern art and foreign cinema, restaurants are still very much an upscale product positioned to grab the cash and business of the society elites, with little regard to the symbolic or economic 
meaning of such activity. That these restaurants are still dominated by a Euro-American, English-speaking crowd and located in big cities is also important to note. But this is changing, as disposable income frees up in the middle classes, from Western hubs like San Francisco and Chicago, to those in the Far East like Kuala Lumpur and Bangkok. The predominance of the rich in dining could also be said of many similar activities: theatre, professional sports like tennis and golf, classical music, dance, and many other initially elitist forms of entertainment.

Disposable income used for leisure and an interest in dining out is spiking in cities that are now part of the global trade and lifestyle trend networks (MacCannell, 2013; Veblen, 2001). Hong Kong, Shanghai, Mumbai - formerly emerging markets are now taking their place alongside the longtime dominant Euro-American ones like San Francisco, Sydney, and London as stops on a global circuit. Bangkok has recently joined this group as an "it-destination" for culture and a celebrated stop on the global dining, style, and travel map. It has recently won World's Best City polls in magazines like Travel+Leisure (The Nation, 2013) and placed multiple restaurants in the World's and Asia's Best List of the influential San Pellegrino World's best survey (San Pellegrino World's Best, 2016). The arrival of such vast media attention is a definitive marker of cultural growth, as restaurants have become important social arenas in which cultural capital is created and where identity is negotiated and constructed (Parasecoli, 2008). The popularity of dining has witnessed a corresponding rise in the power of chefs and restaurant owners as celebrities in their own right, and the subject has become a widely-discussed academic topic (Rousseau, 2012; Johnston and Bauman, 2010; Parasecoli, 2008; Parkhurst Ferguson, 2014). As the role of chefs has grown, the physical and metaphorical nature of the restaurant has undergone a transformation too. The barriers between front and back of house - part of the construction of staged 
authenticity first theorized by Goffman, but adopted by tourist theorists - have been broken down in a way so completely and so suddenly that Dean MacCannell describes kitchens as a "living museum for which we have no analytical terms (99)." Coupled with the newfound emphasis on more-casual design and more-approachable diner experience, this has also led to what Priscilla Parkhurst Ferguson (2014) terms the "informalization" of upscale dining. By this she means the overall phenomenon whose result has been a democratization of the dining experience. White tablecloths and formal, tuxedo-clad service has waned. Exposes surfaces, buzzy bars, open kitchens, and chatty, down-to-earth staff are all widespread examples. While the food may have remained the same in its upscale nature or prices, the experience of eating out is now more about approachability and brand than special occasion itself.

Just as important as cooking the meal itself is the way chefs and owners position themselves in the public eye. The posturing begins and ends with the media, where they work and react strategically to create and circulate narratives about their background, expertise, and goals. Traditional outlets for restaurant criticism and features such as magazines and newspapers tend to provide the initial coverage of an opening, usually in the form of a review. In preparation before and after this, restaurateurs have learned to forge their guest experiences in a way that speaks to their diners and the journalists who set out to cover or critique them. Other media platforms like cookbooks and memoirs, TV appearances, magazine and web features, and print interviews provide occasions for chefs and owners to deliver their story or quotes often in unaltered form to the dining public (Parkhurst Ferguson, 2014; Mennell, 1996; Rousseau, 2012). Blogs, podcasts, trade titles, and smaller media outlets and social media then help further circulate their beliefs about food or cooking styles, creating a public culinary persona in the process. Through this thoughtful brand of storytelling and their ability literally to 
enter into someone's home kitchen through their recipes, books, or media presence, chefs and restaurateurs are able to frame the cultures of taste they represent in a way that serves as an important reference point for large publics of eaters, readers, and travellers whose taste levels vary according to their background and education (Gans, 1999). In the case of the restaurants Kin Khao and Nahm, this process helps their public representatives - Pim Techamuanvivit and David Thompson - constitute not just their personal identities, but what Thai food culture means to them as chef/owners and how it will be experienced by their diners and followers in the broader public culinary sphere.

Given limited space, this section takes as its object of study two modern and urban Thai restaurants and the chef and owner whose personalities their identity is based on. Each is located in a different city and each chef and owner has a different background in terms of nationality and ethnicity. By design, each restaurant presents a proprietary spatial and curated experience with which their guests can engage. In their selection of what stories they tell - gastronomical, stylistic, familial - each creates a narrative centred on or emerging from their respective chef or owner. By marking themselves as sites for consumption and guest identity-creation, varying levels of economic and cultural symbolism, authenticity, and transnationalism are thus engaged (Bell and Valentine, 1997). Symbolically and practically, Nahm and Kin Khao and their chef/owners use their public perch to collectively establish and strengthen their relationship with more than just their guests. They also engage readers and foodies the world over, casual fans, internet and Twitter followers, and potential diners in the way they speak or are spoken of in various newspaper sections and magazines, TV shows, cookbooks, and media coverage both online and offline. A mixture of personal experience-based ethnographic description and broader analysis of the respective 
bodies of selected media clips serves as material for the comparative analysis and discussion that ensues.

The two chosen restaurants are Kin Khao in San Francisco and Nahm in Bangkok. The former is owned by a Thai-born blogger named Pim Techamuanvivit (she is not the official chef, though she is the primary influence on the menu, look, and feel), and was awarded a Michelin star in the last year, a rarity for non Euro-centric cooking and the first Thai restaurant to attain one in San Francisco. The name translates from the anglicized Thai as "to eat rice," but can also mean "let's eat rice." In Thailand, Nahm is the signature dining room of chef/owner David Thompson, a long-celebrated Australian chef, who is supported by his mostly-silent (in the media sense) partner in life and in cooking, Thanongsak Yordwai. Nahm translates, simply, as 'water.'

Kin Khao is located in a non-descript business hotel on Union Square in San Francisco, right in the downtown core of this technology market-driven city. Thanks to its address, Kin Khao is a very strong destination for tourists and office workers, though a loyal crowd of local and Silicon Valley tech workers and food industry form a key crowd here as well. Nahm is located in the financial and media hub of Sathorn Road in Bangkok, and set within a minimalist-chic boutique hotel, The Metropolitan. It is important to note that this is the second iteration of Nahm, by the very same executive team. The first was in the The Halkin Hotel - part of the same chain - in London, and it was the first Thai restaurant in the world to ever receive a Michelin star. The London location is now closed, as Thompson chose to focus his efforts on the new Bangkok restaurant.

To understand the complexity of modern restaurants means looking at them as more than just social arenas, but attempting to understand the political and symbolic economy that they occupy. In his oft-cited work on travelling cultures, James Clifford 
(1997) reconsiders the landscape of modern travel by attending to several concepts that have resonance for modern Thai restaurants in global capitals. He attempts to describe a series of highly specific positions taken by travelers and cosmopolitans, an intellectual cast of characters that matches many of the hard-to-describe segments of today's global restaurant scene. They include discrepant cosmopolitans (highly specific forms of this notion, in culture, geography, and experience), travelling-in-dwelling (people who 'tour' or 'travel' without leaving their own home turf), and dwelling-in-traveling (people who seek home comforts while touring or traveling far away).

Tapping and then repositioning Bakhtin's concept of the 'chronotope' ("a setting or scene organizing time in representable whole form") for comparative analysis, Clifford seeks to identify symbolically unifying spaces where varying types of local, traveller, and tourist can co-exist geographically and thus be assessed from a common space in socio-temporal nature (101). Plotting multiple points on a conceptual continuum, Clifford searches for an intellectual version of a Hollywood green room or a theater suitable for all types of performance and hosting - a space that is neither here nor there, where performers and hosts and guests of all kinds wait their turn in the spotlight. In her introduction to Cosmopolitan Modernisms (2005), Kobena Mercer similarly invokes the chronotope as a temporal-spatial category "to be found in cultural forms themselves (22)." By invoking the restaurants Nahm and Kin Khao as culinary chronotopes and their dining rooms as spatially fixed points along an experiential continuum, this paper will investigate and compare the way their chef/owners construct their dining rooms as modern socio-cultural arenas, as well as how their diners and the media receive and reflect them.

Restaurants, of course, are more than just places where food is consumed. They are also sites of meaning-making and world-making. Every restaurant sets the stage for 
the construction of the restaurant-to-guest relationship differently. They control it in the sense that they make distinct decisions in interior design, the hires and comport of service staff, and the inclusion or exclusion of which dishes can be ordered and eaten by their guests on site with particular proteins, vegetables, and spice profiles. From menu language and graphical layout to the timing of courses and plating standards, chefs and owners must make conscious choices about where to get what ingredients, how to prep, cook, and present them and what stories and narratives to ultimately present to guests. In the larger foodscape, this applies not just to those in the dining room, but to potential guests who read about the experiences of others, cookbook owners who follow chefs from afar in other cities or even just foodies who have several times read an interview with the chef and contribute to his reflected reputation through comments in the blogosphere.

Inside any restaurant, the intimacy of cooking and sensory consumption produces experiences and ideas that operate often at polar extremes. For example, Kin Khao's use of highly local ingredients and embrace of San Franciscan dining passions like a cocktail program by the well-regarded Bon Vivants makes for a very local experience. However, the connection to Thai food culture and the attention given to this in the media, means that there is always a global aspect at work and for consideration. This combination of what is personal and related to a single meal and what is widely textualized have been constants in the world of cuisine, chefs, and public dining since the 1800s in France (Mennell, 134). As the culinary website Table Hopper (2014) observes after dining three separate times, Kin Khao has "a menu that's uniquely Thai by way of San Francisco.”

Through ethnographic exploration and discussion of the aforementioned restaurants, this paper seeks to re-position Shu-mei Shih's (2013) theory of Comparison 
as Relation in the context of modern Thai cooking and restaurants. While comparative literature about former Colonial subjects serves as the object of Shih's arguments (79), in the pages that follow comparative cuisine as it relates to Thai restaurants - or Relational Cuisine - will be explored in both the content of the restaurant and their representation in related food and travel writing. In her essay, Shih makes links between books that were written several decades prior, and uses an integrative world historical lens to help tease out the inter-connectedness between Colonial subjects in geographically and culturally different scenarios. A broad sweep of European, Asian, and Caribbean history and fictional literature using these locations to examine the lives of their characters lies at the core of her discussions. In contrast, this paper will develop its own act of Cuisine as Relation based upon the working chefs, owners, diners, foodies, and locals who interact with them as hosts, creators, and personalities. While Shih takes as her concern Colonial and national histories and unites them through Comparison as Relation, this thesis will inquire in to the journeys of chef/owners as they relate to the culinary history of Thailand, their intentions as embodied in the choices they've made for their restaurants, their brand of cooking and their distinct approaches to cultural translation in the way they re-create and represent Thai cooking in their respective markets and kitchens. An ethnographic contribution based on my first-hand experience as a diner in the restaurants will also account for the fact that the chefs at issue, unlike Shih's authors, are active on a daily basis and are participants in the daily translation of Thai culture their food represents. Due to the relationship of each diner and their experience, the constantly adjusting relationships this creates are in flux and constant negotiation as well.

Like spices used for flavour enhancement and complexity, various aspects of other theoretical works will be used to attend to the particular approach and 
construction taken by each chef/owner in relation to Thai food. Previously discussed in the literature review, Ulf Hannerz's interview on transnational cosmopolitanism (Rantanen, 2005) will be drawn upon to bolster the idea of chefs as culinary cosmopolitans and influencers. Philosopher Kwame Anthony Appiah's essays (2006) promoting cosmopolitan acts as noble and with respect to cultural interests and beliefs, while recognizing "the practices and beliefs that lend them significance (XV)," provide an idealist and humanist way of looking at the world. When considering the interconnected roles of diners, foodies who follow chefs through various media, and the social imaginaries they create surrounding Thai food, Priscilla Parkhurst Ferguson's (2014) assertion that the increasingly informal nature of restaurants has contributed to

their democratization is also a factor (141). Finally, Andreas Hepp's (2015) work helps to foreground the importance of the social aspect of transcultural communication in its ability "to understand the depth, scope, and direction of various levels of hybridity at the social - not individual - level. (15)." Restaurants, after all, are thoroughly social arenas.

\subsection{Thai Cooking 'Far' - Kin Kh ao in San Francisco}

At first glance the interior of Kin Khao seems fairly elemental - boxy room, exposed wood tables, hard surfaces below and above. But it also captures the kind of stylized post-industrial setting that is typical of modern-day cafes in Bangkok, something 
probably not lost on its Thai-born owner. Slate-colored floors and matte black wooden chairs (some with wishbone backs, others similar to those found in university and public libraries ) surround hardwood tables. The deep grain of the wood is given texture by pools of overhead light. Utensils, chopsticks, and bottles of Thai-brand chile sauce are placed in clunky plastic buckets and containers on the tabletop for communal use - a self-consciously informal move in a restaurant that charges $\$ 30$-plus for a bowl of curry, and a suggestive beat to the memories of those who have eaten at street side stalls and seen the same display on the small sois (lanes) of Bangkok. Whitewashed shelving can be found around the walls, and the open kitchen pipes a constant, rattling blend of hissing, chopping, and plate rattling into the near edges of the open-plan dining rooms. The owner, Pim Techamuanvivit, regularly (nervously?) shuffles between tables and the kitchen pass most nights. Though the dishes are said to have been entirely chosen and initially developed by her - often based on family recipes - she also made the conscious choice of hiring an accomplished San Francisco chef (a non-Thai one, which some might say it is important to note) to execute them. As Table Hopper also commented: "When Pim was putting together, her plan for her first restaurant, she knew she didn't have the requisite experience of running a professional restaurant kitchen. Gaines (the Kin Khao chef)...was game to immerse himself in this non-native cuisine, working closely with Pim's exacting demands on how she needed the food to taste, while bringing his tremendous skill set with ingredient sourcing and preparation (Table Hopper, 2014).”

Like a semiotician's map, menus provide a set of signs and symbols that help guide customers and cue servers in their interactions. Linguist Dan Jurafsky contextualizes them as such:" ..every time you read a description of a dish on a menu you are looking at all sorts of linguistic clues (9)." In this case, the chosen header font 
feigns handwriting on a notepad - slightly slanted, slightly chunky, seemingly screaming "Hey, relax, this is Everday Stuff." A mix of anglicized Thai and English descriptions operate on multiple textual and symbolic levels. Dish names are in all-upper case and bold print, while dish descriptions are in lighter block lettering. Depending the dish, there is either a listicle-inspired description of ingredients separated by commas (ex. rabbit meatballs, apple eggplants, Thai basil), or a deeper, explanatory background and context is provided. Khao Kan Jin, for example, explains that this is "Pim's favorite street food from Chiang Mai" and goes on to list all ingredients in the lower case. When servers approach the tables, they seem to use the printed menu as a jumping-in point for initiating conversation, further guiding inquisitive guests through whether dishes have certain flavor profiles, origins, ties to authenticity, or more connections to the personable owner's Thai past and the stories it inspires. Many guests will also ask or naturally get to meet Pim Techamuanvivit herself - in the end, hers is the spirit that is cast over the dining room, a blogging, cooking, hosting human bridge between San Francisco, Kin Khao's customers, and their conception of her native Thailand and its food culture.

Broad narratives and specific stories based on personal experience represent a crucial part of the restaurant-customer relationship - indeed, the more chefs and owners are able to penetrate this boundary, the more they can permeate their culinary public and create emotional connections. And, once this is accomplished, the better the chance they have of finding their way to the holy grail of hospitality ventures: regular, loving, loyal (and paying) customers and fans who read their interviews, watch them on TV, buy their books, and add to their value as personalities and business people. Afar magazine (2016, May), though writing journalistically, presents her almost like an advertisement: "Kin Khao is not a typical Thai restaurant. The very talented Pim 
Techamuanvivit set out to introduce San Franciscans to the kind of food she grew up eating in Thailand - with its bright, fresh flavors, and pristine ingredients. All the curry pastes, sauces, and relishes are made in-house daily."

As a celebrity food blogger, Pim Techamuanvivit built a powerful claim as a culinary insider, leaving her Silicon Valley job, eating at the world's best restaurants, and getting to cook Thai for Martha Stewart in the process. (Chez Pim, 2016). Her connections in real and virtual were ready to be leveraged to full effect when she became a restaurant owner, giving her substantial cultural capital to re-apply as a restaurant owner. People knew her story, and people had already bought into the likability of her personality. She made decisions to help further solidify this foundation. First, the public knowledge of her having a celebrity chef as a romantic partner (the Michelin 3-Star chef named David Kinch), served to bolster her reputation. Second, her decision to hire a group of celebrity cocktail consultants, the Bon Vivants, deepened her connections on a local level. Third and finally, she secured another group of earlyadopter and culinary-influencers in San Francisco thanks to her cultivation of the restaurant business crowd ("the industry" as it is known) with late-night service and an edgy wine and drink program.. "So Kin Khao," describes the New York Times Magazine (Bittman, 2014), "is neither a chef-driven restaurant nor an especially creative one, in that the food is traditional; if it's unusual in the United States, it's because it's largely home cooking."

If economic success and media recognition are yardstick of cultural penetration in the public realm, then Kin Khao has done well to move firmly into this space. This was accomplished in the way Thai culture was first transplanted, then re-created and translated behind the image of its owner in this influential West Coast city. Techamuanvivit chose not to put herself in the role of chef, occupying instead the role 
of proprietor in the dining room. However, she also chose to be the personal representative - and, with her family history, the culinary inspiration - for the menu and its hand-selected dishes. The resulting flavors and recipes are also presented as being her - or her Thai family's' - own, extending the story from the Thailand of her youth to the Union Square, San Francisco of her current workspace.

Like a conductor of an orchestra who leads the music but does not play it, she has assumed the role of cultural translator for Thai taste, using capital she accumulated as a blogger focusing mostly on Euro-American restaurants. The role also applies to the chef whom she first filters ideas about dishes, flavor profiles, and tradition. The New York Times Magazine wrote of the Kin Khao opening chef that "Gaines never imagined cooking Thai food, but after a visit to Bangkok with (David Kinch of Manresa) and Techamuanvivit, he thought is would be a once-in-a-lifetime project, though he now thinks of himself as more translator than chef (Bittman, 2014).”

Based on close reading of 12 reviews and features about Kin Khao (all from major news, food, or travel publications and websites), Techamuanvivit was consistently recognized as not just a restaurant owner, but as a representative or stand-in for Thai culture. This identification was supported in the way the methodology findings revealed how major media and guidebook sources consistently described her food with words such as authentic, traditional, local, and regional. As illustrated by the emphatic and repeated deployment of words that represent Thai flavours and their intense application, Techamuanvivit has been able to transfer the ability she mastered creating narratives and retaining readers as a blogger to the dining room, bolstering her identity as both a Thai and a modern Californian restaurant owner and critically succeeding in the process. Though her education and career arc has been mostly American, the transnational nature of restaurant cooking has once again made her a Thai - if not in 
locale, then certainly in public recognition and taste. As Techamuanvivit's Twitterinspired tagline declared, as quoted in an article from the SF Gate website: "On a mission to liberate her beloved Thai cuisine from the tyranny of peanut sauce (Bauer, 2014)."

\subsection{Thai Cooking 'Near': Nah m in Bangkok}

Whereas Kin Khao is led by a Thai-born owner in a Western city, Nahm is the home of a Western (Australian) chef in the capital of Thailand. The restaurant itself first opened in London, before moving its location to Bangkok. It is celebrated by many in the media as the world's best Thai restaurant, and is consistently ranked in the Top 100 globally of San Pellegrino’s Best Restaurant Survey (World's Best Restaurants, 2016). The kitchen takes measures to develop its cuisine that reveal a push towards what might be considered haute levels of execution. For example, Nahm has used close to 100 suppliers - roughly the same amount used at the very best Michelin 3-Star restaurants in the West, considered the pinnacle of the craft. Instead of sourcing for luxury ingredients like heritage breed animals or foie gras, chef David Thompson has spent years building supply lines for products such as water vegetables like morning glory, the bitter herb acacia, lemon basil, the rare citrus ma dan, and single-vineyard durian, almost all from small farms or even single homes in provincial Thailand. The brightly lit dining room has faux brick-clad pillars, dark teak plank flooring, and polished blonde wooden tables that are as long as the crystal wine stems set upon them are tall, but otherwise the atmosphere is casual, approachable and unremarkable. 
At the heart of Nahm's excellence - and providing fuel for some controversies that followed after opening - is the fact that the public face of the restaurant is not in fact Thai, but rather the Thai speaking chef David Thompson (though it is important to note his partner in life and in cooking for more than two decades is Thai, Thanongsawk Yordwai). What separates Nahm unlike any other Thai restaurant is that the menu is inspired by a hundreds-strong, century-old collection of "funeral" cookbooks dating from the 1800 s to just after the year 1900. These treasured resources are printed in very limited numbers in honor of late Royal Thai women to commemorate their lives and, in a version of gastro-ethnography, inscribe their taste and the culture surrounding it for years to come. To own one means to dedicate one's life to finding the very few who still keep them. Thompson works with his mostly-Thai kitchen brigade by putting themselves in service of summoning the historic and singularly traditional as they translate these recipes, many of which have not been made in decades or even a century, and re-present them to the diners of Nahm.

Printed on thick and glossy stock, Nahm's menu is an elegant booklet that is over a dozen pages long. It is spare in its use of text, with only four or five dishes per page. Headers are written in the Sanskrit- and Pali-influenced Thai script. Sections are divided by the dish types from which Thais construct meals in a typical manner - a shrimp paste-forward relish flanked by rare fruits and vegetables, accompanied by an acidic salad or yam, balancing a rich curry, in turn offsetting a simple seafood stir-fry, all eaten in against the blank canvas of white jasmine rice. Descriptions are elemental and minimal, mentioning technique and main ingredients (salad of river prawns with pork and Asian pennywort). The information gaps are meant to be filled in by the staff, or in the case of the many Thai locals and regulars, assumed to be culturally ingrained and automatic in the way they carefully arrange a meal through their order. Informed by 
decades of training in kitchen techniques, language, and culture, the food at Nahm is also the work of a true auteur - a powerful blend of chef skill and taste acumen aiming to deliver excellence. It is a process that begins with research and recipe adaptation, gains dimension through the sourcing of product, and is given life when dish-by-dish is replicated, night after night. A feature in The Guardian gets right to the question at hand, building the mystique of Thompson along the way: "So how did a 51 year-old Australian end up a world authority on Thai cooking? Thompson's training began in Sydney's French restaurants in the early 80's, but in 1986 after a holiday in Thailand his head was turned. He returned to Bangkok, spending two years learning all he could about Thai food...But Thompson found a teacher called Khun Sombat Janpetchara who had learned to cook at a royal palace...He began to collect memorial books, published when a Thai died and which often included their favourite recipes (Tucker, 2010).”

Nahm's food bears no noticeably over-wrought form of presentation here in the sense of the visually arresting plates of colorful sauce micro-dots and brush strokes that one might find in a contemporary restaurant in Copenhagen - or Singapore and Bangkok, for that matter. Curries are spooned unceremoniously into plain bowls that have been hand-painted by a Southern Thai potter. Vegetable stir-fries and their sauce pool upon onto celadon green or violet plates the size of a human palm, their wok sauce spilling towards the edges. David Thompson puts his craft in service of translating Thai food as it once was, and his cooks focus their efforts in replicating what he decides should be served. Servers, when the food is ready or a choice must be made by the guest, act as front line translators, there to provide background and commentary as one might find in essays accompanying an updated translation of Dante or the disc notes for a new arrangement of a Blue Note jazz classic. 
Gastronomically, Nahm provides a near-perfect blend of technical execution, excellence in product, and cultural specificity in its presentation (or is it representation?) of age-old Thai regional dishes. There is now near-uniform agreement about this amongst critics and diners. And yet, early on after opening, the restaurant faced a social stigma that left the dining room half-empty some nights for the very reason it is now popular: its head chef, David Thompson. When revealed that the chef was a foreigner and trumpeting authenticity, this fact detonated the front dining/back cooking division Nahm was predicated on. Heated conversations and articles of protest from Bangkok's elites were so strong as talking points that even the New York Times sent a hard news journalist to report on the social flare up. From the invocations over cultural propriety to the color of his eyes, it read as if Nahm's chef was a culinary colonialist in a country that had, in modern times, never fallen under the domination of another (Fuller, 2010): 'Mr. Thompson's quest for authenticity is perceived by some Thais as a provocation, a pair of blue eyes striding a little too proudly in to the temple of Thai cuisine."

The consequence of such media coverage was that, for a short period, Nahm was drained of its mystique (to steal a term from Dean MacCannell) in the eyes of its customers, as validation by Bangkok locals was either withdrawn or still missing. Initially, the well-off Thai crowd simply pretended not to care. But from day one they were texting, messaging, and writing opinions online and off with indignance and frequency. The topic became so hot it was a dinner party subject for weeks, but at the same time positive international press coverage kept mounting. As media praise collected, Nahm was marked as something Thailand should be proud about - a shiny, critic-beloved place to show their city's growing culinary prowess. Described the New York Times of one such guest (Fuller, 2010): "The highest compliment came from the wife of a Thai government official who dined (in the past) at Nahm in London. After 
finishing her meal she was leaving the restaurant with a dour expression. 'I came here to complain,' she said, according to Mr. Thompson, 'But I can't.”

Eventually, Nahm earned a flood of praise so enormous and unified from recognized global media sources that even the same residents opposed to patronizing it on the-chef-is-not-one-of-us grounds were mobilized to give it a gastronomic second look. Through its marking as a must-visit in Bangkok, Nahm helped bolster the cultural capital of the city itself. By elevating Nahm's socio-cultural importance, the process of media attention-giving gave new social validation to the restaurant as something Bangkok should be proud of, thus earning it a savory second chance with the locals. Thai diner by Thai diner, they came to eat. Plate by plate, they submitted and affixed their concurrence based on the most elemental product of any restaurant: Was the food good? Excellent maybe? Nahm was now marked in the eyes of locals and foreigners alike, a place to come and experience global excellence and witness local pride. In the end, Nahm's culinary achievements drove cosmopolitans and locals of all types Bangkok-born but foreign schooled, European expats who speak Thai, travelling foodies, third-generation Thai locals, Thais visiting from the South - into a common space where they could each negotiate and produce their own set of meanings, united by the common taste culture of an unusual and rare, authentic and personal brand of Thai cooking. Speaking in an Asia-based travel and lifestyle magazine, David Thompson himself puts it succinctly, giving his kitchen's cooking a goal (Destin Asian, April 2012): "My aim is to cater to locals...Bangkok allows me to cook for Thais in Thailand. I prepare and cook intensely flavored dishes attuned to ingredients that simply cannot be found outside the country."

\subsection{Relational Cuisine - In Authenticity and Chefs We Trust}


Nahm and Kin Khao both operate at a junction of the personal and the cultural. A combination of local social conditioning and geographical demands respectively plotted each at a particular point on the emerging transnational continuum of Thai cuisine. Though Thai by birth, Techamuanvivit has spent most of the last two decades studying and working in the United States, building culinary capital through her blog. Though she ceded kitchen control to a non-Thai chef, Techamuanvivit's presence in the dining room and previous audience familiarity was reinforced by the stories she told through her menu and her staff. Together these choices helped empower Kin Khao to build its own taste culture. The combination of being geographically far from Thailand, but having a recognized kinship tie to the homeland allowed Techamuanvivit to garner praise for her representation of Thai food culture. Her decision to break down the walls between kitchen and dining room, and to allow guests to see her roaming between the two staging areas also bolstered this story arc and emotional connectivity amongst her customers, who placed their faith in the Thai-ness behind her story. They chose not to focus on the mostly Western kitchen staff, or the use of quintessentially Californian ingredients like line-caught seafood or organic green beans

In the end, Kin Khao is a personal tale of cultural translation, negotiated authenticity, and chef-identity that is in formation and in constant interaction with the San Francisco public and the blogosphere. The New York Times Magazine put her unique background in context: "Pim Techamuanvivit is an old-school restaurateur, a person who knows her cuisine inside and out, but she has found an intriguing new way to run a non-European restaurant. Born in Bangkok in the 1970's into a family where delicious food was cooked and showcased daily, she came to the United States in the early 90's to study cognitive science, specifically the subject of group collaboration. The 
skills appear to have set her up perfectly for opening a restaurant. (Bittman, September 2014)."

By contrast, David Thompson's closed kitchen and the initial lack of penetration in both his dining room and the local market in his efforts to tell the whole story (the co-chef is Thai; they've cooked together for two decades; Thompson has been cooking privately in Bangkok for two decades) to their local Thai audience created a controversy that, for a short time, cast a shadow over the actual positioning and focus of the restaurant: historically-tied and regionally-rooted Thai food. After almost three decades in kitchens, Thompson is at a very different part of his career than Techamuanvivit. He's a master, at the peak of his powers, yet he's chosen to put his technique and ability to create a cuisine in service of something greater: an almost-lost culture of taste from decades and centuries past. His is also a research-driven form of the cooking craft, binding his services as chef to the role of food culture translator. Thompson's mark as an auteur is an unlikely one. Rather than have a cuisine bear his obvious imprint, he has made an amazing effort to simply try and not leave a personal mark - to get out of the way of a food culture he believes is more important than his standing as a chef will ever be. Or, more accurately, to put his talent in the service of deep flavours and timeand village-specific recipes from renowned female cooks who, in their time, created what he considers the "Golden Era of Thai cooking," in the 1800's. As the Bangkok city magazine $B K$ described in their review of Nahm (BK.Asia-City.Com): 'We're saying it from the start: we are big admirers of David Thompson and what he is doing (and has done) for Thai cuisine. Let's also make it clear that we don't give a damn if he's Australian or Thai, black or white, male or female. When all is said and done, it all comes down to taste and flavors. On that note Nahm is an undoubted success and, 
while there may be one or two rivals to the throne, it serves the bet Thai food you can eat in Bangkok, as long as price is not an issue."

Kin Khao and Nahm each represent a specific example of cuisine as relation. Geographical distance from Bangkok and ethnic kinship with the food of Thailand both helped define their initial opening receptions, though in very different ways. This same geographic scale was also used as an initial way of measuring their authenticity, at least by those who had yet to eat in their dining rooms. Their audiences are a direct product of their differentiated locales - Kin Khao's being mostly Western business people and tourists, Nahm's equal parts expatriate, tourist, and local Thai. But once their guests are in the dining room the measure switches to a combination of the cultural and the personal. How do they each choose to translate Thai flavors? Does the traditional structure of each dish remain, even if certain central proteins a re substituted for something more local? Food, by necessity, is always constituted locally in the application of its ingredients and the way it is replicated by cooks, even if the culture that inspires or informs it is a foreign or far-flung one. Nahm's is a cuisine of cultural translation and rare, near impossible-to-find-outside-Thailand ingredients. Kin Khao's is a culinary tale of Californian produce and proteins, filtered through the prism of typical Thai techniques and dishes and the memories and personality of the Thai owner to recreate them.

So it is that, in San Francisco, we have a Thai-born blogger whose restaurant kitchen is run by an American, and whose food captures the personal and improvisatory spirit of her native country, even if she serves the very un-Thai accompaniment of brown rice. So it is that, in Bangkok, we have an Australian-born chef, he of blue eyes, who speaks and writes Thai, and who is now cooking once-forgotten Siamese dishes from the 1800's. Kin Khao and Nahm may seem disparate at first - strategic opposites even - but 
in the end they are part of the same project the pursuit of creating their own proportional and personal take on Thai taste. If there is one, the essence of Thai food culture is unlike that of France: there are no master recipes. Instead, about that fleeting moment when a dish is brought into being - from cutting board to sizzling wok to plate in a matter of seconds - all momentarily informed by the hand of an individual cook. It is an act that can only ever be located in the brief but relational space between a single cook, a larger food culture, a malleable set of techniques and ingredients, and the unique way each diner consumes and experiences the intended flavors at hand. It's a fleeting project, to be sure, but a flavourful one as well. 


\section{Chapter 7: Discussion Part 3}

\subsection{Gener al Notes on Thai Food Talk}

There is a common set of considerations and influences that runs through the various publications, texts, chefs, restaurants, and topics that have been addressed so far under the umbrella of Thai cuisine. The shape and taste of Thai food was first confronted in the pages of Saveur magazine, where food journalists, chefs, and travellers shared their experiences from locations near and far - market food in regional towns like Phattalung, Esarn-style Thai cooking in Los Angeles, and many impassioned descriptions of street food in Thailand. The idea of Thai food was given theatricality, shape, and a highly personal imprint from chefs and owners with very specific markets and relationships with Thailand as a source of inspiration and a cultural reference.

Publications on local, national, and global scales were a site of identity formation for these restaurants, but also a forum for chef/owners David Thompson and Pim Techamuanvivit to shape their very own narrative, weaving intention and connection to Thailand together to help build the cultural and culinary capital they have used to support their restaurants as businesses. A final comparison of New York Times articles covering, respectively, Thai food and Thai political news, reinforced the dependence on certain frames and the editorial crutch of keywords used to textualize the Thai food experience. Examined together, this body of evidence beckons a last round of discussion on the recurrent issues and ideas that help frame the way food and travel journalism approaches the cuisine of Thailand. Several ideas and scholars provide a context for a larger discussion and enriching ways in which to reconsider the most pertinent theories. Think of them as theoretical brush strokes, leaving bold impressions that can't be ignored. 
A rich vein of culinary transnationalism connects all the publications, chefs, restaurants, and related topics that come to life and demand engagement under the umbrella of Thai food culture. Saveur magazine approaches - with intense attention to tradition - reporting that spans tens of thousands of miles from the Thai borders to Sydney and all the way to Portland, Oregon. Though the recipes it cooks from are wholly and historically Thai, the multi-cultural make-up of Nahm's kitchen is directly influenced by its two chefs, the more public, well-known Thompson and the private, little-known Yordwai. One is a Thai who speaks English and has cooked in Europe and Australia. The other is an Australian who speaks, reads, and writes Thai, but was trained in French cooking in Sydney.

On the other side of the Pacific Rim in San Francisco, Kin Khao's inspiration channels the Thai upbringing of its owner, while putting to work the family recipes and experiences of her youth. And yet, Techamuanvivit's kitchen is in San Francisco, a renowned food city which is fiercely connected to local producers and the philosophies behind buying as near as possible to one's address when it comes to cooking materials. Kin Khao therein relies heavily upon seafood, meats, wines, and produce from the area, then renders them with Thai techniques and seasonings inspired and shaped by a culture more than 8,000 miles away - and memories that are decades old. For Kin Khao, its ingredients, cooks, and dining audience helps produce a Californian locality, while its cultural baseline and source of technique and flavour spans borders and time zones, reifying Thai culture as a result. In all cases, the culinary identity of Thailand is produced in ways that are at once local and global, in the moment yet reverential of the country's food history. Under the umbrella term of "food talk," Priscilla Parkhurst Ferguson (2014) captures the crucial role of inscription the media plays in giving life to these experiences beyond the dining room or kitchen walls: "Without food talk, from 
recipes to criticism, and without food talkers, from cooks to consumers, the most glorious meal would be forgotten. Just as cookbooks bring cooking out of the kitchen, so food talk memorializes the meal. It translates the experience for those who were not there, who neither partook of the food nor participated in the festival of the meal (193)."

Whether in a bout of food talk over negronis or through a heated round of 140 character volleys on Twitter, the theoretical route to Thai food culture runs through the much-contested idea of authenticity. In the case of Thai food culture, it is a concept that can be attended to in different ways and, like food itself, is intimately tied to personal experience, identity, and context. Much like the cuisine of Kin Khao or Nahm, or the journalistic experiences described in the pages of Saveur or the New York Times, it must be considered in relation to other experiences, for food culture does not deal in absolutes. In their book on foodie culture, Josee Johnston and Shyon Bauman (2010) table a multi-part definition of authenticity that, with slight adjustment to one aspect, simultaneously carries the idea of relational cuisine and another comparative concept: relational authenticity. Much like Robbins approaches cosmopolitanism and Appadurai globalization, they consider authenticity as a "ground up" phenomenon (69) that gains momentum through the media and related foodie and consumer discourse, then collectively lays claims as to who gets to wear the mark of authenticity. For Bauman and Johnston, one can best comprehend authenticity "as both socially constructed and relational. Authenticity is not inherent, but is constructed through the perceptions of food producers and consumers (70)." They break their argument down in to the conceptual components of geographic specificity, simplicity, personal connections, his tory and tradition, and ethnic traditions.

By swapping cultural for geographic specificity and discarding the notion of simplicity, Johnston and Bauman's concept of relational authenticity provides an entry 
point of correlation to our restaurants, their chef/owners, and the larger context of Thai food. Through Pim Techamuanvivit's ethnic and family history in Thailand and her more recent connections to San Francisco, the authentic element of Thai food culture is reified in a highly personal way. David Thompson, meanwhile, masterfully uses his craft and a scholarly dedication to researching and translating Thai traditions from a very specific source - Thai funerary cookbooks. Using recipes sourced from individual women in specific Thai towns and regions, the Nahm kitchen then re-imagines them with an eye to historic accuracy and a commitment to the most specialized and localized ingredients available in the Kingdom of Thailand. The cultural, the historic and traditional, the personal, the ethnic in influence of person - from our methodology to our discussions, each aspect of Johnston and Bauman's theory has been seen in action.

But Kin Khao and Nahm are not just sisters in culinary style, just as the diverse Thai subjects of Saveur and the New York Times are not just related by topic. Together, their existence and the texts that cover and discuss them help create an imagined community of Thai food enthusiasts. The public nature of their audiences helps to build and contribute to the formation of the very same foodscape - one operates under a spirit of cosmopolitanism. Occupied by culinary enthusiasts, foodies, fellow chefs and cooks, and frequent diners, this foodscape is an utterly global network in the ground it covers. The examined texts thus reinforce and circulate common ideas of taste, experience, authenticity, and culture. Remarking on the fluid context of authenticity, philosopher Lisa Heldke (2003) re-assess the idea in a way that well describes the current global conditions in which we've debated various instances and forms of Thai food culture: "If any general definition of authenticity is possible it might make sense for it to emphasize adaptability instead of, or in addition to, replicability. After all, it is only with the emergence of the "global marketplace" that replicability has even been 
possible - that it has been possible to find foodstuffs from everywhere in the world in many places in the world (31)."

Turning to a key human player and audience member in tourism, culture, and gastronomy, the work of Ulf Hannerz asks who or what is an ideal cosmopolitan? In an academic interview on the topic (Ranthanen, 2005), he describes a specific type of individual who moves about and maximizes diversity, while being aware of the singularity of their surroundings and supportive of the inter-connectedness of it all, much like the types of readers who travel to Thailand just to eat (or in the Saveur reporters case, to write about) noodles sold on the streets (18): "an ideal cosmopolitan is more of one who shifts around and goes to many different places and maximizes diversity." Counterbalance this with Hannerz's earlier work (1990) on the cosmopolitanlocal relationship (237): "The world culture is created through increasing interconnectedness of varied local cultures, as well as through the development of cultures without a clear anchorage in any one territory." Despite being written in 1990, the increasingly connected global arena Hannerz describes meshes with the same in which Thai food culture operates, from chef/owner-run restaurants to journalists in foreign food and travel settings.

In the same interview, Hannerz muses about his fascination with the idea that a news correspondent from Sweden could be based in Hong Kong, yet covering Afghanistan or other nations with modern technology (22). What he is identifying is the uncanny ability to produce something globally, while also being respected or understood locally. The chefs, waiters, and cooks found in Thai (or any modern) restaurants around the world similarly drift across borders, bouncing between locations, basing themselves in multicultural urban centres, dedicating themselves to one posting for several years at a time, and then moving on to something newfangled once again 
(different food concept, new location). It is almost precisely the same way that a correspondent moves between assignments and country bureaus. In spite of their ethnicity or nationality and the geo-spatial placement of their restaurant, the chefs we've encountered in their dining rooms and the pages of recent food and travel publications, are readily able to meet or transcend socio-cultural conditions, becoming expert in the representation of one particular cuisine (Thai food) no matter where they may be cooking.

On a broader scale conceptually, food experiences and food cultures are intimately tied to individual memories and the multi-sensory engagement that helps construct them at any given moment of dining. As food is an ephemeral and, at times, transcendent act, the consumption of a dish must be looked at as a wider process made up of many smaller acts - ordering, initial impression, smell, intellectual consideration and/or memory, chewing, tasting, discussion with other guests, and so forth. Arjun Appadurai's essay on the global cultural economy (1996) traces several very powerful ways to look at cultural processes as a whole. "The image, the imaginary - these are all terms that direct us to something critical and new in global cultural processes: the imagination as social practice." Continuing on, Appadurai identifies the kind of organizational elements that are ideal for the structuring of a cultural experience like eating a Phuket-style yellow curry: “...the imagination has become an organized field of social practices, a form of work (in the sense of both labour and culturally organized practice) and a form of negotiation between the sites of agency (individuals) and globally defined fields of possibility (31)."

Appadurai joins many academics in identifying the "tension between cultural homogenization and cultural heterogenization" that is felt across lines of class and country around the world. As the content analysis portion of this thesis revealed, it did 
not matter what publication or topic journalists were working on or for - they all still assessed their Thai food experiences in relation to tradition and authenticity. As an issue, such tension and concerns are timeless. As a space where individuals can have unique experiences and create their own identities, the space surrounding food and culture also offers agency to various social actors, not least diners, eaters, foodies, and chefs. Through personal experience given dimension in media text, these ideas are culturally complex and demand a larger framework for consideration and discussion. Appadurai proposed a series of 'scapes' in which to view the "relationship among five dimensions of global cultural flows," which he further specified as concerning ethnicity, media, technology, finance, and ideas (33). Making emotional and historical connections on a larger and public scale, he contextualizes these scapes as "building blocks of what (extending Benedict Anderson) I would like to call imagined worlds, that is worlds that are constituted by the historically situated imaginations of persons and groups spread around the globe (33).”

By lining up the socio-cultural particularities and textual approaches we've witnessed in Thai food culture alongside the scapes and worlds previously described by Appadurai, the structures that define Thai food culture begin to emerge. They are constituted equally by food and travel journalists and the culinary choices and creations of their subjects and experiences. They are then given unique form by a wide-ranging cast of characters, and herein lies their enduring mystique. From street cooks selling noodles for less than $\$ 1$ a bowl to Thais cooking Northeastern food in Los Angeles, from blue-eyed Thai-speaking Australians to Thai-born bloggers-turned-restaurateurs, it is not just people that travel, but their cultures and tastes as well. Thai food is nothing if not a current example of what is culinary cosmopolitanism, an inclusive group of persons and personalities whose journeys are as particular as the opinions or food they 
produce. As Bruce Robbins (1998) observed in his essay on "Actually Existing Cosmopolitanism," something "has happened to cosmopolitanism." Indeed, it is no longer simply an elite term. Robbins continues, heeding the importance of James Clifford's many in-between modes of existence along the way: "It has a new cast of characters...Now it is attributed, more charitably, to North Atlantic merchant sailors, Caribbean au pairs in the United States, Egyptian guest workers in Iraq, Japanese women who take gaijin lovers...The change in personnel implies a change in definition (1)." Bridging the foreign correspondents Hannerz muses about with the diasporic labourers of Robbins, the prep cooks whose hard kitchen labor help keep Thai restaurants cooking and the adventurous freelance journalists who report on cultures of food and permanently inscribe travel experience join the cosmopolitan fray as well.

These iterations of the cultural and the culinary give breadth to the unique power of food as a form of cultural mediation. They are also the chief fuel for the brand of journalism that serves to record and memorialize them. In something as seemingly innocuous as a series of things one person eats that are cooked by another, we have witnessed a multi-dimensional type of interconnectivity in the way food culture literally and metaphorically brings people to the table. In the fleeting way tastes race across the palate, it is pleasurable. In the way a Thai meal is made up of shared plates passed around a table, it is communal. When compared to other forms of culture, cuisine is highly interactive. Unlike live performances of music, a diner dictates what is to be consumed and in what order. Unlike pictorial art or architecture, guests at a restaurant physically ingest part of the theatre they have chosen to attend at any particular meal. Unlike literature or opera, the creators of the Thai dishes being eaten are also directing, cooking, even touching the food they send to diners on a nightly basis. To this end, Thai food is also a highly particular expression of a certain cuisine from a certain 
country. By choosing to dine, say, at Kin Khao or to read a piece on cooking curries in Saveur or The New York Times Magazine, the respective diners and readers are consciously choosing to have an experience related to Thailand's culture in the form of food. Cultural critic Gayatri Spivak, in the foreword to her book Other Asias (2008), identifies the importance of not being what she calls "competitive" with other continents. Spivak says the Asia she is "thinking of not only respects, but attempts to know the differences within Asia as imaginatively as possible. My field is not policy studies. It is comparative literature. I go toward assessing the other through deep language learning in the collectivity of the classroom (2)."

Though as a scholar she works within the confines of literature, as did Shih with her Relation as Comparison theory, Spivak is in fact talking about how to evaluate culture as a whole. By addressing the specific and the contextual, she aims to tease out more human and universal issues and truths. Food produces meaning in similarly leveled and nuanced ways. By serving a plate of highly specific Thai regional food, cooked from geographically unique ingredients, chef David Thompson is very knowingly marking his cuisine as not unlike that of another - it is a moment that emphasizes difference, and then through the common act of eating and the universal ability to appreciate taste also brings people together. "I believe that paradoxically enough," Spivak writes of this socio-cultural phenomenon, "learning to know our differences keeps leading toward all those words that policy studies conjure with: peace, justice, the rights of humanity...It is a persistent effort at training the imagination, a task at which we have failed throughout the progressive rationalization of education all over the world (2)."

Spivak identifies a failure on a human and global level to recognize difference and convene through the experience of education. In its own way, the power of food 
culture - as amplified and given broader social life by food and travel journalism represents a rare success story in the same global cultural setting. With its singular combination of sensory connection, cultural experience, and social context, cuisines like that of Thailand have the ability to transcend - not just time and space, but people and culture as well. While these ephemeral and experiential aspects make it hard to get beyond the moment, their inscription in journalistic text also provides an arena in which all types of reader and eater can come convene in public ways. If a meal is only ever a very specific moment in time, feeling, and taste, then the texts recording it have the chance to be a powerful theatre in which to witness and connect to memories past, emotions present, and impressions future. In closing, Priscilla Parkhurst Ferguson (2014) cuts to the heart of the sheer humanity that belies any meal in a chapter in her book about food talk entitled "Texts Take Over":

"Why this need to talk about food? Why is food talk so important? First off, eating is a deeply private affair. Because we cannot share the actual food that we consume, we talk about it. We do not share food; we share the experience of food. In so doing we propose our private dining for public perception...Food talk completes the culinary circuit, turning the private into the public, embellishing the personal, and memorializing the idiosyncratic...The most memorable meals are not the ones that we eat, and certainly not at the moment of consumption. The really important food is the food that we think about, dream about, and talk about-meals that trace our lives and connect us to a tradition (51-52)." 


\section{Chapter 8: Conclusion}

This thesis set out to explore the ways in which food-related experiences can serve as a powerful medium in which to connect with those from different cultures. As a way of focusing the research, one food culture - that of Thailand - was chosen as an object of study, to examine what lessons could be gleaned. Further, a specific site in which to examine this process unfold was also selected: the texts of food and travel journalism. As we have seen, these texts served as both a practical and symbolic arena in which varying representations of Thai food could be brought forth by different journalists, and then engaged with by audiences in North America and abroad. After applying a methodology that employed dual quantitative and qualitative methods and written ethnographies of two restaurants, discussions surrounding various examples of Thai food culture - and the different ways in which journalists recorded it as an experience - were initiated. It can be argued that, as a subject, the food and travel texts studied in this thesis are a wholly unique brand of journalism worthy of much more scholarly attention than it currently receives.

As we have seen from the markets described in Saveur to the relational cuisines of the restaurants $\mathrm{Nahm}$ and Kin Khao, food and travel journalism owes much of its singular set of conditions to the fact that it is tied to a subject that is both culturally and sensually unique. As a universal form of consumption that is mandatory for human survival yet highly pleasurable as an endeavour, food is part of a larger, highly

globalized socio-cultural system and has a political economy all its own (Bell and Valentine, 1997). Ferguson and Zukin (1995) underline the academic endemic meanings as they related to these ideas, noting that "the study of food is, in good part, a study of the culinary "worlds" produced by the many interactions that put food on the table, 
ready to eat (197)." Given the results of the content analysis in this paper, it can be argued that the pursuit of flavour - a chief concern for cultural traditions and authenticity - and finding a way to connect to food are common concerns for most diners, at least those who make up the audiences of the food and travel publications in this thesis.

Josee Johnston and Shyon Bauman (2010) identify a two-level concern with another term central to this debate - authenticity. The first is based on using reference and relation in a way that one idea fortifies and gives dimension to the other in an act of meaning-making: "More broadly in foodie discourse, we frequently encounter the idea that we know whether we are getting the "real" or authentic version of something by comparing it to a set of established standards, conventions, or traditions. In order to make such a comparison, though, we need a tradition as a reference point. Food is often framed as authentic through connecting it to a specific historical tradition, which is commonly (but not exclusively) linked to an ethno-cultural tradition. (88)" The second helps illuminate how chef-driven cuisines are cultural acts of interpretation: "..foodie discourse also frames foods as authentic when tradition forms the foundation for artistic experimentation, working in conjunction with the previous discursive strategy of personalized artistic innovation (89)."

Given the media focus on the backgrounds and intentions of chef/owners of Thai restaurants, as well as the highly detailed process of creating menus, layouts, wine lists, and sourcing products, people on all sides of the contemporary dining equation place a lot of value in the decisions that must be taken to create a guest experience. Exhibiting the social value placed on food and travel media as a whole, varied types of texts including restaurant and blog reviews, cookbooks, and awards lists uncover such concerns in the reflective discussions that we witnessed in the various food and travel 
publications we examined. Writing in his book on food and popular culture, Fabio Parasecoli (2008) maintains that "we can never underline enough how the growing impact of media on contemporary societies has generated autonomous fields of meaning where facts, events, and trends are largely determined by the media themselves (137)." Continuing his critique at the more pointed types of food media, Parasecoli emphasizes that "images and information heavily influence other aspects of culture. In the case of food...magazines affect our perception of what good eating is supposed to be (138).”

Unlike other forms of culture that are driven by language (literature, poetry) or coded in ways that makes it difficult for those not from a certain place or time (religious relics, ancient art) to comprehend them, as a medium food can transcend national borders and local conditioning in ways that make it highly appealing to global audiences. This characteristic of being able to remain tied to one place in vital cultural ways (remaining near to the culture's original geographic location), while being able to function in similarly robust ways in other contexts (far from the culture's original location) is summed up by Andreas Hepp (2015), as he quotes G.F. Simons on the nature of what it means to be "transcultural" (14): "Transcultural' is here defined as being "grounded in one's own culture, but having the culture-general and culturespecific skills to be able to live, interact, and work effectively in a multicultural environment." Writing in a book of essays in travel journalism, Ben Cocking (2014) makes fundamental assertions about the essential nature of travel journalism, balancing strengths and weaknesses, commercial concerns and its potential for cultural impact: “It is clear that the commercial environment in which travel journalism is produced means that it has to be attuned to the cultural expectations and aspirations of its readers. The content of travel journalism can, at times, be cliché ridden and ethically and politically 
suspect. Yet, to dismiss it as such is to miss the point. Fundamentally, the significance of this form of journalism is its role as cross-cultural mediator (187)."

Just as theorists such as James Clifford have used hotel and motel lobbies as chronotopes in his ethnographic writings, this thesis has cast restaurants and the journalistic texts that record them as arenas of social and semiotic interaction. When a globally cooked cuisine such as our object of study - Thai food - is added to this equation, a transcultural element becomes part and parcel of the equation. If ethnographies are meant to engender discussions of larger issues based on their inscription of the daily and detailed minutiae of cultures considered different from our own, then so it is with the way food and travel texts operate as well: by recording personal experiences or events based on far-off food cultures, they serve as the entry point for larger discussions on what eating and drinking a certain way in a certain place means to us. Food and travel texts, then, are themselves sites for cross-cultural engagement and understanding, and given the intensely personal nature of dining, they allow for a particular relationship with each individual reader. James Carey, in his treatise Communication as Culture, summed up the layered dynamics behind the human relationship to communication forms as such: "To study communication is to examine the actual social process wherein significant symbolic forms are created, apprehended, and used...We create, express, and convey our knowledge through the construction of a variety of symbol systems: art, science, journalism, religion, common sense, mythology (30)."

Focusing on the socio-symbolic arena of food and travel journalism as Carey theorizes, it is important to review several modes of operation observed during the methodology and discussion sections. By exploring how food and travel writers perform as journalists, the methodology put an emphasis on accounting for how voice, 
description, and experience were approached stylistically. The answers showed that this brand of journalism made substantial breaks from the typical voice, practices, and standards demanded by news-driven publications or taught in journalism schools. While news reporters use a standard neutral voice and focus on presenting facts in an efficient and organized manner, the writers covering Thai food did very much the opposite.

Writers used a first-person voice, effecting personal experience as a way to connect with their readers. News reporters may help set their scene with descriptive adjectives, but their use of "colour" is highly measured as the focus is on delivering information and their pieces are largely driven by facts and a more conservative type of prose. In contrast, the Thai food texts showed a heavy reliance on sensory description using all the available senses. Most of the Thai food and travel pieces also seemed to romanticize a moment in time for the readers to then re-live in their subsequent readings.

Whereas the news reporter aims to treat all subjects and topics the same regardless of location, the results of quantitative and qualitative analysis of food and travel texts in this thesis suggest that the identification of aspects or experiences that represent the cultures of Others - focussing on the authentic, traditional, or exotic - was at some point (addressing the chef) and in some form (describing a market setting) given primacy in almost all the articles examined. While news articles might indicate an aggressor (Russia in the Ukraine) or an ally (the British to the US in Iraq), food and travel pieces tend to be incredibly positive when portraying a foreign food culture like that of Thailand. Compare the New York Times (2015) clips about Thai hard news to the personal narrative-fueled piece on a Thai restaurant, both from the same publication and time frame: 
A Thai restaurant review (Gold, December 2015): "I'll admit this right up front: I've never eaten a meal at a Thai restaurant, no matter how scruffy it was, and not enjoyed it. Partly, this has to do with personal history. I've been lucky enough to travel in Thailand, and whenever I taste the cuisine's signature ingredients - kaffir lime, chilies, shrimp paste, coconut milk - I receive a Proustian jolt pulling me back to the street stalls of Bangkok."

A news piece on Thailand (Fuller, December 2015): “Thailand's aggressive campaign to protect its ailing king from criticism escalated into a diplomatic feud on Wednesday when the Thai police said they were investigating the United States ambassador to the country in connection with a royal insult... The police said the ambassador, Glyn. T Davies, had diplomatic immunity and could not be charged for such a crime."

Right from the first sentence, the piece on Thai food gets personal, invokes memory and even literary metaphor, and provides an image of ingredients and Bangkok street food. The personal and the cultural are at the forefront. Contrast that to the news piece, where context is set, and facts are delivered down to names and municipal and political departments. The factual and the verifiable are at the forefront. Here we can see the contrast of intention, style, and voice laid bare. We can also feel the positive intentions and celebratory nature of the Thai food piece, while the news piece has drama and conflict at its heart, a trend that can be seen through both the Thai food and the Thai news corpus. The content analysis numbers revealed the same patterns. In the same 2015 time frame throughout the 11 articles examined on both subject matters, the news journalists used first-person "I" or the reflective you/we/our not once, zero times, 
whereas the food and travel journalists used them 63 times. The core journalistic idea of using sources and quotes was witnessed 70 times in the news pieces. The Thai food and travel articles? Just 11 times.

As a form of representation that gains its power from its ability to amplify the issues and passions of its readers, journalism has long relied on a generally agreedupon (but not codified as in medicine or law) set of practices and standards to help it build and maintain credibility. While news reporting has had centuries to gain a foothold and also to enshrine certain approaches in the way it teaches students and trains reporters, other newer forms (and uses) of the craft have not had the same time frame to develop more formal normative structures. Based on the examinations and discussions of this thesis and coupled with the growth of dedicated food and travel newspaper sections and magazines globally, it can be said that as a type of journalism, the highly specialized food and travel field has grown steadily in the last several decades. Countries all over the world - Singapore, Thailand, the US, Korea, Spain, the UK - have multiple titles dedicated to some combination of food or travel, and the field is further supported by a restaurant boom and TV networks with primetime programming dedicated to the subject as a whole.

While food and tourism studies have begun to grow as respected fields in academic study, forms of journalism that do not incorporate news and its traditional approaches in the sense of craft and writing are often afforded a lower level of respect or attention by universities and the Academy. Based on the large global communities that champion as pointed a subject as Thai food in the media, this thesis makes the argument that this is a field that deserves a greater level of academic attention. The combination of media, culture, food, and experience is an incredibly rich one, and the generally positive approach that we've seen taken to the portrayal of Others is 
something that should be applauded and supported as it evolves in the years to come. In a world of increasing misunderstanding and conflict between cultures, the ability of food and travel journalism to engender cross-cultural connections must be celebrated and further examined.

Ours is now a fully global world, and while that has the potential to be a great thing, it also demands a certain level of sensitivity and a dedication to a certain type of approach in understanding what it means to encounter - or in our case as journalists, report on and write about - cultures of Others. While front-page news is often beyond the basic interests of most readers, subjects like food and travel are universal concerns. They represent two of the fastest-growing and largest industries in the world, the former a multi-billion dollar industry and the latter a trillion-dollar one. It only makes sense that audiences would take an active interest in a primal act of consumption, as well as a flat out form of fun for most involved. Cocking sets the contrasting but equally powerful missions of news, food, and travel journalism one next to the other, spotlighting their equally robust abilities for forging intercultural connectivity: "First, travel journalism taps into our collective imagination...It has long been accepted that the use of specific representational strategies in the 'hard' news of political reporting comes to bear on our political views and our understanding of politics. It is important to accept that travel journalism similarly shapes our cultural imagination of the world (188)."

Using this thesis as an argument for the importance and socio-cultural power of food and travel journalism, I hereby propose a set of best practices and standards to help editors and writers who work in this specific trade. Beyond the editors' offices and writers' desks, they also consider the vital third dimension of the field - foreign cultures. While invoking some of the same standards that are held to be core beliefs in journalism, these recommendations also respect the dimensions of writing about the 
cultures, places, tastes, and peoples that are encountered as one dines and drinks with those from Other cultures as well. Reverence for the relationship between a journalist and his/her subject is considered with equal weight as being able to capture the powerful experience of sampling (sometimes sharing) the foods of another culture, and how that act might transform in nature or meaning as it crosses borders. As our time spent discussing Kin Khao in San Francisco and Nahm in Bangkok demonstrates, in edible cultures and the performative cookery that defines it, everything is personal and all cuisine is relational. The act of putting these moments down in a permanent form on paper can be just as powerful as that of smelling the lime leaf-bred aromas of a curry for the first time. To be able to share such experience with tens and hundreds of thousands of others is an incredibly powerful act that I hope these standards and practices can go some way towards deepening and shaping as a journalistic field worthy of much greater attention. Here's to sitting at a table, to eat, to write, or to read, and to those who will be doing it time and again over steaming plates of noodles or bowls of curry in the years to come...

\subsection{Tow ards a Set of Normative Practices for Food and Travel Jour nalism}

This final section looks towards the future. By considering the ways in which the voices and editorial frames were deployed and examined in the previous pages, the aim 
is to suggest how a specific and evolved set of practices might ultimately benefit the unique strain of food and travel journalism. Each practice addresses a set of themes that is representative of an idea discussed in the previous pages. While they have been developed as potentially effective practices to put in to editorial play, they also have a normative slant that could eventually help contribute to a new, more robust definition and set of practices for food and travel journalism. The ultimate goal is to help support the development of a specialized brand of journalism, embracing culture where news often ends up embracing conflict. To call on Priscilla Parkhurst Ferguson speaking of the potentially lofty role of writing - and for us - journalism in relation to food and travel: "Food talk, and more precisely, food writing creates the cultural artifact...Texts allow, and indeed encourage, the comparisons that make judgment, criticism, and analysis possible. By extending the reach of culinary practices, these texts lay the foundation for a true culinary culture. To have an effect beyond the individual cook or diner, cooking has to get out of the kitchen; feasting must exit the dining room. That job of conveyance to the larger food world is what food writing does (52)." Here, I believe, are key practises to help the field get there:

ANew Foreign Correspondence: With foreign bureaus closing and international coverage in slow retreat, the importance of food and travel journalism as a site for interaction with places and people of different origins grows stronger with each week. Taking a cue from magazines such as the former Gourmet-which kept staff correspondents on retainer for every major continent or global region - publications specializing in food and travel should appoint and fund foreign correspondents on the basis of their localized expertise, language abilities, and capabilities to present a more complex 
representation of the Other. As Smith and Higgins (2014) discuss in their chapter on magazine journalism, the specialized orientation of glossy monthlies afford opportunities for content creation that can amplify a sense of community "driven by mutual interest, shared beliefs, or a common national or regional identity" (49).

Symbolic Analysts In Journalism: Inspired by Appadurai's (2001) call for symbolic analysts to collaborate in the name of research, food and travel publications should recontextualize this idea in the way they commission long-form articles and provide briefs to both textual and visual journalists (9). While assigning articles and deciding how to present their topics visually, they should call on their foreign titles and experts based abroad in the area of the topic, mixing and matching talents, linguistic capability, and cultural viewpoints to enrich the content that drives their magazine and lures their readers in a more culturally muscular and sensitive assembly of coverage teams.

Audience Platforms - The Extended and The Global: As Thompson (1995) points out, the media have created a "mediated worldliness" that is fed by the "growing importance of forms of communication, and interaction which are not face-to-face in character (5-6). Going forward, all media should capitalize on the growing reach afforded by extended media platforms to engage their audience in a way that makes them as active and potentially public in character and action as possible. It is here, in these overlapping circles of communication, that opportunities for cross-cultural experiences and shared conversation can be found, consolidated, and extended in a powerful and permanent way. 
Activating Voices: Just as Spivak (1988) lamented the lack of voice available to the subaltern in India, just as Robbins (1998) called for a re-definition of cosmopolitanism to recognize the changing nature of the global experience, so too should publications covering food and travel re-adjust their journalistic practices. Their contracts should include an understanding that those being written about should be given a voice through the same reporting and source-usage techniques that news journalism deploys. In countries where language separates subject and journalist, the use of translators or local language-capable scribes should be mandatory. It is understood that the uniquely personal nature of food and travel writing often demands a first-person treatment of experience - and the neutral voice of news journalism must thus be left behind.

However, the voices of people from different points along the socio-cultural continuum of foreign food cultures, must also be heard. Interviews and basic reporting must then become an integral part of food and travel journalism - by editorial decree, and not merely one of many options.

APositive and Open Othering Process: Magazines such as Saveur, the publications who we observed writing about Kin Khao and Nahm, and major newspaper sections specializing in food or travel place the representation of a foreign Other at the centre of their work - especially if concerning a culture from far away. Journalists, photographers, and editors should be made aware of this phenomenon. They should be educated prior to covering foreign cultures, placed in a sort of cultural awareness immersion to comprehend the power they hold in representing Others to large audiences. As we have seen, food and travel journalism is unique in that it presents a largely enthusiastic and positive version of the Other to its readers. This is a good starting point, but it needs to be deepened and accountability must be added to the mix. Beyond training, food and 
travel editors should have a mandate to offer their readers new voices and viewpoints, new experiences and global entry points. An open and aware representation process should be a goal enshrined in the contracts of staffers and freelancers alike. This can begin going some distance towards re-distributing and re-balancing the power/knowledge divide written about by theorists such as Hall (1997) and Foucault (1983).

Enactment of Professional Journalistic Codes: Taking cues from the professional pillars outlined by journalism scholars like Schudson and Anderson (2009) and Kovach and Rosenstiel (2014), food and travel journalism should incorporate the journalistic codes of truth, verification, independence, and fairness into their working process, enshrining them alongside the above practices and standards. Besides giving shape to a sometimesamorphous branch of journalism, they also match up neatly with some of the ethnographic principles of anthropology, which approaches other cultures and travel in a way that is responsible and sensitive. While it is understood that other ideals - more specifically, objectivity and the use of neutrality - are necessarily challenged and re-cast by the singular circumstances of food and travel journalism, the aforementioned ideals will help this journalistic brand command respect and create continued impact and achievement within the field. 


\section{Bibliography}

Afar Staff (2016, May). Kin Khao. Retrieved from http://www.afar.com/places/kin-khao$\underline{\text { san-francisco } ? \text { conte } x t=\text { wanderlist } \& \text { context } i d=34845}$

Anderson, Benedict (2006). Im agined Comm unities: Reflections on the Origin and Spread of Nationalism. New York: Verso.

Appadurai, Arjun. How to Make a National Cuisine: Cookbooks in Contemporary India.

Appadurai, Arjun (2001). Grassroots Globalization and the Research

Imagination. In Appadurai, Arjun (Ed), Globalization. Durham: Duke

University Press. (pp. $1-21$ )

Appadurai, Arjun (2013). The Future As Cultural Fact: Essays on the Global Condition. London: Verso.

Appiah, Kwame Anthony (2006). Cosmopolitanism. New York City: W.W Norton.

Asia’s 50 Best Restaurants. (2016, June). Retrieved from

http://www.theworlds50best.com/asia/en

Bangkok Post - retrieved from http://www.bangkokpost.com/print/298506/ 
Bauer, Michael (2014, April). At Kin Khao, a Chef in Pursuit of Authentic Thai Flavors. SF Gate. Retrieved from http://www.sfgate.com/restaurants/diningout/article/At-KinKhao-a-chef-in-pursuit-o f-au thentic-Thai-5450176.php

Benkler, Yochai (2006). The Wealth of Networks. New Haven: Yale University Press.

BK.Asia-City.com (2016). Bangkok Restaurant Review: Nahm. BK Magazine. Retrieved from http://bk.asia-city.com/restaurants/bangkok-restaurant-reviews/nahm

Bittman, Mark (2014, September. Thai-Style Thai. New York Times Magazine. Retrieved from http://www.nytimes.com/2014/09/28/magazine/thai-style-thai.html?_r=0

Bush, Austin. (2009, July). Bangkok's Banquet. Saveur Magazine. Retrieved from http://saveur.com

Cheung, Tim (20122, September 7). Your Pick: World's Best Foods. CNN.Com Retrieved from http://travel.cnn.com/explorations/eat/readers-choice-worlds-50-most-deliciousfoods-012321/

Clifford, James (1988). The Predicament of Culture: Twentieth-Century Ethnography, Literature, and Art. Cambridge: Harvard University Press.

Clifford, James (1997). Routes: Travel and Translation in the Late $20^{\text {th }}$ Century. Cambridge: Harvard University Press. 
Destin Asian (2012, April). Bangkok: Q\&A with David Thompson of Nahm Restaurant. Destin Asian Magazine. Retrieved from http://www.destinasian.com/countries/a sia/thailand/nahm-bangkok/

Douglas, Mary (1971). "Deciphering a Meal." In Myth, Symbol, and Culture. New York: W.W Norton $(61-83)$.

Entman, R. (1993). Framing: Toward Clarification of a Fractured Paradigm. Journal of Communication 43(4): 51-57.

Feldmar, Jamie. (2013, April). A Khao Soi Affair. Saveur Magazine. Retrieved from $\underline{\text { http://saveur.com }}$

Ferguson, Priscilla Parkhurst (2014). Word of Mouth: What We Talk About When We Talk About Food. Los Angeles: UCLA Press.

Foucault, Michel (1983). The Subject and Power. In Dreyfus, Hubert L. and Rainbow, Paul. Beyond Structuralism and Hermeneutics. Chicago: University of Chicago Press (pp. $208-226)$

Fuller, Thomas (2010, September 23). Thais Bristle at Australian's Take on Thai Cuisine. New York Times. Retrieved from http://www.nytimes.com/2010/09/25/world/asia/25chef.html 
Fuller, Thomas (2015, December 9). Thai Police Investigate U.S. Ambassador on Suspicion of Insulting King. New York Times. Retrieved from http://www.nytimes.com/2015/12/10/world/a sia/thailand-lese-majeste.html

Gans, Herbert (1999). Popular Culture \&High Culture: An Analysis and Evaluation of Taste. New York: Basic Books.

Geertz, Clifford (1971). "Deep Play: Notes on the Balinese Cockfight." In Myth, Symbol, and Culture. New York: W.W. Norton (1-39).

Geertz, Clifford (1994). "Thick Description: Toward an Interpretive Theory of Culture.” In Readings in the Philosophy of Science. Cambridge: MIT Press.

Geertz, Clifford, Editor. (1971). Myth, Symbol, and Culture. New York: W.W Norton.

Gold, Jonathan. (2012, April). Hot, Sour, Sweet, Bitter, Hot. Saveur Magazine. Retrieved from http://saveur.com

Gold, Sarah (2015, December 24). Review: At Bangkok Boulevard in Hamden, a Spectrum of Classic Thai Flavors. New York Times. Retrieved from http://www.nytimes.com/2015/12/27/nyregion/thai-restaurants-in-hamden-connecticutbangkok-boulevard.html

Hall, Stuart (1997). The Spectacle of the 'Other'. In Hall, Stuart (Ed). Representation: Cultural Representations and Signifying Practices. London: Sage (pp. 225 - 279) 
Hanusch, Folker and Fursich, Elfriede. 2014. Travel Journalism: Exploring Production, Impact, and Culture. New York: Palgrave MacMillan.

Hanusch, Folker and Fursich, Elfriede (2014). On The Relevance of Travel Journalism: An Introduction. In Hanusch, Folker and Fursich, Elfriede (Eds.) Travel Journalism: Exploring Production, Impact and Culture. New York: Palgrave Macmillan. (pp. 1-18)

Hannerz, Ulf (1990). "Cosmopolitans and Locals in World Culture.” In Theory, Culture, and Society. Vol. 7: 237-251.

Hartley, John (1996). Popular Reality: Journalism, Modernity, Popular Culture. New York: St. Martin's Press

Heldke, Lisa (2003). Exotic Appetites: Rum in ations of a Food Adventurer. New York: Routledge.

Heldke, Lisa (2005). "But is it Authentic?" in The Taste Culture Reader, edited by Carolyn Kornsmeyer, 385-94. New York: Berg.

Hepp, Andreas (2015). Transcultural Communication. Malden, Mass: Wiley Blackwell.

Hooks, Bell (1992). BlackLooks: Race and Representation. Toronto: Between the Lines 
Kovach, Bill and Tom Rosenstiel (2001). Elements of Journalism: What News People Should Know and The Public Should Expect. New York: Three Rivers Press.

Johnston, Josee and Shyon Bauman (2010). Foodies: Democracy and Distinction in the Gourmet Foodscape. New York City: Routledge.

Joys of Thai Food - retrieved from http://www.joysthaifood.com/thai-foodinformation/thai-food-in-a-global-market/

Jurafsky, Dan (2014). The Language of Food: ALinguist Reads The Menu. New York: W.W Norton.

Kolmer, C. "Methods of Journalism Research - Content Analysis" in Löffelholz, Martin, and David Hugh Weaver, eds. Global journalism research: Theories, methods, findings, future. Blackwell Pub., 2008.

LeCompte, Margaret D. "Analyzing qualitative data." Theory into practice 39.3 (2000): 146-154.

Livingstone, Sonia (2005). On the Relation Between Audiences and Publics. In Sonia Livingstone (Ed.). Audiences and Publics: When Cultural Engagement Matters for the Public Sphere. Bristol: intellect (pp. $17-41)$

MacCannell, Dean (2013). The Tourist. Los Angeles: UCLA Press. 
Mennell, Stephen (1996). All Manners of Food. Chicago: University of Illinois Press.

Mercer, Kobena (2005). Introduction in Contemporary Modernism s: 6-23. Cambridge: MIT Press.

Mintz, Sidney W (1996). Tasting Food, Tasting Freedom: Excursions in to Fating, Culture, and the Past. Boston: Beacon Press

Oseland, James. (2007, August). Southern Heat. Saveur Magazine. Retrieved from http://saveur.com

Oseland, James. (2010, February). Big Flavors. Saveur Magazine. Retrieved from http://saveur.com

Parasecoli, Fabio (2008). Bite Me: Food in Popular Culture. New York: Berg.

Priest, S. (2009). Doing Media Research: An Introduction. New York: Sage Publications.

Rantanen, Terhi (2005). "An Transnational Cosmopolitan: An Interview with Ulf Hannerz." In Global Media and Communication (3): 1.

Reuters - retrieved from http://www.reuters.com/article/us-thailand-tourismidUSKBNOUK0IU20160106 
Ricker, Andy. (2014, February). The Star of Siam - Thai Curries. Saveur Magazine.

Retrieved from http://saveur.com

Ricker, Andy. (2013, May). Best Bird. Saveur Magazine. Retrieved from http://saveur.com

Robbins, Katie. (2011, April). 24 Hours of Thailand in Los Angeles. Saveur Magazine.

Retrieved from http://saveur.com

Robbins, Bruce (1998). Introduction Part I: Already Existing Cosmopolitanism. In Cheah, Pheng and Robbins, Bruce (Eds). Cosmopolitics: Thinking and Feeling Beyond the

Nation. Minneapolis:

University of Minnesota Press. (pp. $1-19$ )

Rojek, Chris and John Urry (eds) (1997). Touring Cultures: Transformations of Travel and Theory. London: Routledge.

Rousseau, Signe. 2012. Food Media: Celebrity Chefs and the Politics of Everyday In terference. New York: Berg.

Said, Edward W. (1979). Orientalism. New York: Vintage Books.

Sanchez-Gomez, Fernando (2013). Cooking Critically: History, Theory, and Practice of Food Reviewing as a Genre of Journalism. USA: Manolito Garabato. 
Saveur Media Kit. 2014. Bonnier Corporation.

http://www.bonniercorp.com/MediaKit/Saveur.pdf.

Schudson, Michael and Anderson, Chris (2009). Objectivity, Professionalism, and Truth

Seeking in Journalism. In Wahl-Jorgensen, Karin and Hanitzsch, Thomas (Eds.). The

Handbook of Journalism Studies. New York: Routledge (pp. 88-101)

Shi, Shu-mei. (2013). "Comparison as Relation.” In Felski, Rita and Susan Stanford

Friedman. Comparison: Theories, Approaches, Uses. Baltimore: Johns Hopkins University

Press.

Smith and Higgins (2014). The Language of Journalism. New York: Bloomsbury (x-y)

Spivak, Gayatri (1988). Can the Subaltern Speak? In Grossberg, Larry and Nelson, Cary (Eds.) Marxism and Interpretation of Culture. Urbana: University of Illinois. (pp. 271 -

Spivak, Gayatri (2008). Other Asias. Malden: Blackwell Publishing.

Staff, The Nation. (2013, July 20). Bangkok is World's Best for Fourth Year. The Nation. Retrieved from http://www.nationmultimedia.com/national/Bangkok-is-Worlds-Best-for4th-year-30210861.html 
Sunanta, Sirijit (2005). "The Globalization of Thai Cuisine.” Paper presented at Canadian Council for Southeast Asian Studies Conference, York University, Toronto, October 2005. http://cites eerx.ist.psu.edu/viewdoc/download?doi=10.1.1.404.1934\&rep=rep1\&type =pdf

Table Hopper (2014, May). Review of Kin Khao. Table Hopper. Retrieved from http://www.tablehopper.com/biz/kin-khao/

Telfer, Elizabeth (1996). Food for Thought. London: Routledge.

Techamuanvivit, Pim (2016, May). About Pim. Chez Pim Blog. Retrieved from http://chezpim.com/about

Thai Select.Com - Retrieved from http://www.thaiselect.com/main.php?filename=about_us

Thompson, John B (1995). Introduction. In The Media and Modernity: A Social Theory of the Media. Stanford: Stanford University Press (pp. 1 -9)

Thompson, John B. (1995). Communication and Social Context. In The Media and Modernity: A Social Theory of the Media. Stanford: Stanford University Press (pp. $10-43$ )

Thai Websites - Retrieved from http://www.thaiwebsites.com/tourists-nationalitiesThailand-2014.asp 
Tiampo, Ming (2011). “Cultural Mercantilism: Modernism’s Means of Production - The

Gutai Group as Case Study," in Jonathan Harris ed., Globalization and Contemporary Art (Oxford: Wiley-Blackwell).

Tourism Authority of Thailand. Retrieved from http://www.tourismthailand.org/Whatnews/detail/TAT-and-VISA-again-launch- $\%$ E2\% $\% 0 \% 9$ CThailand-Splash-Spice2014\%E2\%80\%9D--1644

Tucker, Ian (2010, September 18). One Night in Bangkok on the trail of Thai street food. The Guardian Retrieved from

http://www.theguardian.com/lifeandstyle/2010/sep/19/bangkok-thai-street-food-david$\underline{\text { thompson }}$

delicious-foods-012321/

Valentine, Gil and Bell, David (1997). Consuming Geographies: We Are Where We Eat. New York: Routledge.

Veblen, Thorstein (1900). Theory of the Leisure Class. TKTK

Wikipedia Thai Information and Cuisine Rankings. Retrieved from https://en.wikipedia.org/wiki/Thai cuisine

Witschge, Tamara (2013). Transforming Journalistic Practice: A profession caught between change and tradition. In Peters, Chris and Broersma, Marcel (Eds.) Rethinking 
Journalism: Trust and Participation In a Transformed News Landscape. London:

Routledge. (pp. $160-172$ 